Original article

\title{
Strategic examination of the classical catalysis of formic acid decomposition for intermittent hydrogen production, storage and supply:
}

\section{A review}

\author{
Samuel Eshorame Sanni ${ }^{a,{ }^{*}}$, Peter Adeniyi Alaba ${ }^{\mathrm{b}}$, Emeka Okoro $^{\mathrm{c}}$, Moses Emetere ${ }^{\mathrm{d}}$, \\ Babalola Oni $^{\text {a,e }}$, Oluranti Agboola ${ }^{a}$, Amanda Onyinye Ndubuisi ${ }^{\mathrm{d}}$

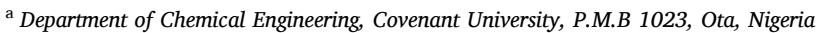 \\ ${ }^{\mathrm{b}}$ Department of Chemical Engineering, Faculty of Engineering, University of Malaya, 50603 Kuala Lumpur, Malaysia \\ ${ }^{\mathrm{c}}$ Department of Petroleum Engineering, Covenant University, P.M.B 1023, Ota, Nigeria \\ ${ }^{\mathrm{d}}$ Department of Physics, Covenant University, P.M.B 1023, Ota, Nigeria \\ e Department of Chemical Engineering, China University of Petroleum, Beijing, China
}

\section{A R T I C L E I N F O}

\section{Keywords:}

Catalyst selectivity

Catalytic dehydrogenation

Copper-active sites

Formate pathway

Hydrogen storage

\begin{abstract}
A B S T R A C T
Practically, an ideal catalyst for Formic acid-decomposition is one that best suits the reaction and significantly lowers its activation energy and improves the reaction rate under favourable conditions. Several catalysts for Formic Acid (FA)-decomposition reactions were examined. Based on the volcano curve and the potential of copper to give high hydrogen yields, emphasis was placed on a Cu-catalysed reaction as potential system for sustainable hydrogen production. Some recent advances in hydrogen production from formic acid were discussed and an effective system for FA-decomposition for hydrogen production was proposed. Since helium can be stored in weather balloons and weighs almost the same as hydrogen, a hydrogen buffer made from polyester fabric and coated with polyurethane or a hydrogen cylinder/tube was proposed for storing hydrogen for use as transportfuel. Also, due to the nature of the mechanisms/pathways describing FA-conversion reactions at the sites or surfaces of the copper-nanocatalysts, it is evident that the $\mathrm{Cu}(211)$ coordination site possesses the highest activation energy relative to those of $\mathrm{Cu}(100)$ and $\mathrm{Cu}(111)$, hence, the reason for the noticeable high or low hydrogen yields. Thus, the potential of $\mathrm{Cu}$ giving high hydrogen yields from FA spans from the reactions of FA at the $\mathrm{Cu}(111)$ and $\mathrm{Cu}(100)$ sites.
\end{abstract}

\section{Introduction}

Hydrogen is an excellent energy carrier, which can be produced from several precursors including natural gas [1] biomethane [2], coal, water [3], formic acid [4], glycerol [5,6], biomass [7] and renewable energy sources. The most abundant sources of hydrogen are hydrocarbons and quite especially, those of the $-\mathrm{COOH}$ family [8]. $\mathrm{HCOOH}$ has been widely adopted as parent material for hydrogen production because it consists of hydrogen-bonded polymers $[9,10]$. Without the involvement of catalysts, hydrogen evolution from formic acid occurs slowly, thus giving very low yield. However, in order to improve on hydrogen yield from FA, elements/metals within the transition group of the periodic table are usually employed [11]. According to Bulushev et al. [12], palladium is one of the most prominent catalysts for formic acid disintegration, and due to its slow enhancement of FA-reaction rate, alternative catalysts are being tested for improved hydrogen production [13]. When no catalyst is involved, the decomposition is usually very slow, inefficient and very uneconomical. Due to the time taken for reaction initiation, as well as $\mathrm{H}_{2}$ generation, several catalysts that possess high time-saving tendencies for FA-breakdown were investigated. According to Sabatier's hypothesis, the most ideal catalyst for a specific reaction must possess the required/minimum binding strength that keeps it in contact with the intermediate products when reaction is in progress [14]. This necessitated a probe into the scientific understanding of the underlying principles of the hypothetical propositions made by Sachtler and Farenfort, where several transition metals were tested as catalysts for effective formic acid decomposition to give hydrogen gas; this then brought to fore, the utmost significance of the "classic volcano

\footnotetext{
* Corresponding author.

E-mail address: adexz3000@yahoo.com (S.E. Sanni).
} 
curve" (Fig. 1).

One very important eye-opener of the volcano curve is that it establishes a relationship between the predicted heat of reaction and formation for a specific conversion using several catalysts. Considering the activation temperatures, it is obvious that for $80 \%$ conversion of the reactant, the order of preference for the catalysts is $\mathrm{Pt}, \mathrm{Ir}, \mathrm{Ru}, \mathrm{Pd}, \mathrm{Rh}, \mathrm{Cu}$, $\mathrm{Ni}, \mathrm{Co}, \mathrm{Fe}$ and W. However, due to the costs of $\mathrm{Ag}$ and $\mathrm{Au}$ as well as the high heat of formations of $\mathrm{H}_{2}$ with respect to $\mathrm{Ni}$, Co and $\mathrm{W}$, it is advisable to stick to catalysts such as Pt, Ir, Pd, Rh, and Cu owing to their lower heats of formation and activation energy requirements. Also, it is important to note that despite the advantages of each of the catalysts, their limitations were reported to be as a result of the non-anchoring of the catalysts on supports during the reactions. The variation in the data generated, and the normalization of the reaction rate, are due to the bulk catalyst-surface-area, however, low surface areas may result in very slow reactions and errors in reaction rate measurements. This then paved way for the successful introduction of a new parameter tagged the Turn Over Frequency (ToF), which gives the number of molecules of formic acid converted per active-catalyst surface area per second (mass flux) [15]. Also, it was observed that the heats of formation of the intermediates (formates) resulting from the various reactions were calculated using statistical mechanics, which considers the stability of the bulk metal formate, rather than the surface formate formed; this is quite more representative of the supposed reaction intermediate complexes formed by the catalysts. It was also suggested that calculations on bulk metal formates are not appropriate to simulate surface properties of intermediates as they interact with catalysts. A study was conducted on the catalytic decomposition of formic acid using Ag, Au, Pt, Pd, Ru, Ni, $\mathrm{Cu}, \mathrm{Co}$, and Fe catalysts. The Temperature-Programmed Decomposition (TPD) spectroscopy and a model-centred approach were used to critically examine the decomposition of FA-surface intermediates (HCOO*) [16]. TPD spectroscopy only measures the superficial properties of formate/intermediates, however, information on the surface kinetics of the preceding step i.e. the adsorption of $\mathrm{HCOOH}$ is not feasible with TPD. The surface decomposition of intermediates resulting from formic acid can be seen to exhibit a volcano-type behaviour when the decomposition temperature is plotted on the Sachtler-Fahrenfort chart. This also leads to the conclusion that the slow steady-state scenario of the rate of formic acid decomposition in the presence of $\mathrm{Ag}$ and Au catalysts, is largely caused by the adsorption step, which is the rate limiting step [14]. The Sachtler-Fahrenfort volcano curve has also attracted applications with respect to its use alongside the Density Functional Theory (DFT), in areas requiring calculations on formic acid decomposition on multifaceted-metallic surfaces/slabs $[17,18]$. In recent times, one very significant subject, spurring research interests, is nano-catalysis, owing to the ease with which the single/lone catalysts are sintered to improve their reactivities and stabilities over their bulk counterparts [19]. Of the available groups, nano-transition metals supported on oxides, have been recommended as the most reliable group of catalysts for catalytic reactions [20]; this is as a result of how they are easily synthesized and isolated when the need arises [21]. In addition, the anchor-metals for nanoparticles kinetically serve as the rate controlling steps for catalytic processes [22], whereas, this is not the case for non-supported colloidal

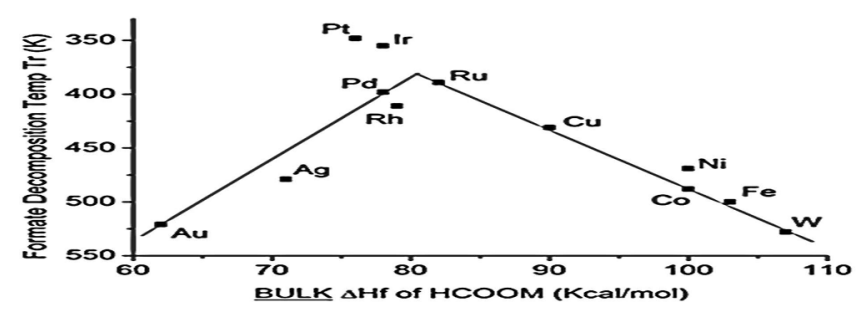

Fig. 1. Classic volcano curve for $80 \%$ hydrogen formation from formic acid using unsupported catalysts at varying temperatures. .

Adopted from $[6,7]$ metal catalysts in semi-homogeneous systems [23]. Although, Sanni et al. [24] synthesized a prominent Cu-tertiary amine catalyst, the chemistry of the synthetic pathway was not studied. This review paper looks into understanding the mechanism and chemistry of the formation step of the formate-intermediate pathway, as one consisting of several elementary steps of the FA-conversion process towards obtaining synthetic hydrogen; the Cu-active sites and coordinates were also examined in relation to hydrogen yield. In addition, efforts were made towards advocating for the recovery of FA from biomass or other chemicals, for further transformation by a reactor system, situated in an automobile, whose engine serves as the source of heat for generating the needed hydrogen as fuel.

\section{Scouting for sustainable hydrogen}

In this section, methods of synthesizing $\mathrm{H}_{2}$ from other sources besides FA, are also discussed. Based on all the works consulted, it is clearly evident that simply considering hydrogen carriers as a sustainable measure for hydrogen production, may not possibly chat the way forward for the existence and commercialization of an economical way of producing hydrogen for use as automobile fuel in IC engines.

\section{Availability status of formic acid from natural sources}

In nature, FA is found in the venom of most ants and stingless bees of the genus Oxytrigona. However, the implied venom is a mixture of toxins and irritants (secrotonin, acetylcholine and histamine), of which FA is predominant. John Ray, an English naturalist, was the first person to have successfully isolated FA from the distilled bodies of ants, this was done in 1671 [25]. Wood ants of the genus Formica family can spray FA as a means of attack on their preys, or in defence of their abode/nests against intruders; for instance, the puss moth caterpillar and the carpenter ant often spray FA against their threatening-predators. FA is also present in the trichomes of stinging nettles and there are also speculations of its occurrence in the atmosphere which is traceable to forest emissions. The human body also makes small but harmless/dilute quantities of FA from ingested, inhaled or synthetic methanol. Liquid-FA freezes at $8.3^{\circ} \mathrm{C}\left(43^{\circ} \mathrm{F}\right)$ and boils at $100^{\circ} \mathrm{C}$. The name formic acid was coined from the Latin word "Formica", which is the Latin name for "ant". It exists as a pungent, corrosive and colourless liquid comprising of hydrogen bonded dimers [25].

Since current studies have alarmed FA as a major compound from which $\mathrm{H}_{2}$ can be produced, an appropriate catalyst system that gives high volumetric yield of hydrogen from the parent compound needs be synthesized, with focus directed to obtaining the activation energy of the reaction system. Some catalytic systems with high ToFs have been identified, however, no estimates of the activation energy requirements of such reactions were provided, hence, it becomes necessary that the energy requirements of such reactions are estimated, with a view to identify several potential catalysts that can give high $\mathrm{H}_{2}$ yield at very low activation potentials. These will provide the necessary information required for efficient designs of suitable fuel housing units in cars for hydrogen storage and thus, inform the type of modifications required in existing IC-engines for their compatibilities with hydrogen gas. Also, it should be noted that reactions beyond $90^{\circ} \mathrm{C}$ are not encouraged since a car begins to show signs of over-heating beyond $90^{\circ} \mathrm{C}$. The authors of this paper have also incorporated some of the findings made by Sanni et al. [24] for a formic acid decomposition process where nano-catalysts (copper nanoparticles) supported on triethanolamine were used to speed up the process.

The continuous advocacy for the use of hydrogen as source of power in fuel cells and automobile engines, will not only encourage energy diversification but also reduce the overdependence on fossils as energy sources. Hydrogen undergoes combustion in air to give less emissions relative to fossil fuels. It also combines with air to release its stored $\mathrm{H}-\mathrm{H}$ bond thereby producing $\mathrm{H}_{2} \mathrm{O}$. It can be stored in pressurized cylinders in 
gaseous or liquid forms. Since it barely releases any greenhouse gases during combustion, it is a potential gas for the future if only the prospective $\mathrm{CO}_{2}$ emissions from the synthetic reactions are carefully minimized. Although, hydrogen can be obtained from several precursors, it barely exists in its free state, hence, it is not a primary source of energy. Also, reports have it that the chemical industries that synthesize $\mathrm{NH}_{3}$, $\mathrm{CH}_{3} \mathrm{OH}$ and refined petroleum, consume about $66 \%$ of their yearly $\mathrm{H}_{2}-$ output which is estimated at 35 million metric tonnes. Hydrogen in fuel cells, helps to convert the inherent $\mathrm{H}-\mathrm{H}$ bond/chemical energy to electrical energy by a process that deviates from that of the Carnot cycle, hence, the energy efficiency of the fuel cell is 2-3 times that of a combustion engine. Polymer-Electronic-Membrane Fuel Cells (PEMFCs) have the capacity to convert the inherent chemical energy in hydrogen, to electrical energy with water released as the only by-product. This serves as a clear justification of the huge potential of hydrogen as an alternative fuel, because, it lowers the energy-burden/over reliance on fossils and generates less-toxic emissions [8]. Therefore, there is no doubt about the perceived role of hydrogen in the near future with consideration for its medium-to-long term effects when used as fuel. With the incorporation of fuel cells in the technology of mobile and stationary systems, large-scale production of $\mathrm{H}_{2}$ gas will help alleviate the overdependence on crude oil whilst reducing environmental pollution. Formic acid can serve as a sustainable hydrogen source because, it can be sourced from biomass. Thus, cultivating plantations on which these biomasses can be grown is of utmost importance and must be given serious attention. According to Fierro et al. [26], other methods for producing $\mathrm{H}_{2}$ include:

\section{Steam reforming of Alkanes/Alkanols}

$\mathrm{H}_{2}$ can be recovered from natural gas (NG), naphtha, fuel oil, coal and higher hydrocarbons. However, the high $\mathrm{H}: \mathrm{C}$ ratio in methane relative to other sources, makes it the most sought-for precursor for $\mathrm{H}_{2}$ production. The process by which methane is processed to give $\mathrm{H}_{2}$ is known as Methanol-Steam Reforming; this method is applied industrially owing to the fact that the technology involved is quite affordable and economical [27]. The stoichiometric equation for the reaction is as given below:

$\mathrm{CH}_{4}+\mathrm{H}_{2} \mathrm{O} \rightarrow \mathrm{CO}+3 \mathrm{H}_{2}$ (1)

Here, NG reacts with steam in the presence of Ni-catalyst in a primary reforming unit at a temperature and pressure range of $1200 \mathrm{~K}$ and 20-30 atm respectively. A preliminary pre-treatment stage is necessary owing to the fact that there is need to eliminate the inherent sulphur/ mercaptans in the gas. Clean $\mathrm{CH}_{4}$ is then supplied as feed gas to a reactor containing the Ni-catalyst. Although the exit gas from the reactor is high in $\mathrm{H}_{2}$ but low in $\mathrm{CO}$, it reacts with water vapour/steam before being converted in a second or third reactor to generate more hydrogen gas. The final product comprises mainly of hydrogen with trace amounts of $\mathrm{CO}_{2}(1 \% \mathrm{v} / \mathrm{v})$ and excess/unreacted $\mathrm{CH}_{4}$. Modern $\mathrm{H}_{2}$-producing plants are designed to incorporate compression, absorption and desorption units in order to improve on the purity of the generated hydrogen gas to as high as $99.99 \% \mathrm{v} / \mathrm{v}$. Also, considering the fact that NG contains small amounts of $\mathrm{C}_{2} \mathrm{H}_{6}, \mathrm{C}_{3} \mathrm{H}_{8}$ and $\mathrm{C}_{4} \mathrm{H}_{10}$, which disintegrate to give carbon residues, a pre-reforming stage becomes very necessary to aid their conversion into $\mathrm{CO} / \mathrm{H}_{2}$. This can be integrated in the upstream reforming unit, thus making it possible to adapt the entire process scheme to a variety of feed stocks. Pre-reforming has a way of influencing the composition of the feed gas in the steam-reforming unit. However, longer chain hydrocarbons can be totally eliminated while fractional/partial methane conversion begins to take place. This is targeted at reducing the tendencies of these long chain carbons giving rise to carbon residues during the reforming process, and thus, preserves the service-life of the catalyst employed in the reforming process. The steam used in the reforming process may be replaced with $\mathrm{CO}_{2}, \mathrm{O}_{2}$ or their mixture. Advanced reforming units of this sort, are similar to classic steam reforming processes. In particular, this route is employed if it is desired to use the $\mathrm{C} / \mathrm{H}_{2}$ mixture to synthesize hydrocarbons or $\mathrm{CH}_{3} \mathrm{OH}$ rather than $\mathrm{H}_{2}$. Also, instead of $\mathrm{CH}_{4}, \mathrm{CH}_{3} \mathrm{OH}$ can be used as raw material for this process, such that, the alkanol is first reacted with steam in the presence of a catalyst to give $\mathrm{H}_{2}$. Given that the reaction is endothermic, the energy required for the reaction is obtained from the heat of combustion of the tail-gas and a light portion of the methanol-feed. The $\mathrm{H}_{2}$ stream is then scrubbed in an absorption/desorption unit i.e. a $\mathrm{CH}_{4}$ reformer. The advantage of this process is that it does not allow for the formation of intermediates/oxygenated constituents. However, for economic reasons, the method is only applied when the methanol to be used is in excess, since part of it is used as fuel for the system. The LPGcontent, quantity of distillates recovered and the good distribution network, make these fractions ideal candidates for $\mathrm{H}_{2}$ production. In lieu of the aforementioned cases, the development of these processes have only gained little attention owing to issues related to catalyst-poisoning by carbon deposits, partial oxidation of the inherent hydrocarbons in the methanol-feed, rise in temperature of the HC-air mixture, expulsion of sulphur in the form of $\mathrm{H}_{2} \mathrm{~S}$ at the reactor outlet, and steam injection which precedes the water-gas-shift reaction. Considering polymer membrane fuel cells, the CO released from this process must be less than $10 \mathrm{ppm}$ which is achieved by passing the mixture over catalysts that are able to convert the $\mathrm{CO}$ to $\mathrm{CO}_{2}$ at room temperature. The release of poisonous mercaptans and coke deposits, on the surface of the catalyst for this system, is yet to be curtailed, however, in lieu of the impact of this technology on the environment, car manufacturers still deem it a suitable/considerable option to use $\mathrm{H}_{2}$ as power source for fuel cells. Do et al. [28] succeeded in producing hydrogen from propane via hydrothermal/steam reforming, which was aided by a nickel-based catalyst supported on $\mathrm{AlSi}_{\mathrm{x}} \mathrm{O}_{\mathrm{y}}$, where they established the effect of acidity on the performance of the catalyst at high temperatures (i.e. $200-600^{\circ} \mathrm{C}$ ); they adopted a steam to propane ratio of $1: 6$, which makes the process somewhat highly energy intensive and expensive in terms of overhead cost of the entire process per $\mathrm{kg}$ hydrogen produced.

\section{Electrolysis of water}

This method is employed for small scale production of $\mathrm{H}_{2}$. The reaction prevails in an alkaline medium at a controlled $\mathrm{pH}$ which helps to boost electrical conductivity. The set-up comprises of terminals (electrodes; cathode and anode) where anions/cations migrate to as soon as electrical pulses are supplied in terms of direct current to the cell. The cathodic hydrogen is impure as it contains certain amounts of $\mathrm{O}_{2}$ and moisture. The moisture is dried over a suitable adsorbent while the $\mathrm{O}_{2}$ is eliminated in a deoxo-converter. Oxygen is also produced at the anode, although, its volume is half that produced at the cathode. The electrolytic reactor takes the form of a rectangular tank with parallel electrodes and the heat released is removed by counter current flow of water recirculating around the cells. The disadvantage of this process is the relative cost of $\mathrm{H}_{2}$ which is worth $4.9-5.6 \mathrm{kWh} / \mathrm{m}^{3}$, thus making it at least twice as expensive as the $\mathrm{H}_{2}$ from NG reforming. Since conventional electrolysis produces high-cost hydrogen, other alternative processes being exploited include steam-phase electrolysis where the reversible potential of the cell is lowered as the temperature of the cell increases; since the cost of energy/electrical power required to produce $1 \mathrm{~mol}$ of $\mathrm{H}_{2}$ from water is proportional to the EMF of the cell, it then implies that, the total cost can be reduced by lowering the temperature of the system. Also, since the reaction is endothermic, the system can be maintained at constant temperature which makes cooling easier. Hence, the electrical energy is electrochemically converted to $\mathrm{H}_{2}$ without necessarily needing to go through an intermediate phase or the energy transition stages of the cycle. Thus, at $1,500 \mathrm{~K}$, the amount of heat spent in the thermo-chemical decomposition of $\mathrm{H}_{2} \mathrm{O}$ is $50 \%$ of the total energy input of the conventional process. Another electrochemical process or alternative route for $\mathrm{H}_{2}$-production is one which employs or takes advantage of electro-catalysts at lower voltages, thus reducing the overall cost of $\mathrm{H}_{2}$ produced. According to the comparative life cycle 
analysis of two hydrogen production routes (i.e. the membrane water electrolysis and methane steam reforming) conducted by Bareiß et al. [29], the adoption of membrane water electrolysis depends on renewable energy as the source of electrical energy for the system. Although this system limits $\mathrm{CO}_{2}$ emissions by $75 \%$, the process is somewhat expensive if it must be commercialized on a large scale; also, the issue of membrane fouling and stability are of paramount concern.

\section{Hydrogen from Thermo-chemical conversion of biomass}

Hydrogen in biomass can be obtained via thermo-chemical processes (combustion, liquefaction, pyrolysis and gasification). Firstly, the biomass is partly oxidized above $1000 \mathrm{~K}$ in order to obtain a gaseous fraction as well as carbon residue, which is subsequently converted to $\mathrm{H}_{2}, \mathrm{CO}, \mathrm{CO}_{2}$ and $\mathrm{CH}_{4}$. Aerobic biomass gasification generates a $\mathrm{H}_{2}$-rich stream which is reformed at the water vapour gasifier-exit to release additional hydrogen. A major shortcoming in hydrogen recovery from biomass gasification is the formation of tar or ash which increases the tendencies for catalyst poisoning [27]. The resulting heavy residues/ components undergo polymerization which give rise to complexes that do not favour the $\mathrm{H}_{2}$-production process. Tar formation can be controlled by retrofitting the gasifier and integrating self-repairing catalysts as well as, adjusting the operating conditions and process variables; the proposed catalysts will help to lower tar formation, improve the quality of $\mathrm{H}_{2}$ produced and enhance the conversion of the intermediate product/gas. On the other hand, ash formation can cause a build-up of solids on the catalyst-surface, which subsequently plugs and deactivates the catalyst, although, this can be controlled by ash extraction and fractionation during the operation in order to reduce the accumulation of these constituents in the reactor or product-channels during the process.

\section{Hydrogen from Microbes: Fermentation and photosynthesis (Bio- photolysis)}

This method takes advantage of bio-photosynthetic/nonphotosynthetic microorganisms (Scenedesmus/green algae, Cyanobacteria- Spirulina species etc.), which are able to breakdown water molecules into its constituents $\left(\mathrm{H}_{2}\right.$ and $\left.\mathrm{O}_{2}\right)$ in the presence of visible light or under anaerobic conditions in the absence of light. Reports have it that, the Scenedesmus species is not only able to stimulate $\mathrm{H}_{2}$ production by irradiation of light, but can also produce $\mathrm{H}_{2}$ via fermentation under anaerobic conditions with starch as starting material. However, the produced $\mathrm{H}_{2}$ obtained by fermentation is more stable relative to that from photosynthesis owing to the absence of oxygen. Despite the low investment cost involved in this process, the challenge with producing hydrogen by this method still remains "non-commercialization", caused by the low energy efficiency of converting solar power to chemical energy by the aforementioned biological systems/microbes. Evidence has it that, photoheterotrophic microorganisms have a $7 \%$ maximum conversion efficiency of solar power to chemical energy. Furthermore, biological reactors have also been exploited for use in producing hydrogen. These reactors require less energy, ambient temperature and pressure, with the requisite advantage of bypassing $\mathrm{CO}_{2}$ production, which may result in terrible consequences for the electrodes of a fuel cell. Two routes are involved in the hydrogen production process, and these include fermentation and photosynthesis. The photosynthetic step is either aided or non-aided by oxygen. Other aerobic photosynthetic microbes include Chlamydomonas and Rheinhardtii, while an example of the anaerobic photosynthetic ones are the Rhodobacter spaeroides. Microbes such as Escherichia coli, Clostridium and Enterobacter species, that undergo fermentation to produce hydrogen, have been studied [30-34]. According to literature, the hydrogen production per cell obtained in a fermentation process is higher than that obtained from photosynthesis. Bio-hydrogen production rates of $151.2 \mathrm{mg} \mathrm{L}^{-1} \mathrm{~h}^{-1}$ and $605 \mathrm{mg} \mathrm{L}^{-1} \mathrm{~h}^{-1}$ by Enterobacter cloacae IIT-BT08 and a consortium of mesophilic bacteria, which have an equivalent volumetric flow rate of $7.4 \mathrm{Lh}^{-1}$ at room temperature, are the highest ever-reported hydrogen production rates till date. However, the major concern still remains that such hydrogen production rates are not commercially viable $[30,35]$. In order to abate this problem, two things to consider include improving on their low $\mathrm{H}_{2}$ yields and volumetric fluxes. According to Woodward et al. [36], $11.6 \mathrm{~mol}$ of $\mathrm{H}_{2}$ can be generated from $1 \mathrm{~mol}$ of glucose 6-phosphate extracted from a microbe. The low quantity of $\mathrm{H}_{2}$ produced was attributed to the growth rate of the anaerobe, its total cell count and low cell density [37]. Yoshida et al. [38] overcame this problem of low hydrogen production by genetic modification/increase in number of microbial cells which served as catalyst for the reaction, and increased the microbial cell density with subsequent conversion of the formate formed as intermediate product from the glucose into the needed hydrogen. Other substrates that have been used besides glucose include Nicotine Adenine Dinucleotide Hydride (NADH) and Nicotine Adenine Dinucleotide Phosphate Hydride (NADPH); both are intermediates formed from their precursors during the breakdown of glucose which need be oxidized prior the commencement of a new cycle of the conversion process. Furthermore, ferrodoxin, cytochrome which enhances electron transfer as well as formate (the end product) formation, have been identified as promoters of microbial hydrogen synthesis. The active catalysts/enzymes in microbes that help in the catalytic dehydrogenation of formate is the Formate Hydrogen Lyase (FHL) complex, which is present in microbes such as Enterobacter, Methanogenes and photosynthetic bacteria [39-41]. Fig. 2 gives the hydrogen production rate for different FHL strains experimented by Yoshida et al. [38] where the highest volume of hydrogen recorded was for the SR13 strain with a production rate of $300 \mathrm{mmol} / \mathrm{gh}$ after $10 \mathrm{~h}$ of production time.

\section{Thermal conversion of $\mathrm{H}_{2} \mathrm{O} /$ Metal sulphates}

This process simply involves the thermal dissociation of water molecules into molecular hydrogen in nuclear reactors/solar furnaces by the application of heat at high temperatures of less or equal to $950{ }^{\circ} \mathrm{C}$. The generated heat in transit, is used to breakdown water into its constituents $\left(\mathrm{H}_{2}\right.$ and $\left.\mathrm{O}_{2}\right)$ [27]. An example of this kind of process is the thermal decomposition of a metal sulphate first at $1100 \mathrm{~K}$ to give a metal oxide alongside $\mathrm{SO}_{2}$ and $\mathrm{O}_{2}$. In the second stage, oxidation of the metal oxide to sulphate and $\mathrm{H}_{2}$ is aided by introducing steam and $\mathrm{SO}_{2}$. Two major advantages of this process are the zero $\mathrm{CO}_{2}$ emission and an achievable efficiency of about $85 \%$ conversion of water to $\mathrm{H}_{2}$. However, the method has not been implemented on industrial/commercial scale and it is highly energy intensive.

\section{Photochemical reactions}

These reactions result in the splitting of water molecules on a

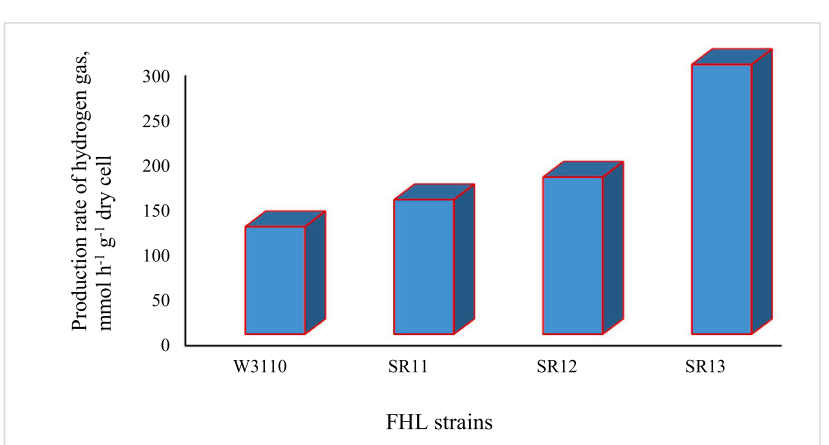

Fig. 2. $\mathrm{H}_{2}$-Production rate over $10 \mathrm{~h}$ culture-resuspension in $50 \mathrm{~mL}$ phosphate buffer in the presence of $100 \mathrm{mM}$ sodium formate at an OD610 of 1.0. Adopted from ref. [38] 
semiconductor using sunlight. The efficiency of this method is highly dependent on the photo-physical properties of the semiconductor. The limitation of this method is that a thorough understanding of its commercial application requires that the $\mathrm{H}_{2}$ produced in the visible spectrum photon is further improved with advanced science and engineering principles in order to be able to achieve stable photocatalysts during the dissociation process [27]. Other unresolved issues include, the unravelling of the mechanism behind the charge transfer between the semiconductor and co-catalyst which will help in understanding its dependence on the inherent morphological and interfacial electronic factors. However, these points pose excellent opportunities for improving the photocatalyst-options available for photo-chemically dissociating water. Also, efforts can be directed towards controlling the structures of the catalysts employed at the nanometric scale, which will in turn foster adequate photocatalyst morphology-modulation and reactivity.

\section{Ethanol/sugar reforming}

Ethanol and glucose are renewable precursors for $\mathrm{H}_{2}$. The reforming process involves the use of high-pressure steam in the presence of catalysts. Glucose and ethanol are neutral in terms of $\mathrm{CO}_{2}$-emmision. One major shortcoming of the process is that other undesirable/by-products such as $\mathrm{CO}, \mathrm{CH}_{4}$ and acetaldehyde are formed as a result of side reactions which also culminate in low $\mathrm{H}_{2}$-selectivity by the catalyst with subsequent reduction in the volume of $\mathrm{H}_{2}$ produced [27]. The low amount of $\mathrm{H}_{2}$ recovered from the process can also be attributed to catalyst deactivation which may be caused by the accumulation of carbon deposits on the catalyst surface; this therefore makes it a herculean task in commercializing the referred reforming process. Furthermore, another major challenge that needs be addressed, is the development of suitable catalysts that will not only operate at lower temperatures but, also help to minimize catalyst-deactivation.

\section{Thermo-catalytic dehydrogenation of formic acid}

Thermo-catalytic dehydrogenation reactions of FA involve the decomposition of formic acid aided by some catalysts. The implied catalysts may be used alone or with some form of supports which help to overcome the required barriers as well as hasten the reactions along favourable pathways at the most selectively active catalyst sites. These reactions prevail under unique steps to bring about the formation of hydrogen as well as $\mathrm{CO}_{2}$. Efforts need also be put in place for the capture of $\mathrm{CO}_{2}$ since an equivalent amount in mole of $\mathrm{CO}_{2}$ as obtained for hydrogen, is released during the process. By the experimental procedure discussed in Sanni et al. [24], where a Cu-tertiary amine system was adopted for the first time in producing hydrogen from formic acid, it is evident that, the process guarantees less release of $\mathrm{CO}_{2}$ by the method of collection (i.e. downward displacement of water) due to $\mathrm{CO}_{2}$ solubility in water. Furthermore, the hydrogen produced can be passed over limewater $\left(\mathrm{Ca}(\mathrm{OH})_{2}\right)$ in order to completely strip the gas of $\mathrm{CO}_{2}$ and other trace gases, this will aim at ensuring the availability of pure hydrogen for storage and fuelling of automobiles. Hence, at a later section, much of the discussions will focus on some of the best published catalysts for high hydrogen production as well as, the use of copper and its special attributes that ensures its reliable use over several cycles (the referred Cu-tertiary amine system has a reusability of 20 cycles in $120 \mathrm{~h}$ ) [24].

In line with the proposal given in the above paragraph, FA holds a lot of prospects as starting material for sustainable hydrogen production. According to Alotaibi [42], formic acid can be sourced from the earth's abundant biomass, can be handled in its aqueous state, has high-energy density, is nontoxic, and highly stable at room temperature. Based on excerpts from ref. [43] where sensitive parameters were used to describe the intensity of the chemical properties of some hydrogen carriers, it can be seen that $\mathrm{HCOOH}$ has the highest flash point amongst all other carriers with the exception of ammonia (Table 1), but owing to the toxic nature of ammonia, FA still gains more preference in terms of being a source material for hydrogen production.

Furthermore, of all the available alternative sources of hydrogen, formic acid has proven to be one of the most benign routes for obtaining synthetic hydrogen. $\mathrm{HCOOH}$ as a formate precursor, can be obtained from glycerol, methanol, water and biomass $[44,45]$. In lieu of the underscored alternatives, formic acid is a very efficient precursor for $\mathrm{H}_{2}$ production owing to its inherent carrier-property, its relative abundance, good activity with catalysts, high yield and sustainability.

\section{Hydrogen from formic acid}

Based on the work of Bulushev et al. [46], hydrogen was produced from FA using Pt/C ( 1 and $10 \mathrm{wt} \%), \mathrm{Au} / \mathrm{C}(0.8 \mathrm{wt} \%)$ and $\mathrm{TiO}_{2} / \mathrm{C}$ of $1 \mathrm{wt}$ $\%$. The highest selectivity of the catalyst was recorded for the $\mathrm{Pt} / \mathrm{C}$ catalyst combination at $390{ }^{\circ} \mathrm{C}$, thus producing about $0.04 \mathrm{~mol} \mathrm{H}_{2}$ per minute per gram of the catalyst. In addition, the estimated catalyst selectivity did not simulate conversion but was only a measure of high catalytic activity. Also, particles of lower molecular weights performed better than particles of higher molecular weights owing to their increased surface area to volume ratios. According to them, catalystselectivity was found to be weakly dependent on the reaction temperature, conversion and time, although, that is never the case for the actual conversion of FA because, it is temperature dependent. Again, the reaction is highly energy intensive as the best results were achieved at about $663 \mathrm{~K}$, whereas, other catalysts can give better results at mild conditions/lower temperatures. The study by Xue-li et al. [47] involves the synthesis of several ionic liquids including 1-(2-Diisopropylaminoethyl)-3-methylimidazolium chloride (i-Pr2NEMImCl) as catalysts by an approach that bothers on the hermetical storage of an already lowpressure-distilled 1-Methylimidazole of $99 \%$ purity. The ionic liquid used as catalyst was produced via several complex steps that are quite time consuming, which in turn make the catalysts, as well as the overall process somewhat expensive. Amongst the tested ionic liquids, iPr2NEMImCl-HCOONa gave the highest activity with a ToF $>600 \mathrm{~mol} /$ $\mathrm{mol} / \mathrm{h}$. The highest volume of hydrogen produced was $1057 \mathrm{~mL}$ in $2 \mathrm{~h}$, thus giving an hourly production rate of $528.5 \mathrm{~mL}$ for 5 moles of catalyst used. Although the reaction temperature was $60^{\circ} \mathrm{C}$, the process routes for the ionic liquid-catalyst syntheses involved several chemicals that made the entire process somewhat complex. Secondly, the catalysts assumed the form of hybrid chemicals/compounds which increase the overhead cost of the entire process. An additive-free formic acid decomposition was carried out at $30-60{ }^{\circ} \mathrm{C}$ using Pd/C catalyst. Catalyst selectivity was found to be $>99.9 \%$ with a turn over frequency of about $1136 \mathrm{~h}^{-1}$ [48]. Despite how wonderful this catalyst performed, no information was given as regards the number of cycles required to produce the highest volume of hydrogen before catalyst poisoning sets in and the threshold tendency for steric hindrance. Also, palladium cannot be easily sourced as it is a precious metal like gold and platinum, hence, it is considered expensive. The authors used a High-Performance Liquid Chromatograph to determine the FA-conversion. Hydrogen production

Table 1

Chemical properties of hydrogen carriers.

\begin{tabular}{lllll}
\hline Parameter & $\begin{array}{l}\text { Formic } \\
\text { acid }\end{array}$ & Methanol & Ethanol & Ammonia \\
\hline $\mathrm{H}_{2}$ content (wt. \%) & 4.4 & 12.5 & 13 & 17.7 \\
Hazard codes & $\mathrm{C}$ & $\mathrm{F}, \mathrm{T}$ & $\mathrm{F}$ & $\mathrm{T}, \mathrm{C}, \mathrm{N}$ \\
Risk statements (R- & $\mathrm{R} 10, \mathrm{R} 35$ & $\mathrm{R} 11, \mathrm{R} 23-25$, & $\mathrm{R} 11$ & $\mathrm{R} 10, \mathrm{R} 23, \mathrm{R} 34$, \\
$\quad$ phase) & & $\mathrm{R} 39$ & & $\mathrm{R} 50$ \\
Boiling point $\left({ }^{\circ} \mathrm{C}\right)$ & 101 & 64.7 & 78 & -33 \\
Explosion limits & $18-57$ & $6-36$ & $3.3-19$ & $15-25$ \\
$\begin{array}{l}\text { (Upper-lower vol. \%) } \\
\text { Flash point }\left({ }^{\circ} \mathrm{C}\right)\end{array}$ & 48 & 9.7 & 14 & 132 \\
\hline
\end{tabular}

Source: Adopted from [43]. 
was simulated and optimized by performing periodic plane-wave DFT simulation adopted from a Vienna ab-initio simulation package (VASP). The durability or reusability of the catalyst, dropped from $84 \%$ to $72 \%$ between the 2 nd and 5 th cycles in $1.5 \mathrm{~h}$. According to them, the Pd/C catalyst had its catalytic activity retained by about $72 \%$ of its initial activity at its fifth time of use. However, despite washing and keeping the catalyst dry for $18 \mathrm{~h}$ before each cycle, they allotted that the slightly evidenced decrease in the catalyst activity may have been caused by: the absorption of FA onto the surface of the catalyst, CO-poisoning as well as the nano-Pd agglomeration or drop in Pd loading caused by leaching, as evidenced by the low concentration of Pd in the supernatant solution analysed with Absorption Electron Microscopy. The investigation conducted by Muller et al. [49] is a comparative study of hydrogen synthesis from two process routes during FA decomposition and water electrolysis. Their advocacy as regards FA-decomposition is in the direction of controlling the reactions to give a formate rather than the carboxyl as intermediate product; this abates the tendency of producing formic acid from $\mathrm{CO}_{2}$ and $\mathrm{H}_{2} \mathrm{O}$ which gives lower conversions. Based on their findings, the formate route is more cost effective relative to the carboxyl route. Also, according to them, the splitting of water in the hydration step is way more expensive than going through the formate-formation step. The enthalpy of decomposition has a high significant influence on the total energy demand of the reaction system. They also asserted that the over dependence on FA-concentration by the bicarbonate route is due to the large heat capacity of the accompanying water at the dehydration stage; thus, the amount of heat required by the process can be quantified in terms of the rate of evaporation of water at the dehydration stage. However, they concluded that with the help of a catalyst, the heat requirement reduces to about $6 \mathrm{kJth}$ per mole FA, for step temperature increases of $20-80^{\circ} \mathrm{C}$.

Reaction Pathways, mechanisms and structural sensitivity of FA on $\mathrm{Cu}$ catalysts when used with, or without any support

FA $(\mathrm{HCOOH})$ has spurred research interests as one of the major byproducts in biomass conversion; it is a carrier of hydrogen gas, and a source of fuel for fuel cells. In spite of the few experimental studies on $\mathrm{HCOOH}$-decomposition as aided by Cu-catalysts, the mechanism of the reaction and its structural sensitivity are still far from being wellunderstood. In the study by Li [50], self-consistent, three model copper coordination sites i.e. $\mathrm{Cu}(111), \mathrm{Cu}(100)$ and $\mathrm{Cu}(211)$, were examined along two basic routes, they include the formate (HCOO)- and carboxyl $(\mathrm{COOH})$-mediated pathways. Based on their findings, the path defined by their energy studies, suggest that the formate mediated route holds more prospects than the carboxyl-mediated route at the coordination sites. According to them, FA-decomposition occurs in two steps, which is immediately preceded by hydrogen desorption. The formate group as compared to the carboxyl group is the rate determining step, owing to its higher transition state and activation energy which are characterized by the three catalytic steps along the HCOO-route. The decomposition was found to be Cu-structure sensitive, and based on the analysis, all three Cu-catalyst facets exhibited different binding strengths for the intermediate "HCOO" while having close activation energies during dehydrogenation. The coordination sites of $\mathrm{Cu}(100)$ and $\mathrm{Cu}(211)$ were seen to bind the formate (HCOO) much more than the $\mathrm{Cu}(111)$ coordination site due to their lower potential energy surfaces relative to $\mathrm{Cu}(111)$. Under the reaction conditions, there may be a substantial surface coverage of the $\mathrm{HCOO}$-intermediate by $\mathrm{H}_{2}$, which may convert the intermediate to its stable form/corresponding acid and store the acid under-coordinated corners or defective sites. $\mathrm{HCOOH}$ acid decomposition is said to be most likely prevalent at the terrace sites of $\mathrm{Cu}$ nanoparticles. Studies have also shown that vapour-phase decomposition of FA is a widely known test for examining the catalytic features of metals [51-54] and their oxides [55-57] including alloys. FA is one of the most common organic-molecules which can be split on metal surfaces via a dehydrogenation or dehydration scheme, both leading to the formation of $\mathrm{CO}_{2}$ and $\mathrm{H}_{2}$ as well as, $\mathrm{H}_{2} \mathrm{O}$ and $\mathrm{CO}$ respectively; the two schemes are interlinked by a water gas shift (WGS) reaction. CO is a known catalyst poisoner for $\mathrm{Cu}, \mathrm{Pt}, \mathrm{Pd}$ and several other catalysts. Furthermore, $\mathrm{Cu}$ can selectively decompose FA via the dehydrogenation step to give $\mathrm{CO}_{2}$ and $\mathrm{H}_{2}$ without $\mathrm{CO}$ being produced [58], however, this requires impeding the WGS-reaction step. Other researchers have recorded similar results for temperature programmed reactions of FA on Cu with single crystal surfaces [59-62], while spectroscopic studies have helped to identify the reason behind this occurrence. However, some researchers have recounted that it is caused by the existence of a stable formate group/intermediate which results from the adsorption of $\mathrm{H}_{2}$ on the surface of $\mathrm{Cu}$ [62]. Iglesia and Boudart [58] based their investigation on the formate reaction-pathway, where they obtained an activation energy of $94.5-100 \mathrm{~kJ} / \mathrm{mol}$ for FA-decomposition using Cu catalysts on different supports; same results were obtained for preferentially oriented (PO)- and polycrystalline (PC)-Cu catalysts [63-65]. Their investigation led to the conclusion that there was no direct correlation between the observed turnover rates (TORs)/Turn over Frequencies (TOFs) of hydrogen and the particle-size of copper as well as the catalyst support. Furthermore, they asserted that FA decomposition on $\mathrm{Cu}$ is not structure-sensitive, however, Nakano et al. [66] gave a contrary opinion stating that the FA-decomposition was structure sensitive with varying activation energies for the dehydrogenation of the formate-intermediate with respect to the $\mathrm{Cu}(111)$ and $\mathrm{Cu}(110)$ coordination sites. They added that formate formation from the $\mathrm{CO}_{2}$-evolution step was structure insensitive at the two $\mathrm{Cu}$ coordination sites. The strong dependence of the energy of adsorption of FA onto the surface of $\mathrm{Cu}$ was also confirmed by Hu and Boyd [67], and they opined that the energy of FA adsorption onto $\mathrm{Cu}$ sites is in the following decreasing order of magnitude i.e. $\mathrm{Cu}$ (110) $>\mathrm{Cu}(100)>\mathrm{Cu}(111)$. Some researchers have also reported the deprotonation of $\mathrm{HCOOH}$ to $\mathrm{H}^{+}$at the $\mathrm{Cu}(110)$ and $\mathrm{Cu}(100)$ coordination sites $[61,68]$ whereas, this is not the case at the $\mathrm{Cu}(111)$ surface where the existence of atomic oxygen is critical for formate-formation. In order to elucidate the reaction mechanism for better understanding of the interaction of $\mathrm{Cu}$ catalysts with FA in terms of reactivity and structural sensitivity, there is need to understand the kinetics of FAdecomposition and $\mathrm{H}_{2}$ formation; several experimental studies, lack adequate systemic theories to provide the required insights as regards FA-decomposition on $\mathrm{Cu}$ surfaces. Most proposals/elementary steps involved in the decomposition process are similar to those of methanol synthesis and WGS reactions in terms of their similar reaction pathway. The work of Sanni et al. [24] gave a plausible reaction scheme as mechanism for FA decomposition where the reaction simply occurs between stable copper catalysts at varied concentrations which are supported on a tertiary amine which helps to disallow the early contamination of $\mathrm{Cu}$ thus extending its service life. Hence, the kinetics of the process can dwell on the dehydrogenation step rather than the COproduction step which stimulates catalyst poisoning. Furthermore, efforts can be made to concentrate the FA attachment to copper catalyst at coordination sites such as $\mathrm{Cu}(100), \mathrm{Cu}(110)$ and $\mathrm{Cu}(211)$ along the $\times, y, z$ planes while being anchored on special supports that can extend its service life thus inhibiting the dehydration step. Previous experimental kinetic studies and micro-kinetic modelling of FAdecomposition, show that the formate formed on the $\mathrm{Cu}$ [69] and $\mathrm{Pt}$ active sites [70] proceed via a carboxyl ( $\mathrm{COOH})$-mediated pathway but this route can drastically reduce the quantity of $\mathrm{H}_{2}$ produced as compared to when the process is routed via the formate formation step hence, the need to control the reaction at optimal conditions where these sites are created by merely manipulating the process conditions rather than focusing on tweaking the adherence of $\mathrm{HCOOH}$ to the active sites of the Cu-catalyst. Since it is quite difficult to restrict or maintain FA decomposition to the active sites of the catalysts, the knowledge gained from the proposed mechanisms will help understand-better, what happens at the optimal conditions and what they seem to offer when the best results are obtained. The proposal here is to optimize the process conditions by varying catalyst size, $\mathrm{pH}$, concentration and reaction time at a 
uniform reaction temperature; this will optimize the FA-decomposition towards high hydrogen yield. In essence, when these catalysts are further examined for their structural sensitivities and coordination sites/ numbers, it might be interesting to find that there may be newly created active sites that are yet to be discovered in literature since $\mathrm{Cu}$ is known to exhibit variable oxidation states.

\section{Influencers/Supports for catalytic formic acid decomposition reactions}

The most pressing challenge in catalyst synthesis is the attainment of highly stable, non-sintering and non-leaching substances with welldefined composition and size/shape-controlled nanoparticles. The influence of large surface area to volume ratio is one of the greatest features of these nano-metals. For a reaction that is morphologically sensitive, catalyst-sizes become the controlling factors owing to their predictive impacts on the surface morphology and electronic/sub- atomic oxidation states of the metals, hence, the need for catalystsupports for improved results. For catalytic processes that largely depend on harsh operating conditions, catalyst-supports become necessary because, sintering and/or leaching of surface bound nanometals bring about a decrease in the activity and unspent life of the catalysts made from them [71]. The FA-decomposition described by Carner et al. [71] involves the use of wet impregnation method to synthesize titanium II oxide nano-fines which served as anchor for PdCoNi alloy (three-in-one nano-alloy), after which they were simultaneously reduced to their metals. Furthermore, in order to enhance their stability to heat and leaching, the atomic-layer deposition (ALD) method was employed as a means of nurturing and dispersing silver oxide layers within the superficial $\mathrm{PdCoNi}$, thus giving rise to $\left(\mathrm{PdCoNi} / \mathrm{TiO}_{2}-\mathrm{ALD}-\right.$ $\mathrm{SiO}_{2}-\mathrm{TiO}_{2}$ ); the resulting nano-alloy (PdCoNi supported on $\mathrm{TiO}_{2}$ ) appeared crystalline and sized $3.52 \mathrm{~nm}$. The performance of the $\mathrm{PdCoNi} / \mathrm{TiO}_{2}-\mathrm{ALD}-\mathrm{SiO}_{2}-\mathrm{TiO}_{2}$ catalyst was measured in terms of its
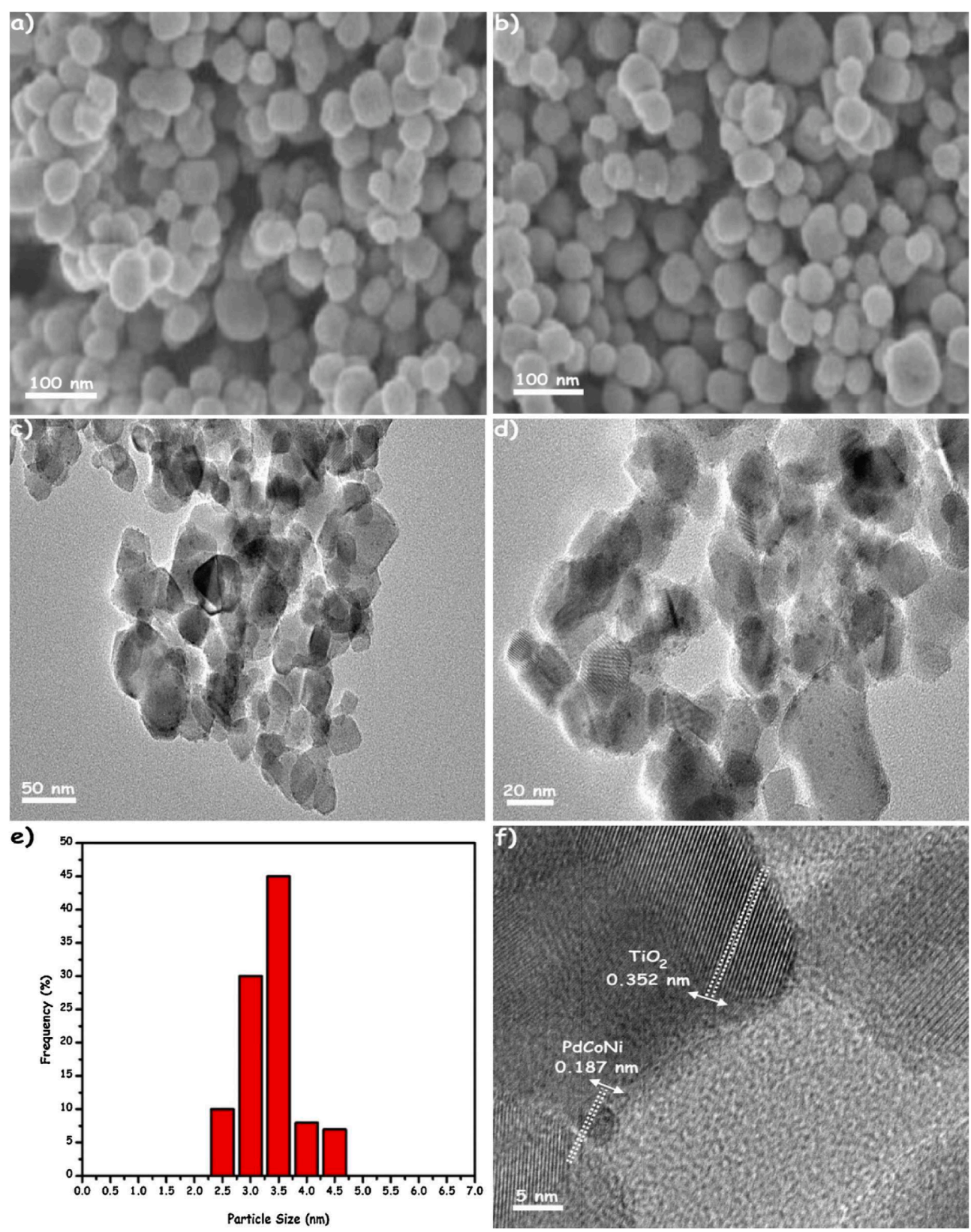

Fig. 3. a-f: a-b. FESEM morphology of $\mathrm{Pd}_{0.60} \mathrm{Co}_{0 \cdot 18} \mathrm{Ni}_{0.22} / \mathrm{TiO}_{2}$ for different sections of the sample taken from different regions, c-d. BFTEM morphology/magnifications of $\mathrm{Pd}_{0.60} \mathrm{Co}_{0 \cdot 18} \mathrm{Ni}_{0.22} / \mathrm{TiO}_{2}$, e. Histogram of $\mathrm{Pd}_{0.60} \mathrm{Co}_{0 \cdot 18} \mathrm{Ni}_{0.22} / \mathrm{TiO}_{2}$ catalyst-size f. HRTEM of $\mathrm{Pd}_{0.60} \mathrm{Co}_{0 \cdot 18} \mathrm{Ni}_{0.22} / \mathrm{TiO}_{2}$.

Adopted from [71] 
selectivity, activity and oxidative/thermal stability during the catalytic dehydrogenation stage; the hybrid catalyst-support adopted here is similar to that in ref. [72]. Formic acid (FA) is a prospective parent material for producing hydrogen [13], however, the percentage composition of hydrogen in the compound is only approximately $4 \%$, hence, large volumes of the organic compound are required if high volumes of hydrogen are desired. According to [13], the dehydrogenation reaction occurred at room temperature with a turn over frequency of $207 \mathrm{~mol} \mathrm{H}_{2} / \mathrm{mol} \mathrm{metal}$ " h and the catalyst selectivity was $>99 \%$ at near-complete conversion. They found that the catalyst-support helped to preserve the service-life by about 20 times i.e., at the $20^{\text {th }}$ time of catalyst reuse, the catalyst still retained its reactivity and inherent abilities in terms of selectivity, conversion and stability, whereas, the non-anchored PdCoNi/TiO catalyst had completely lost its potency under such conditions. Sadovskaya et al. [73] developed a hybrid vanadia-titania oxide hybrid catalyst with metallic ratio of 1:13 respectively, and a specific surface area of $54 \mathrm{~m}^{2} / \mathrm{g}$; this is similar to the surface composition of the hybrid catalyst of the monolayer atom adopted in ref. [72] that had an average density of $8.9 * 10^{18}$ atoms $/ \mathrm{m}^{2}$, which was formed by first dissolving anatase titanium oxide in a solution of vanadyl oxalate $\left(\mathrm{VOC}_{2} \mathrm{O}_{4}\right)$ and subsequently drying the resulting mixture in air for $12 \mathrm{~h}$ and calcining it at $110-450{ }^{\circ} \mathrm{C}$ for $4 \mathrm{~h}$. Liu et al. [74] produced a Pd-Au alloy as catalyst for hydrogen production. Although the Au catalyst did not influence hydrogen production, they added that, it rather prevented any possible adsorption of the produced hydrogen atom, which was subsequently converted to hydrogen molecule. Fig. 3 a-f shows different views of a sample Pd-Co-Ni-TiO 2 catalyst morphology as obtained from SEM.

Zavras et al. [75] used the concept of changing the environment/ reaction system at a metal centre/catalyst surface to stimulate activity/ reactivity. Formic acid was the adopted raw material for synthetic hydrogen production. In their work, gas phase experiments were combined with DFT calculations as a way of examining how a binuclear silver hydride ion $\left(\mathrm{AgH}^{+}\right)$can be manipulated using choice phosphate ligands which initiate hydride protonation and in turn liberate $\mathrm{H}_{2}$ gas (Fig. 4). According to them, this is a very crucial step, because the decomposition of formic acid is almost impossible without ligands. Also, spectroscopic characterization of the $\mathrm{AgH}^{+}$shows that the ionic hydride and its ligated variants can be easily formed when needed.

\section{Catalyst selectivity and activity}

Several homogeneous catalysts have been adopted for formic acid decomposition reactions, however, one of the most recent findings by Sanni et al. [24] puts forth copper-triethanol amine system as a promising catalyst-support system for high FA conversions of about $82.7 \%$. Also, owing to the rising research interests in establishing the mechanisms/kinetics for formic acid decomposition, a homogeneous kinetic model for catalytic-formic acid decomposition was proposed. Several other catalysts have been adopted for formic acid decomposition, but most of them are heterogeneous in kind. Despite the fact that the alloying of transition metals with noble metals is one good and ideal method of obtaining responsive and desirable catalytic FAdecomposition efficiencies, the involvement of heteroatoms makes the entire process somewhat expensive [24]. The folding, doping or encapsulation of sample metal-blends such as palladium and gold (a noble and inert element) for use as catalytic-decomposers of FA, have shown high levels of activity and selectivity for $\mathrm{H}_{2}$ owing to the high rate of conversion obtained as compared with the $\mathrm{H}_{2}$ yield when pure forms of the metals are used [76,77]. According to Allison and Bond [78], alloys of palladium and gold form a serial-continuous face centred cubic structure in their liquefied state which makes them a good blend for

\section{a}

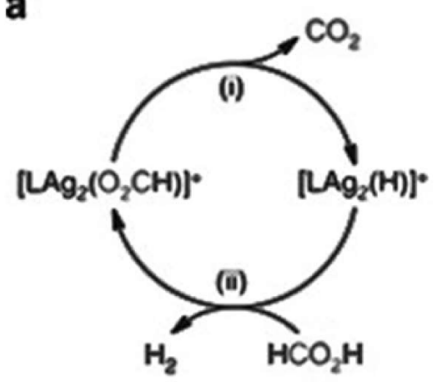

(iii)

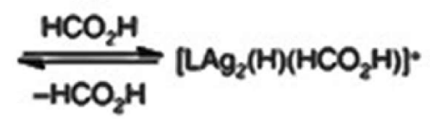

(iv)

b
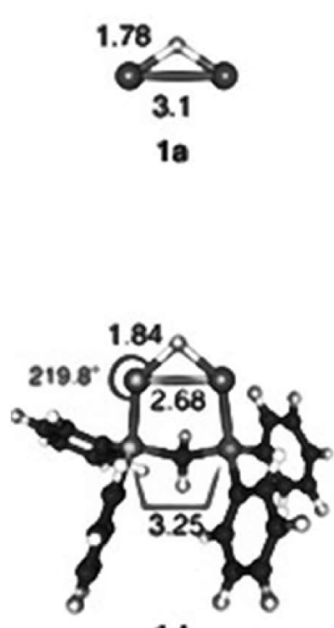

1d
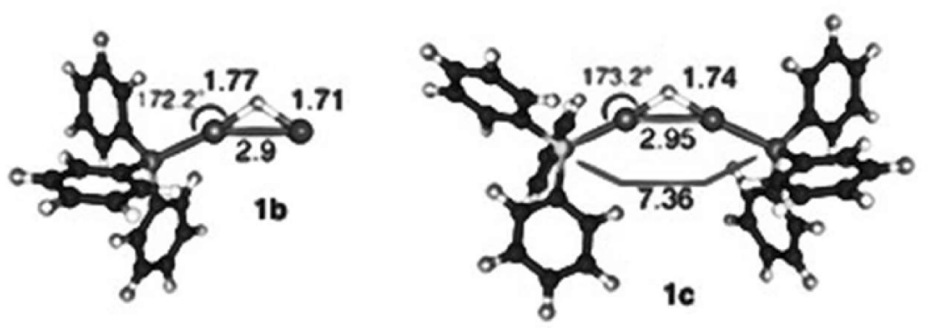

Fig. 4. a-b: Ligated silver hydride ion and its decarboxylation/dehydrogenation of formic: a. catalytic process cycle involving (i) the decarboxylation of $\left[\mathrm{LAg}_{2}\left(\mathrm{O}_{2} \mathrm{CH}\right)\right]^{+}$through collision-induced dissociation (CID) to give $\left[\operatorname{LAg}_{2}(\mathrm{H})\right]^{+}$(ii) ionic reaction of $\left[\operatorname{LAg}_{2}(\mathrm{H})\right]^{+}$ to give $\left[\mathrm{LAg}_{2}\left(\mathrm{O}_{2} \mathrm{CH}\right)\right]^{+}$(iii) ionic combination of $\left[\mathrm{LAg}_{2}(\mathrm{H})\right]^{+}$. (iv), CID of $\left[\mathrm{LAg}_{2}(\mathrm{H})\right.$ $\left.\left(\mathrm{HO}_{2} \mathrm{CH}\right)\right]^{+}$to reproduce $\left[\mathrm{LAg}_{2}(\mathrm{H})\right]^{+}$(v) molecular combination of $\left[\operatorname{LAg}_{2}(\mathrm{H})\right.$ $\left.\left(\mathrm{HO}_{2} \mathrm{CH}\right)\right]^{+}$and $\mathrm{HO}_{2} \mathrm{CH}$ to give $\left[\mathrm{LAg}_{2}(\mathrm{H})\right.$ $\left.\left(\mathrm{HO}_{2} \mathrm{CH}\right)_{2}\right]^{+}$(vi) $\mathrm{CID}$ of $\left[\mathrm{LAg}_{2}(\mathrm{H})\right.$ $\left.\left(\mathrm{HO}_{2} \mathrm{CH}\right)_{2}\right]^{+}$to produce the $\left[\operatorname{LAg}_{2}(\mathrm{H})\right.$ $\left.\left(\mathrm{HO}_{2} \mathrm{CH}\right)\right]^{+}$.b. results from the most stablestructures examined: 1a-f. The DFT hybrid functional B3LYP was used alongside def2TZVP AO as basis for all atoms and with their corresponding relativistic effective Agatoms core potential. Bond distances are illustrated with $\AA$ (black) and $\mathrm{P}-\mathrm{Ag}-\mathrm{H}$ bond angles in degrees (red). Adopted from Zavras et al. [75]. 
hydrogen synthesis. Fig. 5a-k shows the comingling of $\mathrm{HCOOH}$ and hydrogen atoms/molecule on a sample $\mathrm{Pd}_{22} \mathrm{Au}_{33}$ catalyst cluster.

The activity of $\mathrm{PdCoNi} / \mathrm{TiO}_{2}-\mathrm{ALD}-\mathrm{SiO}_{2}$ catalyst was examined by Caner et al. [71] during formic acid decomposition; they accounted for the performance of the catalyst by constantly monitoring the volumetric-hydrogen evolution using gas displacement technology as discussed in previous works [79-92]; in testing the catalyst's performance, the weight of the catalyst reaction flask was monitored per time. In recent times, pure separate atoms of Au and Pd, as well as Pd-Au core shells and Au-Pd core-shells were synthesized as catalytic decomposers of formic acid. The volume of hydrogen produced from the reactions catalysed by the last three catalysts were obtained in the following order: $100 \mathrm{~mL}$ in $600 \mathrm{~min}, 230 \mathrm{~mL}$ in $150 \mathrm{~min}$ and $200 \mathrm{~mL}$ in $50 \mathrm{~min}$, respectively. The results revealed the increased catalytic activities as well as product $\left(\mathrm{H}_{2}\right)$ selectivity of the catalysts for FA [93]; these results are also supported by results obtained by other investigators [87,94-99]. Catalyst-orientation can be in several categories including single crystals [100-102] and bulk forms [103], as supports/anchors [104-106], organic complexes of metals [107,108] and metallic salts [109]. Noble metals only have the capacity to catalyse the dehydrogenation step of formic acid decomposition while base metals and their oxides are useful for the dehydration and dehydrogenation steps [104]; this justifies the idea of catalyst-hybridization in order to take advantage of, as well as maximize the catalytic potential of each class/type of catalyst. However, based on the work of Sanni et al. [24], it is obvious that the Cu-tertiary amine system adopted, has the ability to overcome these odds since the dehydrogenation step induced by noble metalcatalysts takes advantage of the intermediate formates/complexes formed at the dehydrogenation stage $[100,105]$. According to Silbaugh et al. [106] monodentate formate is a key intermediate product of formic acid decomposition that is further converted to bidentate formate; this reaction is reversible in nature which explains the tendency for reestablishing the system's equilibrium. The thermochemical analyses of the decomposition of $\mathrm{HCOOH}$ on sample-facets of $\mathrm{Au}, \mathrm{Ag}, \mathrm{Co}, \mathrm{Cu}, \mathrm{Ni}$, Os, $\mathrm{Pt}, \mathrm{Pd}, \mathrm{Rh}$ and $\mathrm{Ru}$ catalysts have been investigated [18]. The study discussed the use of DFT in examining the mechanisms of $\mathrm{HOOH}$ decomposition to give $\mathrm{HCOO}^{*}$ via surface intermediates or the release of the carboxyl group via $\mathrm{COOH}^{*}$-surface intermediate. Based on the findings, the adsorption of $\mathrm{HCOOH}$ at the water-removal stage helps to disintegrate either the $\mathrm{C}-\mathrm{H}$ bond to form $\mathrm{COOH}^{*}$ or the $\mathrm{O}-\mathrm{H}$ bond to form $\mathrm{HCOO}^{*}$. Thereafter, cleavage and evolution of the remaining proton and $\mathrm{CO}_{2}$ take place respectively. A systemic analysis of bulkmetal catalyst-activity in $\mathrm{HCOOH}$ decomposition was carried out by monitoring parameters such as surface composition of metals, number of catalyst-active-sites, type of surface intermediates formed, formic acid adsorption equilibrium, Density Functional Theory -Thermal Dynamics (DFT-TD) and reaction rates at steady state [103]. According to their hypothesis, all the catalysts provided evidence of $\mathrm{CO}_{2}$ and $\mathrm{CO}$ formation during the dehydration and dehydrogenation steps of surface $\mathrm{HCOO}^{*}$ species, respectively. It was also reported that the TD-Drifts revealed that the surface $\mathrm{HCOO}^{*}$ may be mono- or bi- dentate in kind, depending on the metal-catalyst adopted. Furthermore, they observed that there was no correlation between the resulting gas-ratio (i.e. $\mathrm{CO}_{2}$ to $\mathrm{CO}$ ratio) and the nature of surface formates formed for each catalyst. Based on HCOO* decomposition rates, the following list was established in increasing order of catalyst-performance: $\mathrm{Rh}<\mathrm{Fe}<\mathrm{Ag}<\mathrm{Ni}<\mathrm{Au}<\mathrm{Co}<\mathrm{Pd}<\mathrm{Cu}<\mathrm{Pt}$ and, these were found to bear a poor correlation with the Turn over Frequencies (ToF) at steadystate. The work of Zhong et al. [110] involves the use of a Pd heterogeneous catalyst for the catalytic dehydrogenation of $\mathrm{HCOOH}$, while Li and $\mathrm{Xu}$ [111] also adopted a nano-catalyst in synthesizing high pressure hydrogen from formic acid.

Table 2 contains the rates of formation $\left(\mathrm{W}_{\mathrm{st}}\right)$ of $\mathrm{CO}$ and $\mathrm{CO}_{2}$ measured at steady state (i.e. for varying \%volume of hydrogen produced) for different experimental runs at 120 and $140{ }^{\circ} \mathrm{C}$. The CO conversion $(\mathrm{X} \%)$ and Catalyst Selectivity for $\mathrm{CO}\left(\mathrm{S}_{\mathrm{Co}}\right)$ are also shown as obtained from the experiment. Based on the results, it can be inferred that the rate of decomposition of $\mathrm{HCOOH}$ is less dependent on acid concentration but on $\% \mathrm{vol}$ of $\mathrm{H}_{2} \mathrm{O}$ formed. Looking at the data generated for experimental runs 1 and 2. For zero \%water volume, the transformation rate/conversion and selectivity only varied slightly within the range of $10-13 \%$ and $78-76 \%$, respectively for a change of $2.4-1.3$ $\mathrm{HCOOH}$-acid concentration at $120^{\circ} \mathrm{C}$. Comparing the \%vol of water in runs $3-5$, the conversion dropped from 9 to $5 \%$ with the CO selectivity $\mathrm{S}_{\mathrm{CO}}$ dropping to as low as $47 \%$; the rate of formation of $\mathrm{CO}_{2}$ also dropped from 0.27 to 0.24 , hence, $\mathrm{CO}_{2}$ selectivity shows an indirect variation

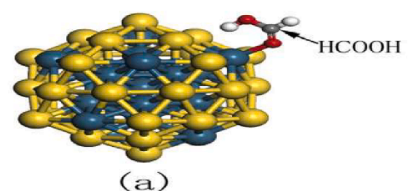

(a)
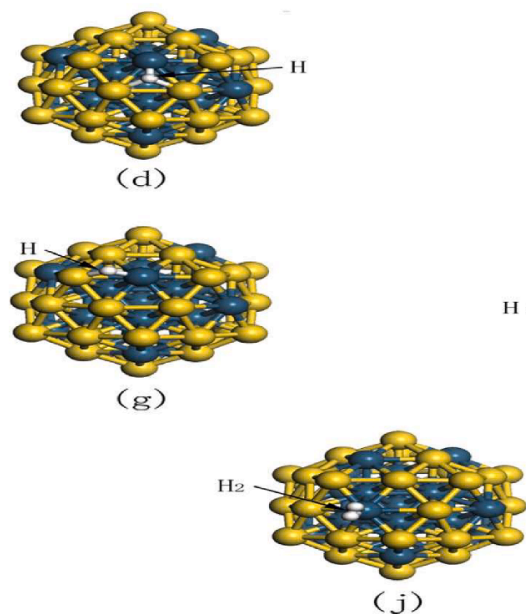
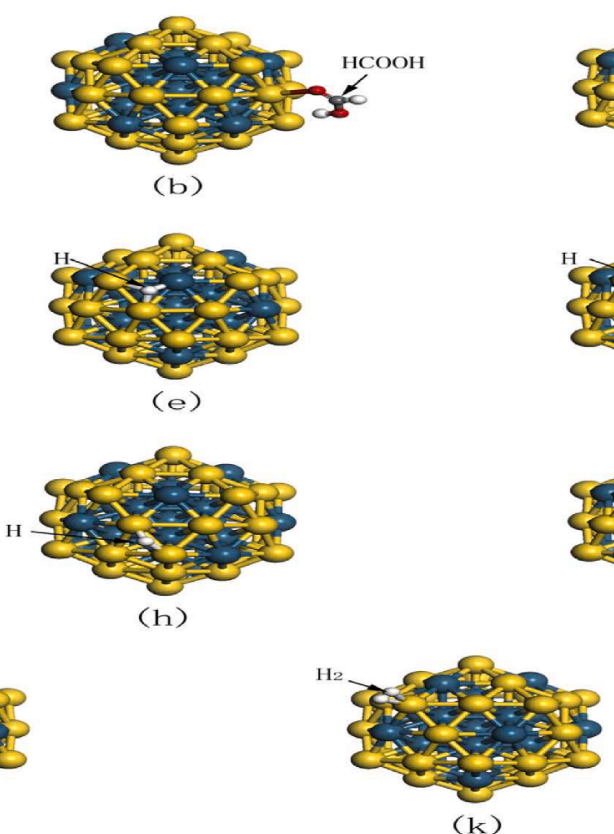
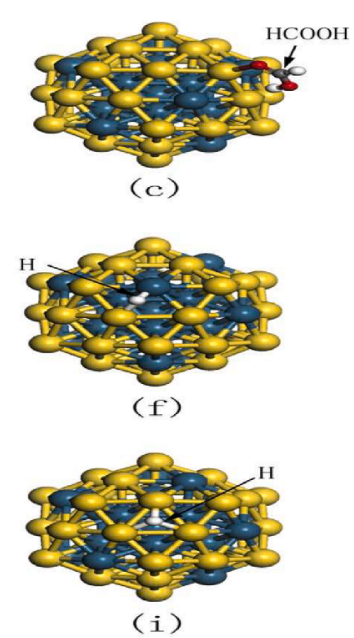

(i)

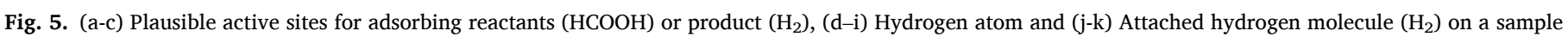
$\mathrm{Pd}_{22} \mathrm{Au}_{33}$ cluster. .

Adopted from [74] 
Table 2

Steady State Formic Acid-Decomposition Data for Different experimental runs.

\begin{tabular}{|c|c|c|c|c|c|c|c|c|}
\hline \multirow[t]{2}{*}{ No } & \multirow[t]{2}{*}{$\mathrm{T}^{\mathrm{a}}, \mathrm{S}$} & \multirow{2}{*}{$\frac{\text { Conc. }}{\mathrm{HCOOH}}$} & \multicolumn{2}{|l|}{$\%$ vol } & \multirow[t]{2}{*}{$\mathrm{X} \%$} & \multicolumn{2}{|c|}{ Wst * $10^{9}$} & \multirow{2}{*}{$\begin{array}{l}\mathrm{S}_{\mathrm{Co}} \% \\
\mathrm{CO}\end{array}$} \\
\hline & & & $\mathrm{H}_{2} \mathrm{O}$ & $\mathrm{O}_{2}$ & & $\mathrm{CO}$ & $\mathrm{CO}_{2}$ & \\
\hline \multicolumn{9}{|c|}{$\mathrm{T} @ 120^{\circ} \mathrm{C}$} \\
\hline 1 & 0.77 & 2.4 & 0 & 20 & 10 & 1.34 & 0.38 & 78 \\
\hline 2 & 0.79 & 1.3 & 0 & 20 & 13 & 1.26 & 0.4 & 76 \\
\hline 3 & 0.45 & 2.3 & 3.8 & 20 & 9 & 0.59 & 0.29 & 67 \\
\hline 4 & 0.50 & 1.4 & 3.8 & 20 & 12 & 0.47 & 0.27 & 64 \\
\hline 5 & 0.44 & 2.2 & 9.5 & 20 & 6 & 0.29 & 0.24 & 55 \\
\hline 6 & 0.46 & 2.3 & 14.5 & 20 & 5 & 0.22 & 0.24 & 47 \\
\hline \multicolumn{9}{|c|}{$\mathrm{T} @ 140{ }^{\circ} \mathrm{C}$} \\
\hline 7 & 1.94 & 1.8 & 0 & 20 & 25 & 8.3 & 1.3 & 86 \\
\hline 8 & 0.56 & 2.0 & 9.8 & 20 & 20 & 1.8 & 0.51 & 78 \\
\hline 9 & 0.46 & 1.8 & 15.0 & 20 & 27 & 1.8 & 0.5 & 78 \\
\hline 10 & 0.49 & 1.7 & 17.0 & 20 & 23 & 1.5 & 0.55 & 73 \\
\hline
\end{tabular}

$\mathrm{T}^{\mathrm{a}}=$ contact time, Conc. $=$ concentration, Wst.

Source: Sadovskaya et al. [73].

with the amount of water recovered. For water concentration in the range of $0-14.5 \%$, the rate of $\mathrm{CO}$ formation dropped by 6 times at $120^{\circ} \mathrm{C}$, while the $\mathrm{S}_{\mathrm{Co}}$ dropped by about $30 \%$. When the reaction temperature was raised to $140{ }^{\circ} \mathrm{C}$, the overall rate of decomposition of $\mathrm{HCOOH}$ and $\mathrm{S}_{\mathrm{Co}}$ increased (see results obtained at $120^{\circ} \mathrm{C}$ ). Since water vapourizes faster at $140^{\circ} \mathrm{C}$ relative to $120^{\circ} \mathrm{C}$, the effect of water vapour on the reaction at $140{ }^{\circ} \mathrm{C}$ is less pronounced. For a $\% \mathrm{vol} \mathrm{H}_{2} \mathrm{O}$ of $0-15 \%$, the rate of formation of $\mathrm{CO}$ dropped by 4.5. Also, the selectivity of the catalyst towards $\mathrm{CO}$ decreased by $10 \%$ approximately.

Because, a catalyst selectivity of less than $50 \%$ CO is poor (Table 2), the values for all 3 parameters in Fig. 6 were chosen from runs 1-3. The optimum $\mathrm{HCOOH}$ concentration for high CO selectivity is between 2 and $3 \mathrm{M}$ for $0.44-0.45 \mathrm{~T}^{\mathrm{a}}, \mathrm{S}$ with respective water volumes of 3.8 and $9.5 \%$ as obtained from the dehydration steps for runs 2 and 3 . An equilibrium point where $\mathrm{S}_{\mathrm{CO}}$ selectivity $=77 \%$ was also established between both runs. Furthermore, in order to obtain the best results, the conditions suggested for runs 2 and 3 must be maintained. Borrowing a leaf from the observations in ref [73], while considering the very high FAconversion obtained by Sanni et al. [24] for both theoretical and experimental hydrogen estimates, it then implies that the CO selectivity was impeded up to the 20th run by the help of the tertiary amine which served as support for the Cu-catalyst, however, $\mathrm{CO}$ selectivity increased after the $20^{\text {th }}$ run because there was an incipient drop in the catalytic activity of Cu-triethanolamine, which further resulted in the reduction in volume of hydrogen recovered for further runs. This they allotted to be caused by catalyst poisoning, $\mathrm{pH}$ alteration, formation of a complex, steric hindrance etc.

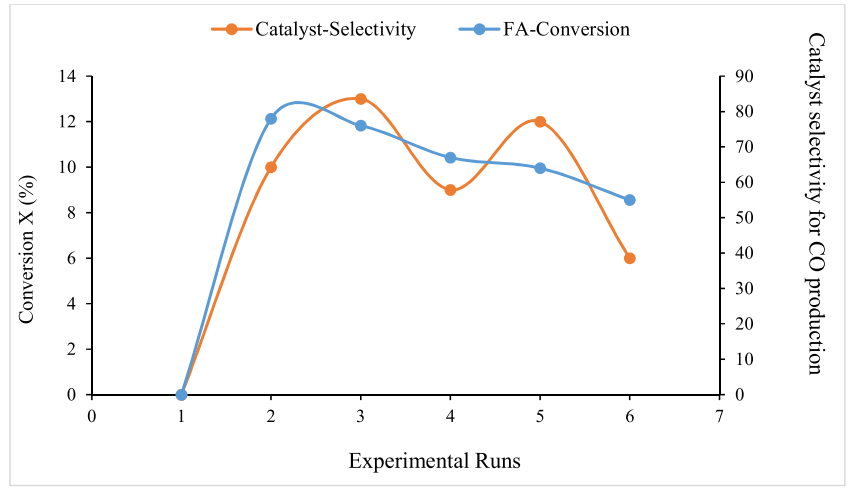

Fig. 6. Catalyst selectivity for $\mathrm{CO}$ vs $\mathrm{HCOOH}-$ Concentration and Conversion (a) $120^{\circ} \mathrm{C}$.

\section{Bond energies of reacting species in FA decomposition reactions}

The catalytic-activities of single metal catalysts are enhanced when they are hybridized or alloyed. This is because of the synergistic effect offered by each of the metals in their combined form, which in turn lowers the activation energy of the reaction to give $\mathrm{H}_{2}$. It has been reported that the superficial energy of Au is smaller than that of Pd [112], which is the reason the surface area/active sites of the hybrid catalyst is rather more-enhanced as induced by $\mathrm{Au}$ [113]. What this then suggests is that, for heterogeneous catalyst-composites, the wrapping material is of utmost concern i.e., it should comprise more of the more/most active metal of any two or more catalyst-options. According to Ding et al. [114], the nano-clustering nature of metallic nano-composites can be examined using a High-Resolution Transmission Electron Microscopy (HRTEM). Based on their findings, after epitaxially-growing the less active metal $(\mathrm{Pd})$ on the more active metal $(\mathrm{Au})$, there was a concentration gradient set up within the crystal lattice of the alloy, which further resulted in the diffusion of Au to the surface, thus annulling the lattice mismatch between both atoms. In addition, the presence of both atoms along the Long Range Ordered Plane (LROP) is approximately 1:1 which is stable below $800 \mathrm{~K}$. According to Wang et al. [102] the decomposition of formic acid on Pd surface to give two moles of hydrogen atoms and one mole of $\mathrm{CO}_{2}$ is possible within surmountable/ permissible reaction constraints, however, there is need for caution since Pd has high affinity for hydrogen thus causing dissociation of the atoms and subsequent binding of the atoms to the surface of Pd; this strong hydrogen adherence makes it almost impossible for the comingling of two $\mathrm{H}$ atoms to form hydrogen molecule on the surface of Pd [115]. On the contrary, the adherence of hydrogen to the surface of Au is characterized by a weak bond [116] and based on the account of Yu et al. [117], the average characteristic bond-energy of hydrogen to the Au-Pd nanocluster-surface lies between the individual bond energies of both atoms. To complement the aforementioned statement, Liu et al. [73] opined that, the increased production of hydrogen from $\mathrm{HCOOH}$ decomposition is as a result of the weak forces of adsorption of $\mathrm{H}_{2}$ on the Au-Pd surface.

Table 3 gives the nature of the active sites and adsorption energies of PdAu clusters to $\mathrm{H}_{2}, \mathrm{H}$ and $\mathrm{HCOOH}$; some of the species are attached to vertices, the face-/hexagonal-cubic centres, along edges, as well as bridges of the catalyst clusters. In accordance with previous discussions, the bridge, face/hexagonal centres and edges mentioned for the single and heterogeneous catalysts in ref. [73], can be likened to the different orientations exhibited by the coordination sites of copper i.e. $\mathrm{Cu}(110)$, $\mathrm{Cu}(101)$ and $\mathrm{Cu}(111)$ when used on catalyst supports such as triethanolamine.

\section{Elementary steps for hydrogen formation from formic acid}

HCOOH-decomposition is largely contributed by the dehydrogenation step. The overall decomposition involves two process routes: dehydrogenation and dehydration whose reaction rates are dependent on the nature/type of catalyst, system-pH as well as the reaction temperature (if not kept constant) [118]; the stoichiometric equations for the reactions are as given by (2) and (3).

Scheme A

$\mathrm{HCOOH}{ }^{\mathrm{Cu} 2+/ \mathrm{R} 1 \mathrm{R} 2 \mathrm{NH} 2} \rightarrow \mathrm{H}_{2} \mathrm{O}+\mathrm{CO} \Delta \mathrm{G}_{353} \mathrm{~K}\left(\Delta \mathrm{G}_{298} \mathrm{~K}=-14.9 \mathrm{~kJ} /\right.$ mol (Dehydration- initiation step) (2)

$\mathrm{HCOOH}{ }^{\mathrm{Cu} 2+/ \mathrm{R} 1 \mathrm{R} 2 \mathrm{NH} 2} \rightarrow \mathrm{H}_{2}+\mathrm{CO}_{2} \Delta \mathrm{G}_{353} \mathrm{~K}\left(\Delta \mathrm{G}_{298} \mathrm{~K}=-35.0 \mathrm{~kJ} / \mathrm{mol}\right.$ (Dehydrogenation-initiation step) (3)

The first step is a dehydration step (2), while the second (3) is the dehydrogenation step where hydrogen is produced.

Mackay et al. [119] proposed two reaction schemes for $\mathrm{HCOOH}$ decomposition as presented in (4) and (5). 
Table 3

Active sites and adsorption energies of $\mathrm{HCOOH}, \mathrm{H}$ and $\mathrm{H}_{2}$ on $\mathrm{Pd}_{55}, \mathrm{Pd}_{27} \mathrm{Au}_{28}$ and $\mathrm{Pd}_{22} \mathrm{Au}_{33}$ clusters.

\begin{tabular}{|c|c|c|c|c|c|c|}
\hline \multirow[t]{2}{*}{ Species } & \multicolumn{2}{|l|}{$\mathrm{Pd}_{22}$} & \multicolumn{2}{|l|}{$\mathrm{Pd}_{27}$} & \multicolumn{2}{|l|}{$\mathrm{Pd}_{55}$} \\
\hline & Active site & $\begin{array}{l}\text { Elec. } \\
\text { Volts } \\
* 10^{-1}\end{array}$ & $\begin{array}{l}\text { Active } \\
\text { site }\end{array}$ & $\begin{array}{l}\text { Elec. } \\
\text { Volts }\end{array}$ & Active site & $\begin{array}{l}\text { Elec. } \\
\text { Volts }\end{array}$ \\
\hline \multirow[t]{2}{*}{$\mathrm{HCOOH}$} & (a) Vertex & -8 & (a) $\mathrm{Pd}$ & -0.7 & (a) $\mathrm{Pd}$ & -0.66 \\
\hline & (b) Edge & -7.3 & $\begin{array}{l}\text { (b) } \mathrm{Au} \\
\text { vertex }\end{array}$ & -0.5 & $\begin{array}{l}\text { (b) } \mathrm{Au} \\
\text { vertex }\end{array}$ & -0.53 \\
\hline \multirow[t]{6}{*}{$\mathrm{H}$} & (c) Fcc & -3.13 & $\begin{array}{l}\text { (c) } \mathrm{Au} \\
\text { edge }\end{array}$ & -0.28 & (c) Au edge & -0.32 \\
\hline & (d) Hcp & -3.10 & (d) & -2.94 & (d) & -2.64 \\
\hline & & & $\begin{array}{l}\mathrm{Pd}_{2} \mathrm{Au} \\
\text { fcc }\end{array}$ & & $\mathrm{PdAu}_{2} \mathrm{fcc}$ & \\
\hline & (e) Bridge & -3.01 & (e) & -2.91 & (e) & -2.61 \\
\hline & $\begin{array}{l}\text { (Vertex- } \\
\text { edge) }\end{array}$ & & $\begin{array}{l}\mathrm{Pd}_{2} \mathrm{Au} \\
\text { hcp }\end{array}$ & & $\mathrm{PdAu}_{2} \mathrm{hcp}$ & \\
\hline & (f) Bridge & -3.00 & $\begin{array}{l}\text { (f) } \\
\mathrm{PdAu}_{2} \\
\text { hcp }\end{array}$ & -2.63 & $\begin{array}{l}\text { (f) PdAu } \\
\text { bridge (Au } \\
\text { edge) }\end{array}$ & -2.62 \\
\hline \multirow[t]{5}{*}{$\mathrm{H}_{2}$} & (g) Vertex & -0.48 & $\begin{array}{l}\text { (g) } \\
\text { PdAu } \\
\text { bridge }\end{array}$ & -2.74 & $\begin{array}{l}\text { (g) PdAu } \\
\text { bridge }\left(A_{u}\right. \\
\text { vertex })\end{array}$ & -2.65 \\
\hline & (h) Edge & -0.51 & $\begin{array}{l}\text { (h) } \\
\text { AuAu } \\
\text { bridge }\end{array}$ & -2.5 & $\begin{array}{l}\text { (h) AuAu } \\
\text { bridge } \\
\text { (vertex- } \\
\text { edge) }\end{array}$ & -2.42 \\
\hline & & & (i) Pd & -0.5 & (i) $\mathrm{Au}_{3}$ fcc & -2.3 \\
\hline & & & $\begin{array}{l}\text { (j) } \mathrm{Au} \\
\text { vertex }\end{array}$ & -0.14 & (j) Pd & -0.46 \\
\hline & & & & & $\begin{array}{l}\text { (k) Au } \\
\text { vertex }\end{array}$ & -0.16 \\
\hline
\end{tabular}

Source: Liu et al. [73].

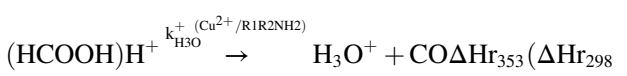

$=78 \mathrm{~kJ} / \mathrm{mol}$, protonation - final step)

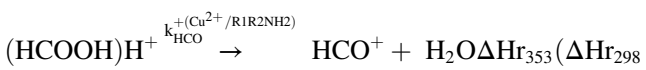

$$
\begin{aligned}
& =181 \mathrm{~kJ} / \mathrm{mol} \text { (Dehydration - final step) }
\end{aligned}
$$

If it is assumed that all four reactions are important steps in formic acid decomposition, then, in combining those two schools of thought, one can see all four steps as being very important to the hydrogen formation step, hence the proposed scheme of elementary steps for $\mathrm{HCOOH}$ decomposition is in the order of (4-5 or 2-3). The distribution ratio of $\mathrm{HCO}^{+}: \mathrm{H}_{3} \mathrm{O}^{+}$is $7: 3$ and the reactions in equations (4)-(5) show that the decomposition of protonated metastable ions of $\mathrm{HCOOH}$ give hydroxonium and formyl ions $[120,121]$. The difference in heat of reaction values for both steps was reported to have some measure of thermochemical variations during their product formation steps. The percentage composition of the products of the reactions in equations (2)-(5) are as shown in Table 4a. However, the heat of reaction is obviously lowered alongside the estimated $\Delta \mathrm{G}$ at $353 \mathrm{~K}$; more explanation is given on this in section Structural forms and activation energies of reactions at the active sites of copper considering the active sites of copper.

\section{Table 4a}

Energy requirement for the protonation and dehydration steps of FA decomposition.

\begin{tabular}{lll}
\hline Temperature, $\mathrm{K}$ & Products (\%) \\
\cline { 2 - 3 } & $\mathrm{H}_{3} \mathrm{O}^{+}+\mathrm{CO}$ & $\mathrm{HCO}^{+}+\mathrm{H}_{2} \mathrm{O}$ \\
\hline 298 & 60 & 40 \\
1000 & 40 & 60 \\
This work & & 17.8 \\
353 & 82.2 & \\
\hline
\end{tabular}

Adapted from ref. [121].
Other supplementary reactions proposed by Sekiguchi et al. [121] for FA decomposition can be mimicked for the Cu-triethanolamine-FA system:

$$
\begin{aligned}
& \mathrm{k}_{1} \\
& \mathrm{CuR} 1 \mathrm{R}_{2} \mathrm{NH}_{2}{ }^{+}+\mathrm{HCOOH} \rightarrow[\mathrm{HCOOH}] \mathrm{H} \\
& \mathrm{k}_{2} \\
& (\mathrm{HCOOH}) \mathrm{H}+\stackrel{\mathrm{k}_{3}}{\longrightarrow} \mathrm{H}_{3} \mathrm{O}^{+}+\mathrm{CO} \\
& \rightarrow \mathrm{HCO}++\mathrm{H}_{2} \mathrm{O} \\
& \mathrm{H}_{3} \mathrm{O}^{+}+\mathrm{HCOOH} \rightarrow[\mathrm{HCOOH}] \mathrm{H}^{+}+\mathrm{H}_{2} \mathrm{O} \\
& \mathrm{k}_{5} \\
& \mathrm{HCO}^{+}+\mathrm{HCOOH} \rightarrow[\mathrm{HCOOH}] \mathrm{H}^{+}+\mathrm{CO}
\end{aligned}
$$$$
\text { Scheme B }
$$

$\mathrm{Cu}-\mathrm{R} 1 \mathrm{R} 2 \mathrm{NH}_{2}+\mathrm{HCOOH}^{\mathrm{k}_{6}} \rightarrow \mathrm{Cu}-\mathrm{R} 1 \mathrm{R} 2 \mathrm{NH}_{2}+\mathrm{HCOOH}^{+} \Delta \mathrm{Hr}$

$=137 \mathrm{kJmol}^{-1}$ (dehydration)

$\mathrm{HCO}^{+}+\mathrm{HCOOH}^{\mathrm{k}_{7}} \rightarrow \mathrm{H}_{2}+\mathrm{Cu}-\mathrm{R} 1 \mathrm{R} 2 \mathrm{NH}_{2}+\mathrm{HCOO}^{+}$(final step) $\Delta \mathrm{Hr}$

$=49 \mathrm{kJmol}^{-1}$ (dehydrogenation)

$T o F=\frac{P_{\text {atmospheric }} V_{\text {gas }}}{\frac{R T}{2^{*} n_{C u} t}}$

Where:

$P_{\text {atmospheric }}=$ atmospheric pressure in N/m $\mathrm{m}^{2}=(101325 \mathrm{~Pa})$,

$V_{\text {gas }}=$ generated volume of $\mathrm{H}_{2}-\mathrm{CO}_{2}$ gas $(815 \mathrm{~mL} / 2=407.5 \mathrm{~mL})$ at half-life of the gas generation,

$R=$ universal gas constant $\left(8.3145 \mathrm{~m}^{3} \mathrm{~Pa} \mathrm{~mol}^{-1} \mathrm{~K}^{-1}\right)$,

$T=$ reaction temperature $(333 \mathrm{~K})$,

$\mathrm{n}_{\mathrm{Cu}}=$ total mole number of $\mathrm{Cu}$ atoms in catalyst $(0.8315 * 1$; obtained from Table 4), and $t$ is the time of half-completion of gas generation (180 min).

$\mathrm{HCOOH} \stackrel{\mathrm{R} 1 \mathrm{R} 2-\mathrm{NH} 2 / \mathrm{Cu} 2+}{\rightarrow} \mathrm{CO}_{2}+\mathrm{H}_{2}$

The energy difference of the dehydration step at $298 \mathrm{~K}$ as given in equation (4) is expected to be less than the energy requirement of equation 8 (whose value was not reported), this is evident due to the difference in the dehydrogenation steps of schemes A and B as seen in equations (4) and (12), respectively, giving a change of $29 \mathrm{kJmol}^{-1}$. Comparing the total heat of reaction for the dehydrogenation step in scheme A (heat-summation of equations 2 , initiation step and 4 , final step $=$ i.e. $\left.(-35+78)=43 \mathrm{kJmol}^{-1}\right)$ to that of the final step of scheme B i.e. equation (11) $\left(49 \mathrm{kJmol}^{-1}\right)$, it is obvious that the latter (dehydrogenation step- scheme B) gives more energy consumption than the former (dehydrogenation step- scheme A) with the energy difference of both schemes' being $6 \mathrm{kJmol}^{-1}$. Also, the quantity of heat required for the dehydration step is far higher than that required for the dehydrogenation step. This then justifies the reason why some reactions are initiated at higher temperatures depending on the ability of the catalyst to alter the reaction rate or impede the dehydration step, so that most of the energy supplied to the system is not used in producing water and $\mathrm{CO}$, which reduces the tendency for hydrogen release from FA. When scheme $A$ is critically examined, the reaction in 5 then looks to comprise of the series of elementary steps shown in scheme B's (reactions (6)-(12)) dehydrogenation-step, that is, both schemes seem to have similar characteristics/features despite the difference in the heat of dehydrogenation (i.e. $6 \mathrm{kJmol}^{-1}$ ) of both schemes, which may have been stimulated by the nature of the reactions in the schemes, variation in catalyst type, support(s) and process conditions. Table $4 \mathrm{~b}$ gives a summary of the metallic cations and conditions for exemplifying the FA dehydrogenation steps explained in scheme B.

The average ToF of hydrogen gas produced from FA dehydrogenation reactions, as well as the estimated activation energies of the 
Table 4b

Summary of some metallic cations alongside $\mathrm{Cu}^{2+} / \mathrm{R} 1 \mathrm{R} 2 \mathrm{NH}_{2}$ conditions responsible for the $\mathrm{HCOOH}$ decomposition.

\begin{tabular}{|c|c|c|c|}
\hline Cation & $\begin{array}{l}\text { Radical/ } \\
\text { atom }\end{array}$ & $\begin{array}{l}\text { Difference in proton affinity } \\
\Delta \mathrm{P}_{\mathrm{r} . \text { aff }}\left(\mathrm{kJmol}^{-1}\right)\end{array}$ & Method of synthesis \\
\hline $\mathrm{HCl}^{+}$ & I & 138.8 & $\begin{array}{l}\text { Electron ionization of } \\
\text { ammonium iodide }\end{array}$ \\
\hline $\mathrm{H}_{2} \mathrm{Cl}^{+}$ & $\mathrm{HCl}$ & 185.1 & $\begin{array}{l}\text { Chemical ionization of } \\
\mathrm{NH}_{4} \mathrm{Cl} \text { to } \mathrm{H}_{2} \mathrm{Cl}^{+}\end{array}$ \\
\hline $\mathrm{CH}_{5}^{+}$ & $\mathrm{CH}_{4}$ & 198.5 & Chemical ionization \\
\hline $\mathrm{HCO}_{2}^{+}$ & $\mathrm{CO}_{2}$ & 201.5 & $\begin{array}{l}\text { Electron ionization of } \\
\mathrm{HCOOH}\end{array}$ \\
\hline$\stackrel{\mathrm{HCl}}{\mathrm{Cu}^{2+}}$ & $\begin{array}{l}\mathrm{Cl} \\
\mathrm{R} 1 \mathrm{R} 2 \mathrm{NH}_{2}\end{array}$ & $\begin{array}{l}228.4 \\
\text { Not measured }\end{array}$ & $\begin{array}{l}\text { Electron ionization of } \\
\mathrm{NH}_{4} \mathrm{Cl} \\
\text { Chemical vapour } \\
\text { deposition }\end{array}$ \\
\hline
\end{tabular}

Adopted from Sekiguchi et al. [121]; Lias et al. [122].

$\Delta \mathrm{P}_{\text {r.aff }}=\Delta \mathrm{P}_{\text {r.aff }}$ (Metal) $-\Delta \mathrm{P}_{\text {r.aff }}$ (formic acid). All values have uncertainties in the region of $10 \mathrm{kJmol}^{-1}$ while $\Delta \mathrm{P}_{\mathrm{r} . \mathrm{fff}}(\mathrm{HCOOH})=228.4 \mathrm{kJmol}^{-1}$.

$\mathrm{M}=$ metallic cation and $\mathrm{MH}^{+}=$metallic composite.

reactions at different temperatures, for different catalysts, are documented in Table 5 .

Table 6 compares the results of the estimated ToFs as obtained for

Table 5

Catalytic performance of different catalysts used in the dehydrogenation of formic acid.

\begin{tabular}{|c|c|c|c|c|c|}
\hline Catalyst & $\mathrm{T}(\mathrm{K})$ & $\begin{array}{l}\text { ToF initial } \\
\left(\mathrm{h}^{-1}\right)\end{array}$ & Con. (\%) & $\begin{array}{l}\text { Ea kJ } \\
\text { mol-1 }\end{array}$ & Ref. \\
\hline $\begin{array}{l}\mathrm{Pd}_{60} \mathrm{Au}_{40} / \mathrm{ZrSBA}- \\
\quad 15-\mathrm{AP}\end{array}$ & 298 & 1185 & 95 & 42.5 & [123] \\
\hline $\mathrm{Pd} / \mathrm{CNx}$ & 298 & 639 & 98 & 48.8 & [124] \\
\hline Ag@Pd/C & 298 & 157 & 43 & - & {$[82]$} \\
\hline $\mathrm{AgPd} / \mathrm{C}$ & 298 & 274 & 46 & 22.0 & [125] \\
\hline $\mathrm{AuPd} / \mathrm{C}$ & 298 & 41 & 24 & 28.0 & {$[86]$} \\
\hline CoAuPd/C & 298 & 54 & 91 & - & [97] \\
\hline NiAuPd/C & 298 & 20 & 73 & - & [126] \\
\hline $\mathrm{AgAuPd} / \mathrm{rGO}$ & 298 & 95 & 100 & - & [127] \\
\hline CoAuPd/r-GO & 298 & 63 & 51 & - & [128] \\
\hline $\begin{array}{l}\text { CoAuPd/DNA- } \\
\text { rGO }\end{array}$ & 298 & 130 & 96 & - & [128] \\
\hline AuPd/N-mrGO & 298 & 39 & 93 & - & [83] \\
\hline $\mathrm{Au} @ \mathrm{Pd} / \mathrm{N}-\mathrm{mrGO}$ & 298 & 111 & 98 & - & [83] \\
\hline AuPd/N-rGO & 298 & 17 & 57 & - & [129] \\
\hline $\begin{array}{l}\mathrm{AuPd}-\mathrm{CeO}_{2} / \mathrm{N}- \\
\quad \mathrm{rGO}\end{array}$ & 298 & 68 & 98 & - & [129] \\
\hline AuPd/ZIF-8-rGO & 298 & 532 & 83 & - & [99] \\
\hline $\begin{array}{l}\text { AuPd-MnOx/ZIF- } \\
\text { 8-rGO }\end{array}$ & 298 & 764 & 94 & - & [99] \\
\hline $\begin{array}{l}\mathrm{PdAg}-\mathrm{MnOx} / \mathrm{N}- \\
\mathrm{SiO}_{2}\end{array}$ & 298 & 482 & 99 & 72.4 & {$[88]$} \\
\hline $\mathrm{CrAuPd} / \mathrm{N}-\mathrm{SiO}_{2}$ & 298 & 707 & 87 & 49.8 & [89] \\
\hline $\mathrm{PdAu} / \mathrm{N}-\mathrm{SiO}_{2}$ & 298 & 164 & 76 & 26.2 & [87] \\
\hline $\begin{array}{l}\mathrm{PdAu}-\mathrm{MnO}_{\mathrm{x}} / \mathrm{N}- \\
\mathrm{SiO}_{2}\end{array}$ & 298 & 981 & 92 & 26.2 & [87] \\
\hline $\begin{array}{l}\text { AgPd@MIL-100 } \\
\text { (Fe) }\end{array}$ & 298 & 58 & 37 & - & [130] \\
\hline $\mathrm{Pd} / \mathrm{SBA}-15-\mathrm{NH}_{2}$ & 298 & 127 & 28 & - & [131] \\
\hline PdNiAg & 323 & 85 & 94 & - & [90] \\
\hline SR13 FHL strain & 310 & 1228 & - & - & [38] \\
\hline $\begin{array}{l}\mathrm{PdAu}-\mathrm{MnO}_{\mathrm{x}} / \mathrm{N}- \\
\mathrm{SiO}_{2}\end{array}$ & 298 & 78.5 & 92 & - & [132] \\
\hline $\begin{array}{l}\mathrm{MnO}_{2} \& \mathrm{MnO}_{\mathrm{x}} / \\
\mathrm{RGO}\end{array}$ & 298 & $0.0003-0.003$ & - & - & [133] \\
\hline $\mathrm{Au}-\mathrm{ZrO}_{2}$ & 325 & 1590 & - & - & [81] \\
\hline $\begin{array}{l}\mathrm{PdAg}-\mathrm{MnO}_{\mathrm{x}} / \mathrm{N}- \\
\mathrm{SiO}_{2}\end{array}$ & 363 & 1400 & 99 & - & [88] \\
\hline $\mathrm{CuI}$ & 368 & 1.8 & $28 \mathrm{mmol}$ & - & [134] \\
\hline $\mathrm{Cu}(\mathrm{OAc})_{2}$ & 363 & 0.98 & $28 \mathrm{mmol}$ & - & [134] \\
\hline $\mathrm{IrNaO}_{2} \mathrm{CH}$ & 363 & 964 & 99 & - & [134] \\
\hline $\mathrm{Ru}$ & $36-400$ & 964 & $12.7 \mathrm{mmol}$ & - & [108] \\
\hline $\mathrm{Pd}^{2+/} \mathrm{C}$ & 353 & 7,256 & 98 & - & [135] \\
\hline Fe-pincer/LiBF 4 & 298 & 247 & $2.9 \mathrm{mmol}$ & - & [136] \\
\hline
\end{tabular}

Table 6

Number of Active sites (Ns), Steady-state, ToF for homogeneous catalysts at $250{ }^{\circ} \mathrm{C}$ and the $\mathrm{Cu}$-amine catalyst synthesized at $60^{\circ} \mathrm{C}$.

\begin{tabular}{llll}
\hline $\begin{array}{l}\text { Catalyst } \\
(\mu \mathrm{mol} / \mathrm{g})\end{array}$ & $\begin{array}{l}\text { Number of } \\
\text { active sites }(\mathrm{Ns})\end{array}$ & $\begin{array}{l}\mathrm{HCOOH} \text { Activity } \\
250{ }^{\circ} \mathrm{C}(\mu \mathrm{mol} / \mathrm{g} \bullet \mathrm{s})\end{array}$ & TOF $250\left({ }^{\circ} \mathrm{C} / \mathrm{s}\right)$ \\
\hline $\mathrm{Co}$ & $3.1 * 10^{1}$ & $9.3 * 10^{-2}$ & $3.0 * 10^{3}$ \\
$\mathrm{Fe}$ & $1.8^{*} 10^{2}$ & $4.0^{*} 10^{0}$ & $2.2 * 10^{-2}$ \\
$\mathrm{Ag}$ & $7.6^{*} 10^{0}$ & $3.0^{*} 10^{0}$ & $3.9 * 10^{-1}$ \\
$\mathrm{Au}$ & $5.2 * 10^{1}$ & $4.0^{*} 10^{1}$ & $7.7 * 10^{-1}$ \\
$\mathrm{Ni}$ & $1.6 * 10^{2}$ & $1.5^{*} 10^{3}$ & $9.3 * 10^{0}$ \\
$\mathrm{Rh}$ & $1.5 * 10^{1}$ & $4.8^{*} 10^{1}$ & $3.3 * 10^{0}$ \\
$\mathrm{Pd}$ & $9.9 * 10^{1}$ & $1.6 * 10^{2}$ & $1.6 * 10^{1}$ \\
$\mathrm{Cu}$ & $1.6 * 10^{1}$ & $5.2 * 10^{1}$ & $3.2 * 10^{1}$ \\
$\mathrm{Pt}$ & $1.9 * 10^{1}$ & $1.8 * 10^{3}$ & $9.8 * 10^{2}$ \\
$\mathrm{CuNP}-$ & $4.35 * 10^{0}$ & $\mathrm{ND}$ & $358.8 * 10^{0} @ 60^{\circ} \mathrm{C}[24]$ \\
$\quad$ & & \\
\hline
\end{tabular}

Source: Adopted from [24,103].

some catalysts and that of the referred Cu-tertiary amine system synthesized by Sanni et al. [24]. The data shows that the only single catalysts that performed better than the Sanni et al. [24] catalyst system, are cobalt and platinum with ToFs of 3000 and $980 \mathrm{~s}^{-1}$ respectively. The Estimated ToFs of the catalyst systems in Table 6, as well as that of the 1 M CuNP-tertiary amine system, were obtained from (13). The value of the Turn over Frequency (ToF) estimated here is an apparent ToF which is dependent on the number of $\mathrm{Cu}$ atoms in the CuNP-catalyst, and was estimated based on the half-life of the gas $\left(\mathrm{H}_{2}\right)$ produced.

Based on the sizes of the CuNPs obtained, the best CuNPs were those with an average particle size of $1.5 \mathrm{~nm}$ size. Particle size, $\mathrm{pH}$, concentration and reaction time were recounted as variables that affected the performance of the CuNP-tertiary amine system (Fig. 7). The loop in Fig. 8, shows the variation of $\mathrm{Cu}$ loading, $\mathrm{pH}$ and concentration. Knowing the value of any two of the three variables shown in the loop, will help ascertain what the value of the third variable would be without the need for any form of experimentation. Also, the optimum $\mathrm{pH}$, concentration and particle size for obtaining a theoretical conversion of $100 \%$ and an actual conversion of $82.7 \%$ were estimated to be $3.19,1 \mathrm{M}$ and $1.5 \mathrm{~nm}$, respectively (Fig. 8a). Fig. $8 \mathrm{~b}$ is a profile of the variation of partial pressure with time for the $\mathrm{Cu}$-triethanolamine system.

According to the Differential Method of Analysis (DMA) established by Sanni et al. [24], for a single catalyst-support system, the estimated order of the reaction for FA-decomposition using the CuNP-tertiary amine system, is a first-order type with intercept $-\mathrm{RTlnk}=0.004091$ (Fig. 9) and a corresponding rate constant or k-value of $1.0041 \mathrm{~s}^{-1}$. They also mentioned that, the methods used in establishing the dehydrogenation kinetics can be adopted for other single catalyst systems, whereas, for multi-catalyst or heterogeneous catalyst-support systems, the approach discussed might require some form of modification owing to the complex nature of such systems. Based on their explanations, it is the first study that adopted the differential method of analysis to establish the dehydrogenation kinetics of FA in terms of partial pressures of the species in the system.

\section{Exploring the plausible reaction pathways and copper surfaces for FA-} Decomposition

Unlike the case of Au catalyst used in FA decomposition, where three pathways i.e. $\mathrm{HCOO}$ (formate), $\mathrm{COOH}$ (carboxyl) and $\mathrm{HCO}$ (formyl) are possible as illustrated in Fig. 10, the HCO intermediate is not a feasible pathway for the case of Cu-FA decomposition, because, the HCO pathway occurs as a result of dehydroxylation of $\mathrm{HCOOH}$ by Au catalyst, which has higher activation energy compared to those of HCOO and $\mathrm{COOH}$ pathways, hence, the $\mathrm{HCOO}$ and $\mathrm{COOH}$ pathways are the only pathways considered for $\mathrm{Cu}-$ catalysed FA reactions. 
(a)

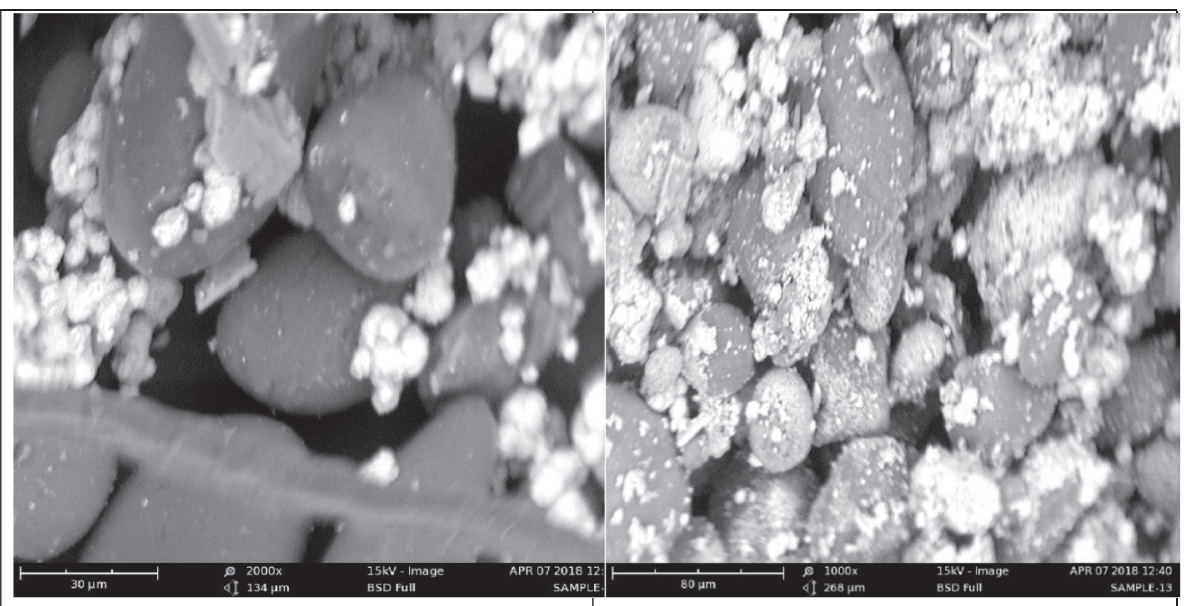

(c)

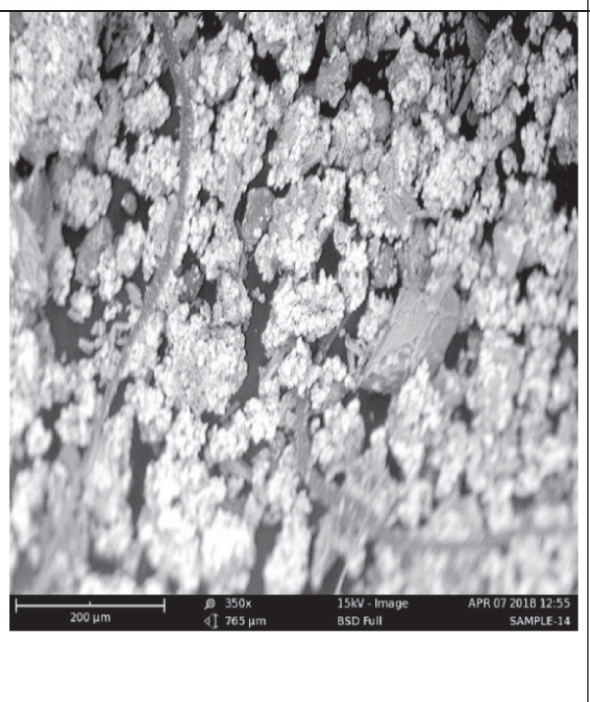

(d)

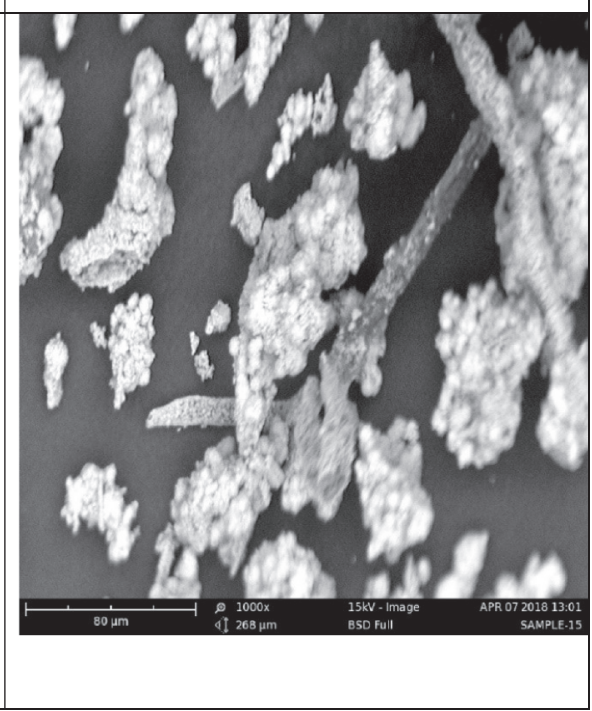

Fig. 7. SEM images of the: a. $0.6 \mathrm{M}$, b. 0.8 M, d. 1.0 M and d. 1.2 M CuNPs. Adopted from Sanni et al. [24].

Structural forms and activation energies of reactions at the active sites of copper

Adsorption configurations of five intermediates have been extensively studied on three $\mathrm{Cu}$ facets as illustrated in Fig. 11a and b. Hydrogen atom selectively binds at the three fold Face Centred Cubic (fcc) site of $\mathrm{Cu}(111)$ with an energy of $-2.26 \mathrm{eV}$, while the binding energy at the $\mathrm{Cu}(100)$ site is lower by $-0.01 \mathrm{ev}$ at its readily available four-fold site. According to the investigation, the 3 -fold fcc site nearest to the edge, is the preferred end for H-adsorption at the $\mathrm{Cu}(211)$ site; there is also a lower H-binding energy of $-2.38 \mathrm{eV}$ at the $\mathrm{Cu}(100)$ site. The $\mathrm{CO}_{2}$ released during the decomposition was seen to exhibit null preference for the three $\mathrm{Cu}$ facets, thus retaining its gas-phase linear geometry, which is characterized by a weaker binding energy i.e., $-0.1 \mathrm{eV}$ that is suggestive of physiosorption on the Cu-surface.

Also, Li et al. [50] mentioned that the carboxyl group binds to two $\mathrm{Cu}$ atoms at the $\mathrm{Cu}(111)$ surface via its free carbon and oxygen atoms, whose $\mathrm{C}-\mathrm{O}$ bond almost runs parallel to the $\mathrm{O}-\mathrm{H}$ bond pointing to the surface with an estimated bond energy of $-1.44 \mathrm{eV}$; this type of adsorption is also similar to what was observed at the $\mathrm{Cu}(211)$ step edge-surface. At the $\mathrm{Cu}(100)$ facet, the $\mathrm{COOH}$ group attaches to two opposite bridge sites in a square surrounding a hollow site. $\mathrm{COOH}$ has stronger affinity for $\mathrm{Cu}(100)$ and $\mathrm{Cu}(211)$ sites as compared to $\mathrm{Cu}(111)$ by 0.30 and $0.46 \mathrm{eV}$ energy differences, respectively. On all three coordinates, formate attaches in a bidentate configuration with its oxygen atoms bound to adjacent top sites, whereas, step-edge top sites are preferable for HCOO-attachment to the $\mathrm{Cu}(211)$ site; the approximate binding energy of $\mathrm{HCOO}$ at the $\mathrm{Cu}(111), \mathrm{Cu}(100)$, and $\mathrm{Cu}(211)$ sites are $-2.57,-2.95$, and $-3.17 \mathrm{eV}$, respectively. FA binds to the top site of all three surfaces of $\mathrm{Cu}$ with its free oxygen atom. While its $\mathrm{C}-\mathrm{H}$ bond points away from the site, the $\mathrm{O}-\mathrm{H}$ bond points inwards. At the $\mathrm{Cu}(211)$ surface, $\mathrm{HCOOH}$ attaches itself to the top-side of the step edge during the reaction and the $\mathrm{O}-\mathrm{H}$ bond is seen pointing at the step-foot atoms positioned on the terrace. The bond energy of FA increases in the order of $\mathrm{Cu}(111)<\mathrm{Cu}(100)<\mathrm{Cu}(211)$, with corresponding energies of $-0.16,-0.32$, and $-0.47 \mathrm{eV}$ at all $\mathrm{Cu}$-surfaces respectively. $\mathrm{CO}_{2}$ is also physically adsorbed and both intermediate pathways tend to attach to the step edge of $\mathrm{Cu}(211)$, thus giving binding energies in decreasing order of magnitude at all sites i.e. $\mathrm{Cu}(211)>\mathrm{Cu}(100)>\mathrm{Cu}(111)$; this was found to be in support of the notion that adsorbates exhibit higher binding strengths for unoccupied/open facets.

The profiles of the transition states of each minimum energy path is shown in Fig. 11b. Tentatively, HCO formation during dehydroxylation of FA on $\mathrm{Cu}(111)$ has a binding energy and activation energy of $1.10 \mathrm{eV}$ and $1.52 \mathrm{eV}$ [31] respectively, which triples the activation energy of $\mathrm{HCOO}$ (formate) formation from FA; this value is $0.39 \mathrm{eV}$ higher than the value for the carboxyl path $(\mathrm{COOH})$ formation from $\mathrm{HCOOH}$ at the $\mathrm{Cu}$ 
(a)

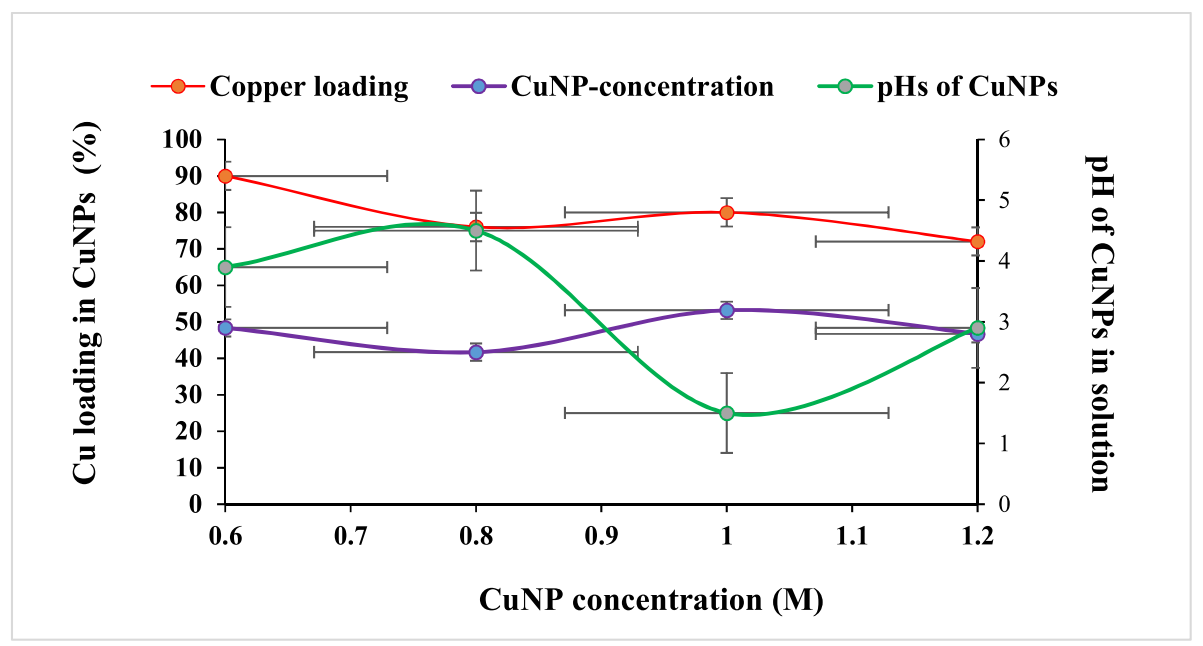

(b)

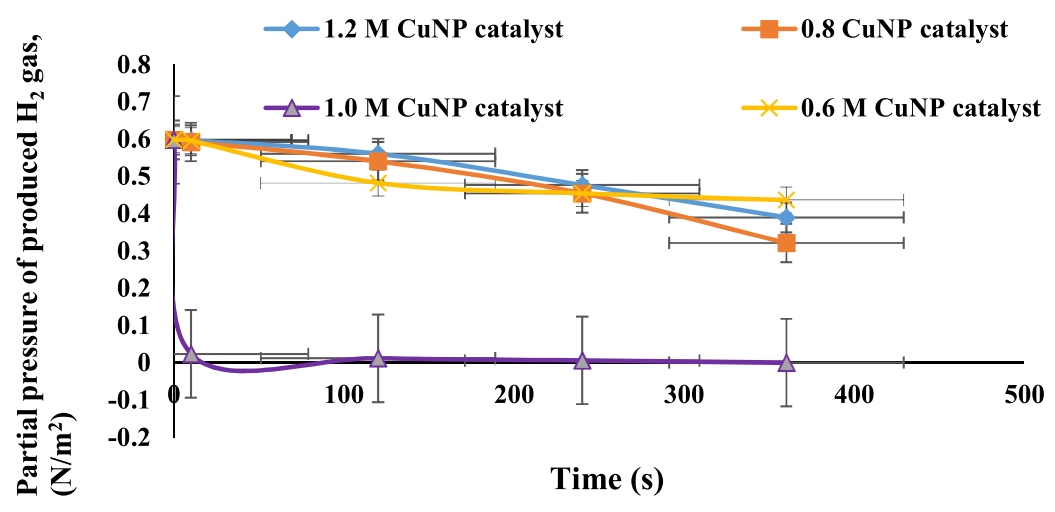

Fig. 8. a. \% composition of copper in CuNP, $\mathrm{pH}$ of CuNPs solution vs concentration, b. Variation of Partial pressure of the $\mathrm{H}_{2}$ gas with time. Source: Sanni et al. [24].

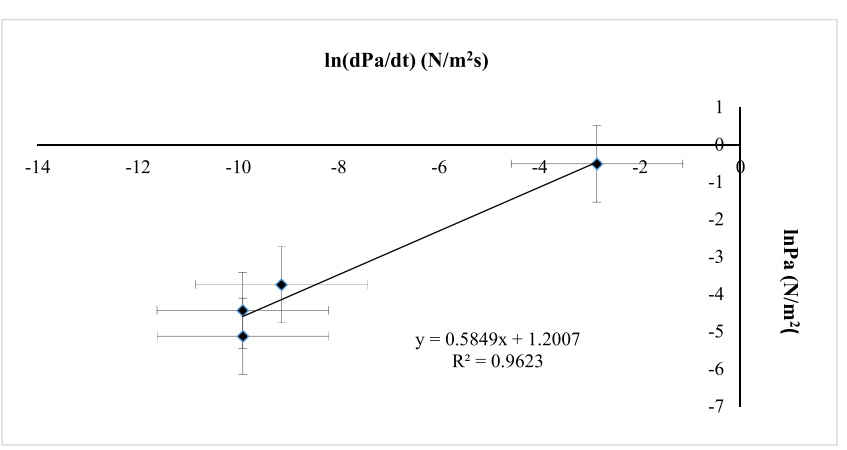

Fig. 9. Plot of $\ln (\mathrm{dpa} / \mathrm{dt})$ vs $\ln (\mathrm{pa})$. .

Adopted from [24]

(111) site, hence, a true confirmation that FA decomposition cannot occur via the formation of $\mathrm{HCO}$ as intermediate. HCO can only give rise to $\mathrm{CO}$ production, whereas, there is substantial evidence that $\mathrm{CO}_{2}$ and $\mathrm{H}_{2}$ are the only feasible products of FA-decomposition on Cu-catalysts [24].

During FA decomposition, the formation of formate (HCOO) proceeds with the breaking of $\mathrm{O}-\mathrm{H}$ bond over bridges at the $\mathrm{Cu}(111)$ and $\mathrm{Cu}(100)$ sites, and on the step-edge at the $\mathrm{Cu}(211)$ surface. The reaction is exothermic with corresponding reaction energies of $-0.33,-0.57$ and $-0.74 \mathrm{eV}$, and decreases in the following order $\mathrm{Cu}(111)>\mathrm{Cu}$

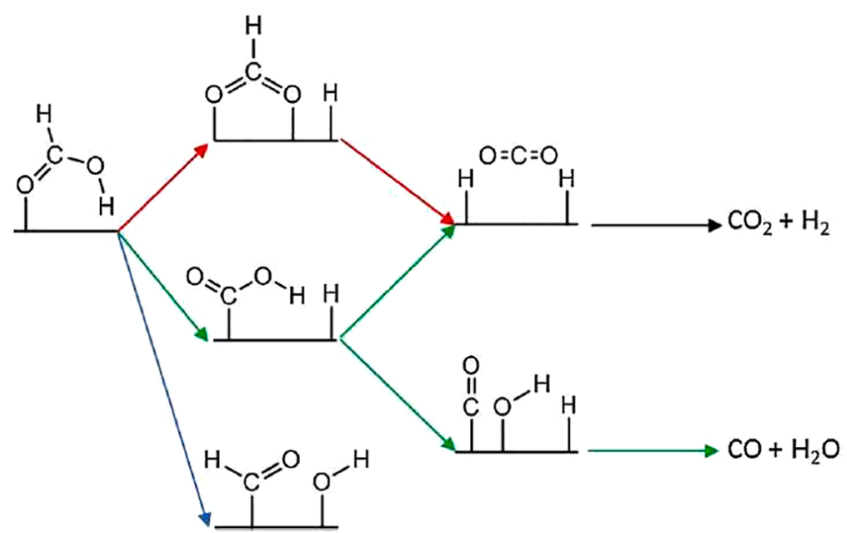

Fig. 10. Pathways of FA decomposition for reaction catalysed by Cu catalysts; the red arrows signify HCOO pathway; green arrows depict $\mathrm{COOH}$ pathway; the blue arrow shows the HCO pathway. The shared desorption step for $\mathrm{H}_{2}$ production for the $\mathrm{HCOO}$ and $\mathrm{COOH}$ pathways is indicated by the black arrow. Adopted from Li et al. [50].

(100) $>\mathrm{Cu}(211)$, which is caused by the higher binding strength of the formate/intermediate $\mathrm{HCOO}$ at the more open sites. The estimated activation energies of the weak structural sensitivity of the $\mathrm{O}-\mathrm{H}$ bond at the three sites, was found to fall within the range of $0.41-0.48 \mathrm{eV}$, hence, configurations of the transition states appear similar. The $\mathrm{C}-\mathrm{H}$ bond- 
(a)

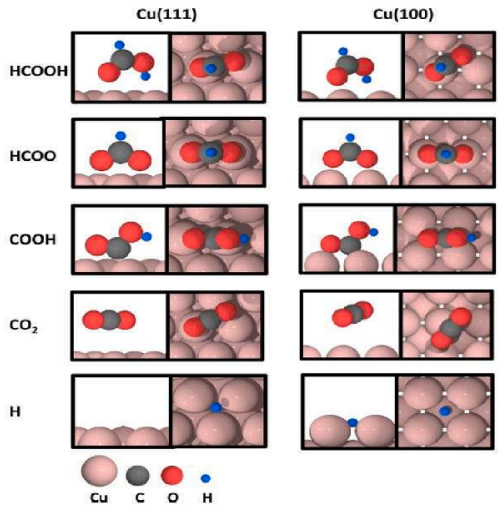

(b)

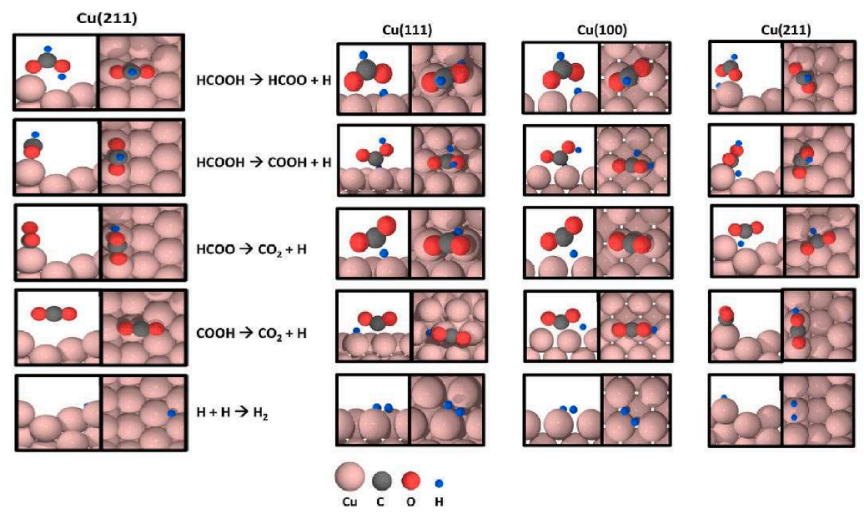

Fig. 11. a. Different configurations of reaction intermediates at the $\mathrm{Cu}(111), \mathrm{Cu}(100)$ and $\mathrm{Cu}(211)$ facets. b. Cross-sectional and top views of transition states of the elementary steps at the $\mathrm{Cu}(111), \mathrm{Cu}(100)$ and $\mathrm{Cu}(211)$ sites/plane. For the intermediates, the cross-section (left side) and top (right side) are as illustrated with $\mathrm{Cu}$, $\mathrm{C}, \mathrm{O}$ and $\mathrm{H}$ atoms depicted by pink, grey, red and blue spheres. Adopted from Li et al. [50].

isolation in FA to give $\mathrm{COOH}$ and hydrogen atom involves a rotation of the reactant molecule with the $\mathrm{C}-\mathrm{H}$ bond pointing at the surface. Upon attaining the transition state, $\mathrm{C}-\mathrm{H}$ bond scission may occur at the top site where $\mathrm{COOH}$ is absorbed via the carbon atom formed from the reaction; the atomic- $\mathrm{H}$ formed adheres to the closest fcc or bridge sites of the $\mathrm{Cu}$
(111) and $\mathrm{Cu}(100)$ facets, whereas, at the $\mathrm{Cu}(211)$ surface, $\mathrm{C}-\mathrm{H}$ bond breaking occurs above the top site step-edge. After decomposing the reactant, the carboxyl group $(\mathrm{COOH})$ is absorbed at the two adjacent topsides of the step edge, while hydrogen atom attaches to the hollow site of the edge. In essence, FA-decomposition via the HCOO is
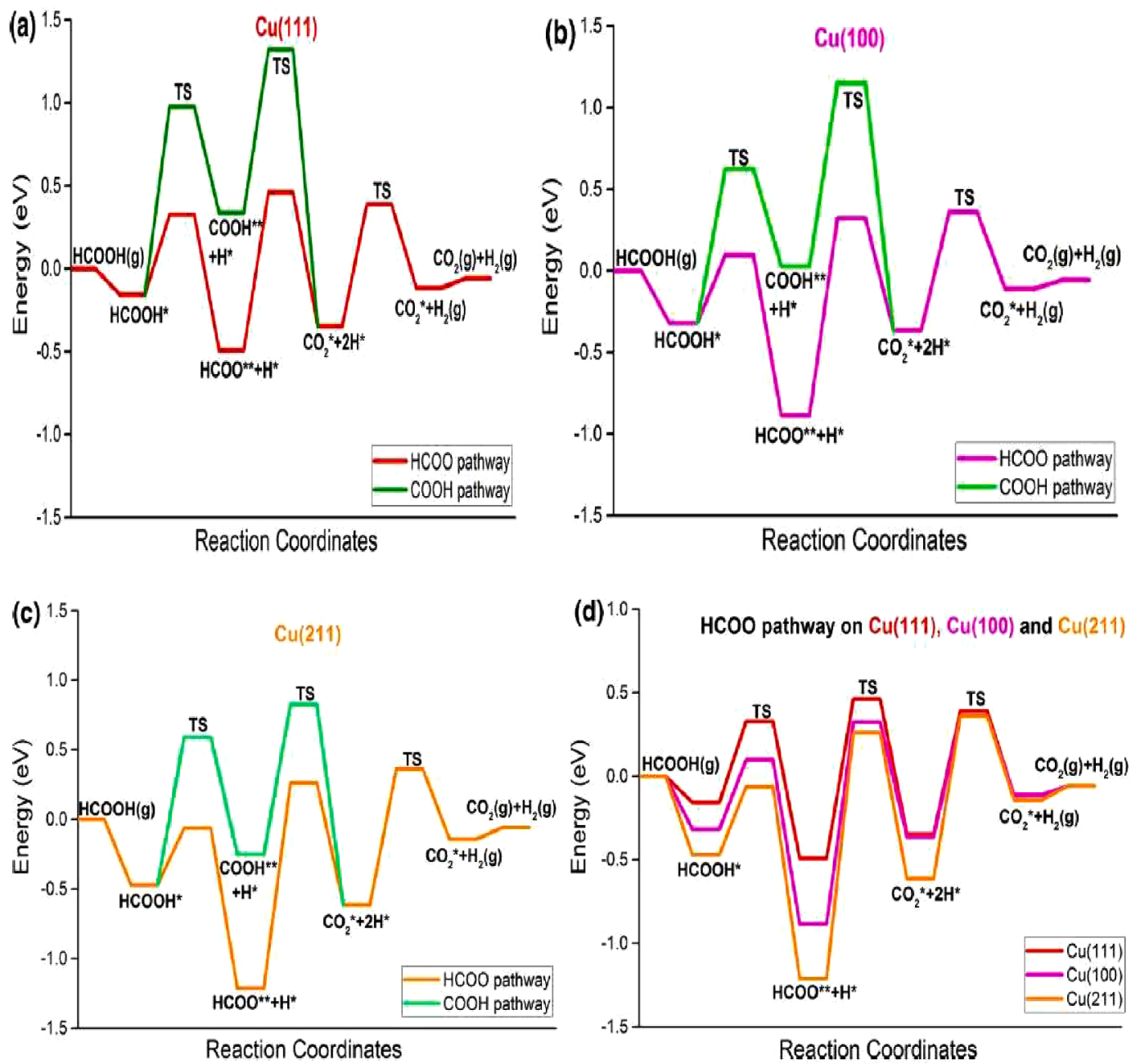

Fig. 12. Potential energy profile of FA-decomposition for the $\mathrm{HCOO}$ - and $\mathrm{COOH}$-mediated pathways at: a. the $\mathrm{Cu}(111)$ surface, b. the $\mathrm{Cu}(100)$ surface, $\mathrm{c}$. the $\mathrm{Cu}$ (211) surface, and d. $\mathrm{Cu}(111)$ surface. Adopted from Li et al. [50]. 
exothermic, while, it is endothermic for the $\mathrm{COOH}$ pathway for all three surfaces owing to the heat/energy-gain during the adsorption of $\mathrm{COOH}$ relative to HCOO. Across the three surfaces, the estimated activated energies are $1.13,0.94$ and $1.06 \mathrm{eV}$ at the $\mathrm{Cu}(111), \mathrm{Cu}(100)$ and $\mathrm{Cu}$ (211) sites, respectively. Since the $\mathrm{COOH}$-pathway involves much higher (i.e., $>0.5 \mathrm{eV}$ ) energy than the $\mathrm{HCOO}$ pathway, Cu-catalyst will preferentially attack the $\mathrm{O}-\mathrm{H}$ bond in FA to form the formate (HCOO) as intermediate product on all three surfaces of the catalyst. Also, the $\mathrm{C}-\mathrm{H}$ bond scission in $\mathrm{HCOO}$ also involves a rotated molecule where the $\mathrm{C}-\mathrm{H}$ bond points to the surface. At the transition state, one $\mathrm{Cu}-\mathrm{O}$ bond appears broken with the $\mathrm{C}-\mathrm{H}$ bond isolation occurring at the topside of a bridge at the $\mathrm{Cu}(111)$ and $\mathrm{Cu}(100)$ sites, as well as the bridge-site on the $\mathrm{Cu}(211)$ step, thus giving equivalent reaction energies of $0.15,0.52$ and $0.60 \mathrm{eV}$ at the $\mathrm{Cu}(111), \mathrm{Cu}(100)$ and $\mathrm{Cu}(211)$ sites, respectively; these are all indicative of the endothermic nature of the reaction on the surfaces. Both reaction and activation energies increase in the order of $\mathrm{Cu}(111)<\mathrm{Cu}(100)<\mathrm{Cu}(211)$, which are suggestive of the structure sensitivity of the reaction at the three $\mathrm{Cu}$ surfaces. There is a constant change of $0.26 \mathrm{eV}$ in the activation energy of HCOO decomposition at all sites giving increased values of $0.95 \mathrm{eV}$ to $1.21 \mathrm{eV}$ to $1.47 \mathrm{eV}$ for the $\mathrm{Cu}$ (111), $\mathrm{Cu}(100)$ and $\mathrm{Cu}(211)$ surfaces respectively, because of the strong attachment of $\mathrm{HCOO}$ to free open facets. These results agree with the variation in the structure-sensitive character of HCOO dehydrogenation, which is responsible for its varying activation energies at the $\mathrm{Cu}$ (111) and $\mathrm{Cu}(110)$ surfaces [66] where the measured activation energy by Nakona et al. [66] is $108 \mathrm{~kJ} / \mathrm{mol}$ or $1.12 \mathrm{eV}$ greater than the measured value $(0.95 \mathrm{eV})$ as obtained by $\mathrm{Li}$ et al. [50]. Since, the activation energy of the $\mathrm{COOH}$ pathway is higher than that of the HCOO formation-step, it therefore suggests that the formate formation step is the rate limiting step.

\section{Surface potential energies at the copper sites}

The thermochemical properties and activation energies of the different reaction pathways were used to obtain the potential energy of the three Cu facets; see Fig. 12 a-d. The PESs shown in Fig. 12a-c can be used to compare both the $\mathrm{HCOO}$ and $\mathrm{COOH}$-mediated pathways for all three $\mathrm{Cu}$ facets. However, it is evident that the PE at the HCOO-mediated pathway is more favourable than that of the $\mathrm{COOH}$-mediated pathway for the FA-decomposition at $\mathrm{Cu}(111), \mathrm{Cu}(100)$ and $\mathrm{Cu}(211)$, owing to the lower TS (transmission state) energies along the HCOO-mediated path. In Fig. 12(d) the most favourable HCOO-mediated path was examined along the three $\mathrm{Cu}$ facets, and it was observed that higher TS and activation energies were obtained for the HCOO decomposition step than that obtained for the HCOO formation step along the HCOOmediated pathway. The estimated surface PEs are in the order of $\mathrm{Cu}$ (111) $>\mathrm{Cu}(100)>\mathrm{Cu}(211)$. Thus, $\mathrm{Cu}(211)$ binds intermediates more strongly than $\mathrm{Cu}(100)$, and gives lower energies of adsorption with higher corresponding activation energies than those of $\mathrm{Cu}(100)$ and $\mathrm{Cu}$ (111). Since FA-decomposition on $\mathrm{Cu}(211)$ surface has a similar transition state (TS) energy with $\mathrm{Cu}(100)$, but lower in terms of comparing their activation energies, hence, the $\mathrm{Cu}(211)$ surface is therefore considered less active than $\mathrm{Cu}(100)$ for HCOOH-decomposition. From the PES profile, co-adsorbed formate and hydrogen (i.e. HCOO and $\mathrm{H}$ ) depict a very stable stage, therefore, these surfaces i.e. the $\mathrm{Cu}(100)$ and $\mathrm{Cu}(211)$ surfaces, are most likely to be partly covered by the attached HCOO at the surfaces of $\mathrm{Cu}(100)$ and $\mathrm{Cu}(211)$; the last two sites bind HCOO more strongly than $\mathrm{Cu}(111)$ with binding energies in the tune of 0.38 and $0.60 \mathrm{eV}$, respectively. In addition, FA decomposition may prevail at the terraces of $\mathrm{Cu}$ catalyst, while the under-coordinated step and defect sites may become inaccessible as a result of strongly adsorbed formate (HCOO) intermediate.

Therefore, for application of an efficient catalyst system with optimum performance in ICEs, the proposed reactor-chamber for FA decomposition in automobiles can have charging pots for any of the catalysts indicated in "red colour" in refs. [38,81,87,88,108,134-136] (Table 5) and ref. [24] (Table 6). The listed catalysts that can give higher
ToFs are as indicated for the references listed/highlighted in red colour in Tables 5 and 6, hence, they are all recommended for use but in terms of cost, the CuNP-tertiary amine system should be given preference, because, even the cobalt and platinum reaction systems that gave higher ToFs can only be initiated at higher temperatures say, $250{ }^{\circ} \mathrm{C}$ which gives $523 \mathrm{~K}$ i.e. $190 \mathrm{~K}$ more than the temperature required for initiating the FA-CuNP tertiary amine reaction. The intended car engine can serve the purpose of heating the reaction mixture when it runs on gasoline. Since the maximum temperature for utmost catalyst performance as indicated in this review is $90^{\circ} \mathrm{C} / 363 \mathrm{~K}$, it then implies that this is achievable. The heat generated by the engine can be transferred to the reactor which must be positioned somewhat close to the engine in order to abate temperature loses. A connector system/pipe network can then help transport the gas to the hydrogen storage tank. The configuring/ construction of a basal section through which catalysts/residues from the reaction can be collected for catalyst regeneration is also necessary.

Fig. 13 is the proposed reaction configuration for the automobile engine where the reaction of the amine, copper and FA is stimulated by the engine which supplies the required heat at $80-100^{\circ} \mathrm{C}$. The produced hydrogen which is collected by upward displacement of water is about $82 \%$ pure owing to the presence of $\mathrm{CO}_{2}$. This mixture is then collected over lime water to dissolve the residual $\mathrm{CO}_{2}$ so that the hydrogen gas becomes pure as it is stripped of $\mathrm{CO}_{2}$. Furthermore, the gas is sent to the tank for storage and is delivered through another line that supplies fuel to the engine for mobility.

\section{Storage and dilivery systems for hydrogen from formic acid}

Despite propositions to store hydrogen in its carriers such as formic acid, there have been several concerns owing to the fact that the decomposition reaction of $\mathrm{HCOOH}$ for product/hydrogen-recovery will only be initiated on intermittent basis; this will not only amount to time consumption but also mar the possibility of the existence of hydrogen fuelled cars. Also, it then means that, research advancements may then necessitate the need to create reaction chambers for formic acid decomposition for hydrogen production upon the occurrence/indication of low fuel levels in cars. Also, the notion it gives strongly advocates for the purchase of formic acids at filling stations rather than $\mathrm{H}_{2}$. Again, there may be need to constitute fuel/gas stations with plants/reactor systems for FA decomposition at such places. Since hydrogen is lighter than helium which is usually stored in weather balloons, it is therefore recommended that hydrogen from formic acid is cased in already calibrated high pressure balloons (as discussed in Sanni et al. [24] prior gas analysis), or tubes that are housed in fuel tanks with protruding hoses through the tank inlet for refuelling. It is therefore believed that this will serve as a special-housing-unit for the gas. In addition, cars with dual fuel systems i.e. with partitioned engines that can work like a partitioned

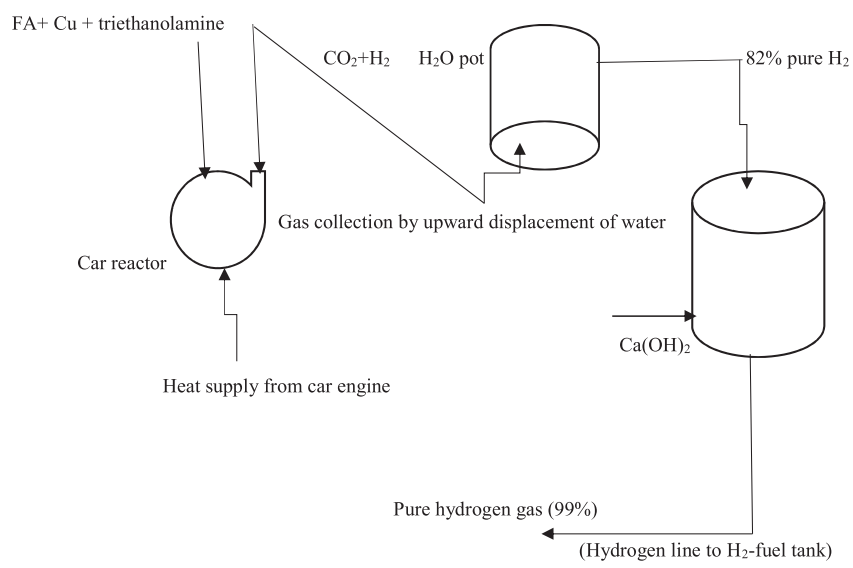

Fig. 13. Proposed reactor configuration for automobile engine. 
desktop can be adopted as a way of integrating/hybridizing a dual purpose engine that can serve this purpose, such that, when a car runs short of gasoline, the car automatically activates the hydrogen fuel system to aid mobility. In lieu of the points raised, the cost of FA is also a major contributor to the marketability of this proposed system Fig. 14a-c gives an overview of the plant layout, hydrogen bank and hydrogen dispenser respectively.

\section{Features:}

Area $=4,000 \mathrm{~m}^{2}$

Hydrogen filling capacity: $100-500 \mathrm{~kg}$

Hydrogen Compressor/pump specification: booster pump / diaphragm compressor

Compressor rated working pressure: $45-87.5 \mathrm{Mpa}$

Hydrogen Storage pressure: $45-87.5 \mathrm{Mpa}$

Hydrogen filling-rated working pressure $35 \mathrm{Mpa} / 70 \mathrm{Mpa}$

Hydrogen flow rate: $0.5-3 \mathrm{~kg} / \mathrm{min}$

Hydrogen Supply Method: external hydrogen supply (hydrogen
bank)/FA decomposition reaction

The external hydrogen supply unit/station comprises of a hydrogen tank for unloading hydrogen from a long tube trailer. Also domiciled in the station, is a hydrogen diaphragm compressor, a storage/bank and a filling machine. The hydrogen from the tube is first compressed into at high pressure hydrogen storage cylinder by means of the compressor via the unload-line. As soon as unloading is complete, the long tube trailer can then be withdrawn from the station. After the hydrogen is stored in the hydrogen bank, the received hydrogen is then transported via a high, medium and low three-stage filling-cylinder-trail alongside the lone pipe trailer which directs the hydrogen required to fuel a typical $\mathrm{H}_{2}$-fuelled vehicle. The merits of this design include high efficiency and early filling time; there is an assurance of good safety and reliability. Also, it is projected that 10 fuel cell buses of $8 \times 140 \mathrm{~L}$ hydrogen tank can be filled/fuelled with hydrogen in $\leq 20 \mathrm{~min}$. Based on the requirements of the process design and controls, a central control system for data generation/acquisition alongside a system monitor/Supervisory Computer Aided Data Acquisition (SCADA) system will be used in monitoring hydrogen generation and supply.

(a)

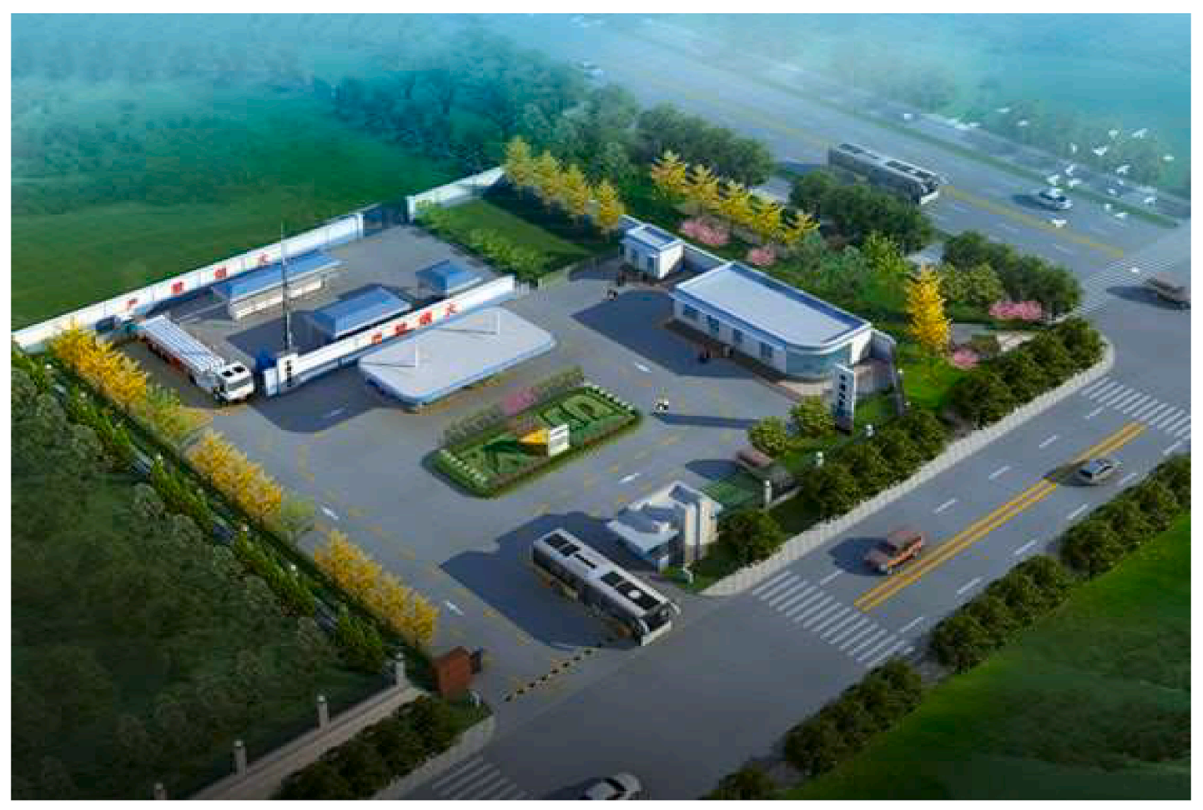

(b)

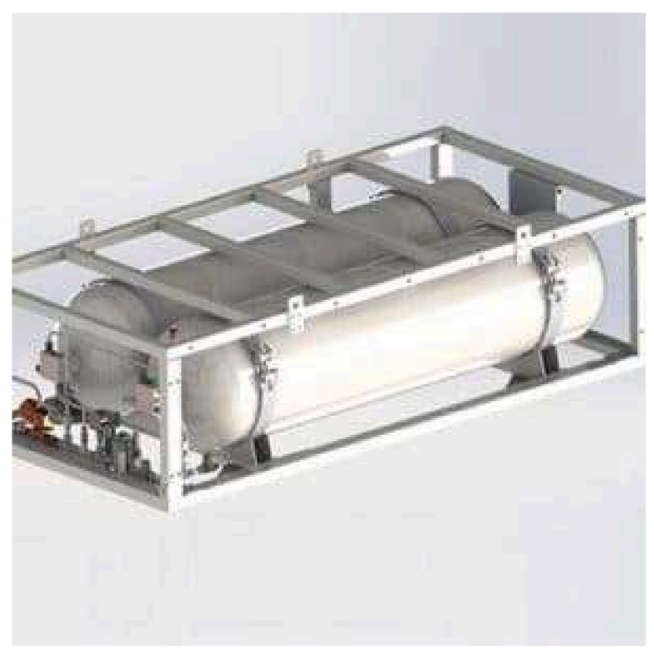

(c)

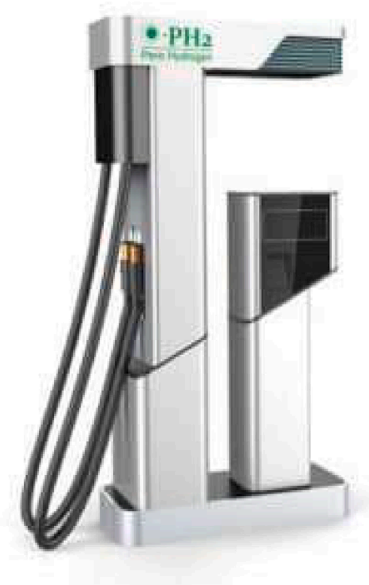

Fig. 14. a. A typical hydrogen fuel station; b. Hydrogen tanks/bank; c. Hydrogen dispenser. Adopted from webmaster@peric.com. 


\section{Life cycle assessment of the dehydrogenation process}

\section{Materials and equipment}

The chemicals used for the preparation of the copper catalysts used in carrying out the dehydrogenation of $\mathrm{FA}$ include $99 \%$ pure $\mathrm{CuSO}_{4} \cdot 5 \mathrm{H}_{2} \mathrm{O}$ salt (Fisher Chemicals), 99-100.5\% Ascorbic acid $\left(\mathrm{C}_{6} \mathrm{H}_{8} \mathrm{O}_{6}\right)$ (LOBAChemie), 99\% Polyvinylpyrrolidone (PVP) $\left(\mathrm{C}_{6} \mathrm{H}_{8} \mathrm{NO}\right)_{\mathrm{n}}$ (J.T Baker), 89.5\% Formic acid (Fisher Chemicals), Triethanolamine of $85 \%$ purity $\left(\mathrm{C}_{6} \mathrm{H}_{15} \mathrm{NO}_{3}\right)$ (Jinhuada Chemicals), Deionized water. The equipment/apparatus used include Weighing balance, Magnetic hot plate, Measuring cylinder, Hanna pH $211 \mathrm{~m}$, Gas analyser, Spatula, Beaker (1000 mL, J-Sil Borosilicate), Separating funnel (J-Sil Borosilicate, India), 3-neck round-bottom flask ( $\mathrm{J}$-Sil Borosilicate, India), Thermometer (0-360, Brannan, UK), Hoses, L-connector and Tconnector, Magnetic hot plate, Measuring cylinder (J-Sil Borosilicate, India) and Retort stand ( $8 \times 5$ Inch, Standard Steel, India); details can be found in Sanni et al. [24]. The chemicals and equipment were handled based on the manufacturers' instructions.

\section{CuNP-Catalyst synthesis}

Environmentally friendly Cu-nanoparticles (CuNPs) were synthesized via the chemical reduction method as given in ref. [24]. 12.2 g of PVP was mixed with $1000 \mathrm{~mL}$ deionized water. The mixture was heated and stirred thoroughly at $60^{\circ} \mathrm{C}$. The mixture was split into two portions of $600 \mathrm{~mL}$ and $400 \mathrm{~mL}$ in separate flasks. To the $600 \mathrm{~mL}$ solution, $90 \mathrm{~g}$ of $\mathrm{CuSO}_{4} \cdot 5 \mathrm{H}_{2} \mathrm{O}$ was added while $25.4 \mathrm{~g}$ of ascorbic acid was added to the $400 \mathrm{~mL}$ solution and heated at $60^{\circ} \mathrm{C}$. Upon complete mixing, both solutions, were combined, heated and stirred for $2 \mathrm{~h}$ at $60^{\circ} \mathrm{C}$; thereafter, the mixture was kept for 3 days to allow for efficient cooling and settling/crystallization of the nanoparticles. The supernatant solution and precipitates $(0.6 \mathrm{M}$ CuNps) were separated via filtration. The recovered CuNPs were washed with ethanol in order to remove excess PVP that may be bound to the CuNPs. The above procedure was repeated by preparing three separate solutions which were heated at $60^{\circ} \mathrm{C}$ to give $12.2 \mathrm{~g}$ of PVP in $1000 \mathrm{~mL}$ of deionized water. 4 PVP solutions were prepared, each of $500 \mathrm{~mL}$ volume. In two of the $4 \mathrm{PVP}$ solutions, 75 and $90 \mathrm{~g}$ of $\mathrm{CuSO}_{4} \cdot 5 \mathrm{H}_{2} \mathrm{O}$ salts were added, while 59.8 and $70.4 \mathrm{~g}$ ascorbic acid were added separately to the other two PVP solutions respectively, which gave corresponding molarities of 0.8 and $1 \mathrm{M}$ CuNPs. To another PVP solution, $120 \mathrm{~g}$ of $\mathrm{CuSO}_{4} \cdot 5 \mathrm{H}_{2} \mathrm{O}$ was dissolved in $12.2 \mathrm{~g} / 1000 \mathrm{~mL}$ PVP solution, $70.4 \mathrm{~g}$ ascorbic acid was added and the mixture was heated to $60^{\circ} \mathrm{C}$. The CuNPs of $0.8-1.2$ CuNPs were then recovered as already discussed for the case of $0.6 \mathrm{M}$ CuNps. The $\mathrm{pHs}$ of the solutions were measured.

\section{The reaction system}

Fig. 15 is an illustration of the simulated glass reactor and gas collection set-up. Control experiment: $10 \mathrm{~mL}$ FA was measured and transferred into a three-neck flask and heated to $80^{\circ} \mathrm{C}$ using a magnetic hot plate; the volume of hydrogen evolved was recorded. $25 \mathrm{~mL}$ triethanolamine was added to $10 \mathrm{~mL} F A$ in a flask. The mixture temperature was raised to $80^{\circ} \mathrm{C}$. Four mixtures, each containing $25 \mathrm{~mL}$ triethanol amine and $10 \mathrm{~mL}$ FA were prepared. $1.0 \mathrm{~g}$ each of the $0.6,0.8,1.0$ and 1.2 M CuNP was measured and added separately to 4 mixtures and heated to $80^{\circ} \mathrm{C}$. The volume of gas evolved was measured using water displacement method. The reaction was very slow for FA-amine system without catalyst compared the reaction aided by the CuNPs. To justify the reusability of the best catalyst ( $1 \mathrm{M}$ CuNPs) as established from the reaction, $1 \mathrm{~g}$ of the $1 \mathrm{M}$ CuNPs was collected for reuse after $6 \mathrm{~h}$ of hydrogen production. The produced hydrogen was measured and contained in a balloon after each run. The system was allowed to cool to $25^{\circ} \mathrm{C}$, after which it was recharged with $10 \mathrm{~mL}$ FA for the next operation vis-à-vis the 23rd run.

Note: It is necessary to add the amine prior the nanoparticles rather than the reverse because, the latter will not give any visible reaction. Also, the $\mathrm{CO}_{2}$ release was about $9.5 \%$ with $82.7 \%$ volume of hydrogen recovered. A total of twelve components were identified by the gas analysers. Also, the automobile reactor will simulate the glass set-up and its material of construction is stainless steel, which is durable, sustainable and corrosion resistant. However, in situations of minimal corrosion which may exist in form of oxygen corrosion- caused by the contact with $\mathrm{O}_{2}$, sweet corrosion- caused by $\mathrm{CO}_{2}$, sour corrosion- caused by $\mathrm{H}_{2} \mathrm{~S}$, crevice corrosion- which occurs by stagnation of fluid in narrow clearances, microbial corrosion- which is caused by the metabolic activities of microbes, fretting corrosion- caused by friction on metallic parts, galvanic corrosion- caused by the difference in the nature of metals that make up an alloy such as steel, erosion corrosion- caused by the removal of an initial deposition of a protective corrosion product/impervious layer that serves as protection for a metal, leaching- the destruction/ reduction in the properties of one metal relative to another in an alloy, stress-induced corrosion- caused by the continuous application of stress on a metal surface, fatigue corrosion- caused by failure of a metal due to fatigue which is caused by cyclic concentration of stress on a localized area, flow-induced corrosion caused by the flow of a fluid onto/over a metal surface, in the presence of an electrolyte, all of which can be controlled via any of the following methods when applied under the most suitable conditions.

Cathodic protection: This is of two forms (impressed current and sacrificial anode-protection); for impressed current mode of protection, a direct current is applied in the reverse direction of the flow of current through the affected metal surface since corrosion is influenced by the setting up of an electrochemical cell within the metal. For the sacrificial

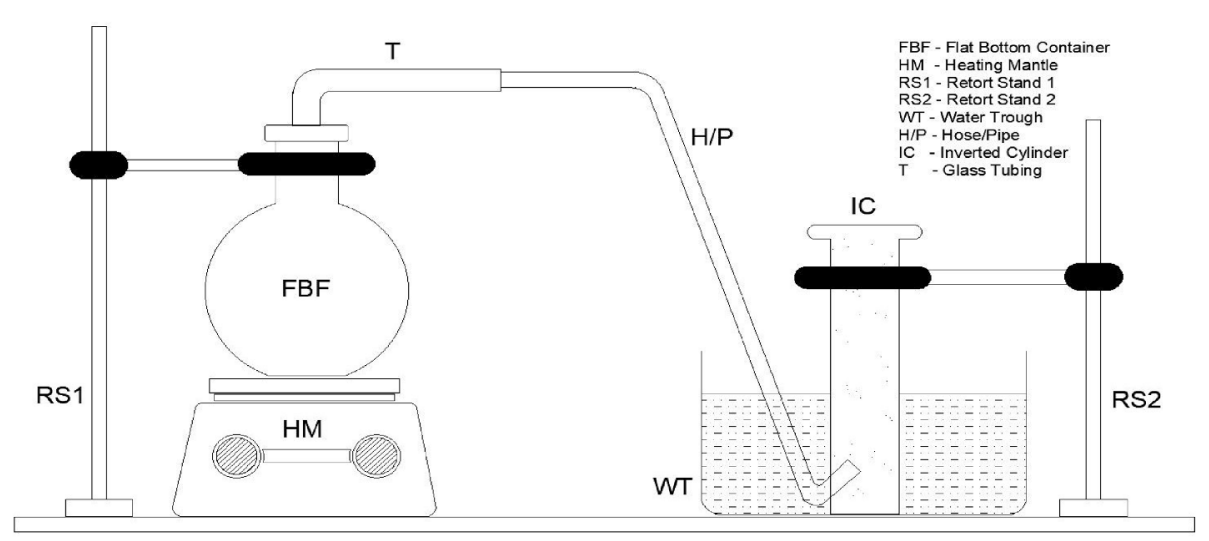

Fig. 15. Experimental setup for the dehydrogenation of formic acid. Adapted from ref. [24]. 
anode mode of protection, a metal higher up in the galvanic series than the supposed donor-metal in an alloy, is coated with the metal of higher activity; the essence is to sacrifice it for the actual anode, hence, the sacrificed metal is termed the sacrificial anode [137]. James and Bushman [138] discussed pipe/metallic corrosion and inhibition in relation to the use of impressed current or sacrificial anode methods of corrosion protection.

Coating and painting: This method involves the use of coloured pigments such as corrosion resistant liquid-pigments or paints and coats that have high binding strengths with the metal to be protected [139]. Although, in some instances, however good a coat is or however well applied, it may peel off over time owing to mesa attack or cathodic disbondment, hence the need to carefully select very effective choice pigments/coats as corrosion inhibitors Sanni et al. [140].

Curable coatings at temperatures less than $80^{\circ} \mathrm{C}$ with low hydrothermal stabilities are required for preventing the corrosion of $\mathrm{HX}$ heat exchanger tubes and pipe joints after roller expansion or welding. However, for higher temperature applications, these equipment need to be coated with materials that can withstand temperatures $>200^{\circ} \mathrm{C}$, have good adherence to the metal surfaces and possess the ability to become cured at temperatures up to $80^{\circ} \mathrm{C}$ and can be applied with a paint, brush or spray gun. Poly(tetrafluoroethylene)/(hexafluoropropylene) (PTFHFP) polymer coatings have been tested as corrosion mitigators for carbon steel joints in brine heated up to $200^{\circ} \mathrm{C}$. However, the efficacy of the inhibitor was found to gradually wane after 20 days of application at such temperatures, thus suggesting that they may perform better at lower temperatures since thermal oxidation sets in after the $20^{\text {th }}$ day [141], hence, there is need to modify this inhibitor for application within longer periods at high temperatures using high temperature resistant materials such as multiwalled carbon nanotubes (MWCNTs), zeolites, metal organic frameworks etc. for improved performance.

The pulsed magnetic sputtering method (PMS) is an approach used to deposit/coat a wide range of materials for the enhancement of film properties and flexibility in low friction titanium nitride coats and aluminium doped zinc oxide conductive transparent oxide sputtered directly from powder targets of thin film photovoltaic devices comprising of copper (indium/gallium) diselenide; sputtering is usually done at radiation frequencies of $20-350 \mathrm{kHz}$ [142].

Chemical inhibition/injection: This involves the use of chemicals (organic or inorganic) such as glutaraldehyde, sodium tungstate, etc. in single or combined forms such as sodium nitrite, zinc nitrite and sodium tungstate [140] as means of protecting metal surfaces against corrosion. Ngobiri et al. [143] compared the performance of Sulfadoxine-Pyrimethamine (SP) as a corrosion inhibitor for petroleum steel pipe. The work of Li et al. [144] confirms the protective ability of D-phenylalanine as a corrosion inhibitor for Q235 carbon steel.

Continuous monitoring and inspection: Till date, this remains one of the most effective approaches of guiding against any form of corrosion since, it involves constant survey and observation/visual inspection of the metal while carefully checking for the appearance of corrosion spots/scales in order that apt measures are taken to abate the degradation of the metal [138]. Hector and Liz [145] extensively reviewed biocorrosion and biofouling of industrial equipment in which real time environmental monitoring and inspection were adopted as a means of mitigating metal decay.

The use of plant extracts: This is one of the most current environmental technologies adopted till date. It involves the use of extracts of plants such as Fenugreek seed oils and bitter leaf oils [146], modifiedtannin solutions, plant DNA (Calf thymus gland-DNA) [147] etc. as corrosion inhibitors. The inhibiting behaviour of leave and seed extracts of Phyllantus amarus on mild steel corrosion in aqueous $\mathrm{HCl}$ and $\mathrm{H}_{2} \mathrm{SO}_{4}$ have been studied using weight loss and gasometric methods [148]. Henna (Lawsonia inermsis) extract and its constituents (lawsomne, gallic acid, $\alpha$-D-glucose and tannin acid) were also confirmed to exhibit corrosion protection abilities for steel by Ostovari et al. [149].
Additive manufacturing and laser/light cladding: This method involves the integration of corrosion resistant metals $(\mathrm{Cu}, \mathrm{Ni}, \mathrm{Cr}$, etc.) or alloys such as $\mathrm{TiC}$ in other metals/alloys as a means of improving the metal's composition all aimed at taking advantage of the synergistic effects offered by the blended metals; with the help of high laser concentration of beams some of these metals with high melting points can be brought to their molten states for easy/efficient mixing with other metals. In laser cladding, one metal i.e., the more corrosion resistant metal clothes or wraps the other in order to improve the service life of the less corrosion resistant metal. This approach helps to moderate the costs involved in using an expensive metal in entirety in combatting corrosion; for instance, the cladding of TiC and TiN on tungsten carbide [150]. The method employed involves the physical vapor deposition (PVD) by cathodic arc using a system bias and Cathodic arc evaporation techniques.

AM technologies are in two categories namely (a) powder bed fusion (PBF) which includes selective laser melting (SLM) or electron beam melting (EBM) and (b) direct laser deposition (DLD) or direct energy deposition (DED), which entails the simultaneous surface-supply of the material and energy needed to build the desired surface. Other AM methods include welding and cold spraying [151]. Additive manufacturing (AM)/3D printing is currently one of the mainstream approaches for producing metallic components from alloys owing to the different advantages which the process offers, which include net shape, material management, adaptability to low volume of production runs, and the flexibility towards exploring alloy compositions which were not accessible to conventional casting methods. AM entails the use of laser/ electron-based local melting which plays a significant role in ensuring a well-blended alloy microstructure. In the review conducted by Sander et al. [151], the corrosion of alloys made by AM/laser/electron-based methods were considered, where they considered several works that bother on metallic corrosion in relation to AM; the relationship between corrosion resistance of AM-manufactured metals and their unique features such as porosity, grain structures, dislocation networks, residual stress, solute segregation, and surface roughness were discussed and they affirmed that, AM-manufactured metals were found to be more corrosion resistant than those manufactured by conventional casting methods.

\section{Gas collection approach and volumetric estimation of $\mathrm{H}_{2}$ gas}

The gas produced from the reaction of $1 \mathrm{M}$ CuNPs and the formic acid-triethanolamine mixture already discussed, was determined by water displacement of the gas. The setup adopted includes an inverted graduated cylinder which was placed over a trough filled with water. At the expulsion of gas from the reaction flask, the light gas meandered through the water in the trough by diffusion and found its way to the top of the cylinder since it is lighter than water; this helped to balance the pressure within and outside the cylinder. Using the ideal gas and Dalton's laws, the partial pressure of hydrogen gas collected over water and the total pressure of the system were determined (see Sanni et al. [24] for details).

Hint: The pressure of the released gases, are indicative of the relative pressure of hydrogen compared to other gases. Based on the estimated pressures, the partial pressure of the gas is not high enough to engender unsafe conditions, however, since, hydrogen gas is highly flammable, four options may suffice for the gas containment in tubes, banks/cylinders or balloons made from polyester and coated with polyurethane.

i. Hydrogen can be stored in high-pressure resistant cylinders

ii. The produced hydrogen can be stored in special balloons constructed with pressure resistant/high texture-polymers and lined with non-porous membranes to avoid leaks in the event of any piercing of its external part by any object. However, for safety, the balloons can be enveloped in an inert atmosphere blanketed with $\mathrm{N}_{2}$ or solid $\mathrm{CO}_{2}$ to avoid eventualities, in case of tendencies for fire hazards caused by other operations within the plant. Better still, owing to the fact that, the 
scientific world still finds it difficult to accept the sustainability of balloons for hydrogen storage, hydrogen tubes/banks made of stainless steel, can be adopted for storing the produced hydrogen.

iii. The produced hydrogen can be liquified at $-252.87^{\circ} \mathrm{C}$ in order to increase its energy density prior storage; till date, this appears to be the most appealing and promising alternative for storing hydrogen, however, the process is energy intensive and will add to the overall cost of producing hydrogen, hence, options ii and iii require considerations with good safety practices for efficient implementation.

\section{Gas analysis}

The composition of other gases released are as given in Table 7 with the measured proportions of the $\mathrm{CH}_{4}, \mathrm{O}_{2}, \mathrm{CO}, \mathrm{H}_{2}, \mathrm{CO}_{2}, \mathrm{NO}_{2}, \mathrm{NO}, \mathrm{SO}_{2}$, $\mathrm{HCOOH}, \mathrm{H}_{2} \mathrm{~S}, \mathrm{CO}_{3}, \mathrm{NO}_{3}$ taken from the gas analyser being $12 \%, 4 \%$, $12 \mathrm{ppm}, 82.2 \%, 9.5 \%, 6 \mathrm{ppm}, 24 \mathrm{ppm}, 1 \mathrm{ppm}, 0.01 \%, 0.01 \mathrm{ppm}, 13 \mathrm{ppm}$ and $19 \mathrm{ppm}$ respectively. This clearly reveals the quantities of emissions associated with the product (hydrogen). Furthermore, almost all the FA was used up, such that only $0.01 \%$ of FA was left unconverted. The low compositions of the other gases such as $\mathrm{CO}, \mathrm{CO}_{2}, \mathrm{NO}, \mathrm{NO}_{2}, \mathrm{SO}_{2}$ and $\mathrm{H}_{2} \mathrm{~S}$ resulting from the dehydrogenation process, are also evidences of the impact of the resulting emissions associated with this process. There are also supporting evidences that hydrogen burns as a clean fuel. Furthermore, the alkaline system for trapping $\mathrm{CO}_{2}$, is so that there is little or no release of $\mathrm{CO}_{2}$; there is also the likelihood of $\mathrm{CO}$ being trapped by the alkaline solution shown in the process flow scheme of the designed reactor.

\section{Kinetics of the FA-Dehydrogenation: Volume-conversions for FA- dehydrogenation and gas emissions}

The plausible mechanism for the reaction between FA-amine mix and CuNPs is given below:

$\mathrm{HCOOH} \stackrel{\mathrm{R} 1 \mathrm{R} 2-\mathrm{NH} 2 / \mathrm{Cu} 2+}{\rightarrow} \mathrm{CO}_{2}+\mathrm{H}_{2}$

The kinetics of FA-decomposition is somewhat complex because, for one to be able to properly study the process kinetics, the system's species-concentrations need be monitored as reactants and products disappear and evolve respectively. This is somewhat herculean since the reaction ought to be interrupted at different times so as to be able to adequately estimate the amount of FA spent or left while the reaction is in progress. Striving to monitor the rate of formation of hydrogen while the reaction is in progress will cause some of the produced hydrogen to be lost, hence, the need to adopt the DMA with a few basic assumptions (i.e. major products being $\mathrm{CO}_{2}$ and $\mathrm{H}_{2}$ ) which helps to overcome that challenge; stoichiometric quantities of hydrogen can then be expressed in terms of the formed products $\mathrm{CO}_{2}$ and $\mathrm{H}_{2}$ only, as given in the

Table 7

Percentage composition of gas in $\mathrm{H}_{2}$ sample.

\begin{tabular}{lll}
\hline Component & $\begin{array}{l}\text { Chemical } \\
\text { formula }\end{array}$ & $\begin{array}{l}\text { Composition }(\%, \\
\text { ppm) }\end{array}$ \\
\hline Methane & $\mathrm{CH}_{4}$ & $12 \%$ \\
Oxygen & $\mathrm{O}_{2}$ & $4 \%$ \\
Carbon monoxide & $\mathrm{CO}$ & $12 \mathrm{ppm}$ \\
Hydrogen & $\mathrm{H}_{2}$ & $82.2 \%$ \\
Carbon dioxide & $\mathrm{CO}_{2}$ & $9.5 \%$ \\
Nitrogen dioxide & $\mathrm{NO}_{2}$ & $6 \mathrm{ppm}$ \\
Other (Nitrogen oxide gas & $\mathrm{NO}_{\mathrm{X}}$ & $24 \mathrm{ppm}$ \\
$\quad$ derivatives) & & \\
Sulphur dioxide & $\mathrm{SO}_{2}$ & $1 \mathrm{ppm}$ \\
Hydrocarbon (Unused HCOOH) & $\mathrm{HCOOH}$ & $0.01 \%$ \\
Hydrogen sulphide & $\mathrm{H}_{2} \mathrm{~S}$ & $0.01 \mathrm{ppm}$ \\
Trioxo carbonate VI gas & $\mathrm{CO}_{3}$ & $13 \mathrm{ppm}$ \\
Trioxonitrate V gas & $\mathrm{NO}_{3}$ & $19 \mathrm{ppm}$ \\
\hline
\end{tabular}

Source: Sanni et al. [24]. mechanism for dehydrogenation. This then implies that going by the process kinetics, other constituents such as $\mathrm{CH}_{4}, \mathrm{NO}_{3}$, $\mathrm{CO}$ etc. were assumed to be present in insignificant quantities, otherwise, the kinetic scheme established by Sanni et al. [24] would involve complex species which makes it very difficult to resolve; however, the kinetic scheme showed appreciable levels of accuracy of about $82.7 \%$.

Here, a back-calculation approach was used in investigating the kinetics of FA-dehydrogenation. It was assumed that the reaction reached completion in $6 \mathrm{~h}$ and that the highest volume of recovered hydrogen was $815 \mathrm{~mL}$ since no gas was evolved at further times, hence, the volume of gas produced was taken to be the maximum recoverable value (i.e. $100 \% \mathrm{H}_{2}$ in $\mathrm{FA}=4.3 \mathrm{wt} \%=815 \mathrm{~mL}$ ). The reactants and products were also assumed to exist in liquid phase all through the reaction time, thus implying that the system was homogeneous and the reactor was described as a variable volume batch reactor whose expansion factor was estimated to be 1 i.e. $\varepsilon_{a}=1$. Since no free-hydrogen was initially present in FA and the reaction is deemed irreversible at the stated conditions, the volume produced/max volume = approximate conversion of FA to hydrogen.

Comparing the results from the process kinetics with the results obtained from the gas analyser, the process scheme guarantees about $82.7 \%$ accuracy with an estimated inefficiency of $17.8 \%$, hence, the kinetic data is dependable and reliable. Although, improvements are required considering the need to involve other species in the Differential Method of Analysis (DMA) calculations i.e. since $\mathrm{CO}_{2}$ and $\mathrm{H}_{2}$ make up about $91.7 \%$ of the total gas released, $8.2 \%$ of the constituents need to be factored into the process kinetics. In addition, the 1st order description of the dehydrogenation process, assumes that all the FA is used up with zero/negligible amount of $\mathrm{CO}_{2}$, whereas, based on the data obtained from the gas analyzer, only $82 \% \mathrm{H}_{2}$ was formed. Furthermore, the formation of $\mathrm{NO}_{\mathrm{X}}$ gases may be due to the reaction between nitrogen in the triethanolamine and oxygen in FA. Other constituents such as sulphur and hydrogen sulphide, found in the gas, may have been introduced by the CuNP-catalyst which had some sulphur imposed on it by its precursor during synthesis and the combination of $\mathrm{H}_{2}$ from FA and sulphur in the CuNPs, respectively. It is also important to note that the reactor size should be about $110 \mathrm{~mL}$ to provide for clearance and reduce the pressure of hydrogen which somewhat raises its energy density and limits the tendency for emergencies.

\section{Pros and cons of the $1 \mathrm{M}$ CuNP-catalyst for FA-dehydrogenation}

Pros

- The $1 \mathrm{M}$ CuNPs had an induction period of 10 mins which is quite impressive.

- $815 \mathrm{~mL}$ of $\mathrm{H}_{2}$ was collected after $6 \mathrm{~h}$ of reaction time.

- The process of synthesizing the catalyst is not herculean and its precursor $\left(\mathrm{CuSO}_{4} .5 \mathrm{H}_{2} \mathrm{O}\right)$ is readily available/affordable

- Problems such as the influence of steric hindrance begin to arise after 20 cycles of hydrogen production within $120 \mathrm{~h}$ with an established reusability of $1 \mathrm{~g}$ CuNP catalyst for every $2000 \mathrm{~mL}$ FA.

- A low catalyst-amine ratio is required for the dehydrogenation process.

- There is a high theoretical conversion of $100 \%$ with a corresponding actual conversion of $82 \%$, in $6 \mathrm{~h}$; comparing this with the results in Table 8 , shows that the degree of conversion for other heterogeneous catalysts are quite lower relative to that estimated for the CuNp catalyst-system, thus confirming a better performance of the CuNPcatalyst.

- The CuNPs + FA-amine reaction system gave a boost in hydrogen production by 11.3 times the uncatalyzed reaction (i.e. the FA + amine system, whose volume of produced $\mathrm{H}_{2}=72 \mathrm{~mL}$ in $6 \mathrm{~h}$ ), whereas, it was about 13.81 times the volume of $\mathrm{H}_{2}(59 \mathrm{~mL})$ obtained for the reaction involving only FA without the amine and CuNPs. 
Table 8

Efficiencies of catalysts for FA-dehydrogenation reactions.

\begin{tabular}{|c|c|c|c|c|c|}
\hline Catalyst & $\begin{array}{l}\mathrm{T} \\
(\mathrm{K})\end{array}$ & $\begin{array}{l}\text { ToF initial } \\
\left(\mathrm{h}^{-1}\right)\end{array}$ & Eff.Conv.(\%) & $\begin{array}{l}\mathrm{Ea} \mathrm{kJ} \\
\mathrm{mol}-1\end{array}$ & Ref. \\
\hline $\begin{array}{l}\mathrm{Pd}_{60} \mathrm{Au}_{40} / \mathrm{Z}_{\mathrm{r}} \mathrm{SBA}- \\
\quad 15-\mathrm{AP}\end{array}$ & 298 & 1185 & 95 & 42.5 & [123] \\
\hline $\mathrm{Pd} / \mathrm{CNx}$ & 298 & 639 & 98 & 48.8 & [124] \\
\hline Ag@Pd/C & 298 & 157 & 43 & - & [152] \\
\hline $\mathrm{AgPd} / \mathrm{C}$ & 298 & 274 & 46 & 22.0 & [125] \\
\hline $\mathrm{AuPd} / \mathrm{C}$ & 298 & 41 & 24 & 28.0 & [86] \\
\hline CoAuPd/C & 298 & 54 & 91 & - & [84] \\
\hline $\mathrm{NiAuPd} / \mathrm{C}$ & 298 & 20 & 73 & - & {$[126]$} \\
\hline $\mathrm{AgAuPd} / \mathrm{rGO}$ & 298 & 95 & 100 & - & [127] \\
\hline CoAuPd/r-GO & 298 & 63 & 51 & - & [153] \\
\hline $\begin{array}{l}\text { CoAuPd/DNA- } \\
\text { rGO }\end{array}$ & 298 & 130 & 96 & - & [153] \\
\hline $\mathrm{AuPd} / \mathrm{N}-\mathrm{mrGO}$ & 298 & 39 & 93 & - & [83] \\
\hline $\mathrm{Au} @ \mathrm{Pd} / \mathrm{N}-\mathrm{mrGO}$ & 298 & 111 & 98 & - & [83] \\
\hline AuPd/N-rGO & 298 & 17 & 57 & - & [129] \\
\hline $\begin{array}{l}\mathrm{AuPd}-\mathrm{CeO} 2 / \mathrm{N}- \\
\quad \text { rGO }\end{array}$ & 298 & 68 & 98 & - & [129] \\
\hline AuPd/ZIF-8-rGO & 298 & 532 & 83 & - & [99] \\
\hline \multirow[t]{2}{*}{ CuNPs } & 353 & $\begin{array}{l}135.8 \mathrm{~mL} / \mathrm{h} \\
(5.98)\end{array}$ & 82 (actual) & - & [24] \\
\hline & & & $\begin{array}{l}100 \% \\
\text { theoretical }\end{array}$ & & \\
\hline
\end{tabular}

$*$ ToF $=$ Turn over Frequency, Eff.Conv. = Efficiency of conversion, Ea = Activation Energy.

Adopted from ref. [24].

- Higher conversions were attained for the Cu-tertiary amine system than many heterogeneous catalysts which are composites of very rare and scarce metal-precursors that make the FA-dehydrogenation more expensive (see Table 8 for some listed heterogeneous catalysts for FA-dehydration).

- The dehydrogenation kinetics is reliably accurate considering the accuracy of the estimated volume of the synthesized hydrogen, as well as the kinetic parameters (reaction-order, rate constant, conversion, partial pressure etc.), which gave a clear insight on the influence of $\mathrm{pH}$, catalyst concentration, time and catalyst size on the dehydrogenation process.

Cons

- The $1 \mathrm{M}$ CUNP-catalyst used is restricted to activation temperatures $\geq 80^{\circ} \mathrm{C}$.

- The catalyst loses its reactivity after 20 cycles hence, catalyst regeneration/refilling is required after the $20^{\text {th }}$ cycle [24].

- The energy requirement for reaction initiation of the CuNP + FAamine system is higher relative to those of some available heterogeneous catalysts, i.e., the reaction described for the CuNP + FAamine system requires higher energy input. However, this should not pose any problem as the heat required to initiate the reaction will be harvested from an automobile engine.

- The process kinetics discussed here, will need some form of modification if it must be adopted for situations involving heterogenoeus catalysts.

The results in Table 8 show that the 1 M CuNP-catalyst gave higher conversion than the catalysts adopted in refs. $[86,125,126,129,152,153]$. Although, a lower turnover rate of $\mathrm{H}_{2-}$ production i.e. ToF of $5.98 \mathrm{~h}^{-1}$ was recorded for the CuNP-tertiary amine system, the new Cu-tertiary amine system gave higher conversion relative to some of the multitudinous/heterocatalysts presented in Table 8. No doubt, these hybrid catalysts, will increase the overhead cost incurred in producing the catalysts. Comparing some homogeneous catalysts as presented in Table 9, it is somewhat obvious that the recorded ToFs are lower than that obtained for the CuNP-tertiary-amine system because, the recorded ToFs are measures of the average
Table 9

Number of Active sites (Ns), Steady-state activity and ToFs of other homogeneous catalysts at $250{ }^{\circ} \mathrm{C}$ compared to the Cu-tertiary amine system.

\begin{tabular}{|c|c|c|c|}
\hline $\begin{array}{l}\text { Catalyst Ns } \\
\text { a }(\mu \mathrm{mol} / \mathrm{g})\end{array}$ & $\begin{array}{l}\text { Number of } \\
\text { active sites } \\
\text { (Ns) }\end{array}$ & $\begin{array}{l}\mathrm{HCOOH} \\
\text { Activity } \\
250^{\circ} \mathrm{Cb}(\mu \mathrm{mol} / \\
\text { g•s })\end{array}$ & TOF $250^{\circ} \mathrm{C} \mathrm{s}^{-1}$ \\
\hline Co & $3.1 * 10^{1}$ & $9.3 * 10^{-2}$ & $3.0 * 10^{3}$ \\
\hline $\mathrm{Fe}$ & $1.8 * 10^{2}$ & $4.0 * 10^{0}$ & $2.2 * 10^{-2}$ \\
\hline $\mathrm{Ag}$ & $7.6 * 10^{0}$ & $3.0^{*} 10^{0}$ & $3.9 * 10^{-1}$ \\
\hline $\mathrm{Au}$ & $5.2 * 10^{1}$ & $4.0 * 10^{1}$ & $7.7 * 10^{-1}$ \\
\hline $\mathrm{Ni}$ & $1.6 * 10^{2}$ & $1.5 * 10^{3}$ & $9.3 * 10^{0}$ \\
\hline $\mathrm{Rh}$ & $1.5^{*} 10^{1}$ & $4.8 * 10^{1}$ & $3.3^{*} 10^{0}$ \\
\hline Pd & $9.9 * 10^{1}$ & $1.6 * 10^{2}$ & $1.6 * 10^{1}$ \\
\hline $\mathrm{Cu}$ & $1.6^{*} 10^{1}$ & $5.2 * 10^{1}$ & $3.2 * 10^{1}$ \\
\hline Pt & $1.9 * 10^{1}$ & $1.8 * 10^{3}$ & $9.8 * 10^{2}$ \\
\hline $\begin{array}{l}\text { CuNP- } \\
\text { amine }\end{array}$ & $4.35^{*} 10^{0}$ & ND & $358.8 * 10^{\circ} @ 80^{\circ} \mathrm{C}$ (this work) \\
\hline
\end{tabular}

Source: Sanni et al. [24].

hydrogen production rate for each catalyst. Thus, it is apt to infer/ conclude that the $\mathrm{Cu}$-amine system outperforms all the homogeneous catalysts presented in Table 9 owing to its higher ToF value of $358 \mathrm{~s}^{-1}$ as well as the volume of hydrogen produced from the reaction-system.

The durability of the CuNP-catalyst was determined by carrying out several runs of the FA-conversion using the $1 \mathrm{M}$ CuNPs. It was observed that the catalysts retained their colour and catalytic activity in the reactor up until the $20^{\text {th }}$ run/cycle (see details in ref. [24]), beyond which the CuNPs began to appear slightly oxidized/decolourized; they assumed a greyish black colour which is the colour of copper I oxide. This may have been caused by the influx of oxygen into the reactor upon recharging/replenishing the flat-bottom flask with fresh FA. Also, beyond the $20^{\text {th }}$ cycle, catalyst poisoning by CO may become prominent, thus reducing the number of surface-active sites on the CuNP-surface. Upon adding more FA, it was observed that, the resultant rise in the volume of hydrogen produced may have resulted from the erosion of any deposited inhibitor on the active sites of the CuNPs, thus ensuring higher reactivity, hence the reason for the slight undulating rise in $\mathrm{H}_{2}$ production despite the drop in $\mathrm{H}_{2}$ production at some point where the system began experiencing appreciable drop in the volume of synthetic hydrogen over previous runs. The stability of the CuNPs in the reactor would have been altered by the uncapping/removal of the capping agent which helps secure their stability.

\section{Essentials of the CuNP + FA-Amine system}

The efficiency of the reactor is a function of the degree of conversion of the FA to hydrogen gas. Four factors responsible for the degree of conversion of FA to hydrogen include $\mathrm{pH}$ of catalyst-solution, concentration of the CuNPs catalyst, reaction time as well as the size of the catalyst.

\section{Particle-screening tests for the best CuNP-concentration for FA- dehydrogenation}

Even when the same quantity of catalyst i.e. $1 \mathrm{~g}$ of catalyst was used for the entire process, changes in the CuNP-concentration from 0.6 to $1.0 \mathrm{M}$ increased the theoretical and actual FA-conversions from 59 to $100 \%$ and $59-82.2 \%$, respectively after $6 \mathrm{~h}$. However, at higher than $1 \mathrm{M}$ concentration of the CuNP-catalyst, FA-conversion/hydrogen production dropped to $52 \%$. This then shows that, the highest hydrogen production corresponds to CuNP-catalyst concentration of not less or $>1 \mathrm{M}$; this obeys the law of mass action, which states that an increase in concentration, can speed up the rate of a chemical reaction. The observed trend justifies the results of the catalytic dehydrogenation process, especially at the optimum CuNP-concentration (i.e. $1 \mathrm{M}$ concentration) as observed by Sanni et al. [24] (Table 10). Catalyst-concentration is a 
Table 10

Volume of hydrogen produced for catalyzed/noncatalyzed reactions involving FA.

\begin{tabular}{|c|c|}
\hline \multicolumn{2}{|l|}{ Akbayrak et al. [154] } \\
\hline Catalyst & $\begin{array}{l}\text { Volume per hour of Hydrogen produced (mL/ } \\
\text { h) }\end{array}$ \\
\hline $\mathrm{Pd} / \mathrm{CeO}_{2}$ & 65 \\
\hline $\mathrm{Pd} / \mathrm{ZrO}_{2}$ & 10 \\
\hline $\mathrm{Pd} / \mathrm{TiO}_{2}$ & 10 \\
\hline $\mathrm{Pd} / \mathrm{SiO}_{2}$ & 12 \\
\hline $\mathrm{Pd} / \mathrm{Al}_{2} \mathrm{O}_{3}$ & 5 \\
\hline $\mathrm{Pd} / \mathrm{HfO}_{2}$ & 0 \\
\hline \multicolumn{2}{|l|}{ Sanni et al. [24] } \\
\hline FA only & 10 \\
\hline FA + Triehanolamine & 16 \\
\hline $0.6 \mathrm{M}$ & 10 \\
\hline CuNPs + FA + Triehanolamine & \\
\hline $0.8 \mathrm{M}$ CuNPs FA + Triehanolamine & 80 \\
\hline 1.0 M CuNPs FA + Triehanolamine & 800 \\
\hline 1.2 M CuNPs FA + Triehanolamine & 50 \\
\hline
\end{tabular}

Source: Sanni et al. [24].

measure of the number of moles of catalyst used per unit volume, therefore, at $1 \mathrm{M}$ concentration of the catalyst, there were more FAmolecules interacting to produce the desired hydrogen, whereas, at lower catalyst-concentrations i.e. below the optimum CuNPconcentration, the relative number of active catalyst-molecules, per unit volume of solution reduces, which results in lower conversions or lower volumes of hydrogen.

\section{The need to control catalyst-size}

It is often difficult to produce nanoparticles of same size, hence, the need for an improvised approach for establishing the effect of CuNPparticle size. In ref. [24], the synthesized CuNPs were of varying sizes, however, an average particle-size was obtained for every batchconcentration of synthesized CuNP-particles. For larger particles, the surface area to volume ratio is usually lower compared to particles of smaller diameters, hence, there are more active sites in the latter relative to the former. Furthermore, considering the law of mass action, a reduction in particle/catalyst-size enhances the degree of conversion. This justifies the fact that the highest possible conversion/hydrogen production was obtained for the smallest particle size of $1.5 \mathrm{~nm}$ with corresponding concentration of $1 \mathrm{M}$.

\section{Essentials of controlled solution-pH of the CuNP catalysts}

The $\mathrm{pH}$ of a system is a measure of its alkalinity or acidity, thus, low pHs inform higher acidic strengths and vise-versa. Based on the investigation, in order to achieve $>50 \%$, but less than $70 \%$ hydrogen production from FA, the $\mathrm{pH}$ of the CuNP-catalyst should span from 2.5 to 2.9. However, if a theoretical/actual conversion of $100 / 82 \%$ is desired, the most desirable $\mathrm{pH}$ of the CuNP catalyst is 3.19 , this also doubles as the optimum pH. At CuNP catalyst-pH of 2.5-2.9, the actual hydrogen volume was less than $82 \%$, thus giving a conversion $>52$ but less than $82 \%$. Comparing the results with the results of Wang et al. [7], in which a pH of 6.5 and a maximum amount of hydrogen of $2.46 \mathrm{mmol} / \mathrm{L} / \mathrm{D}$ was obtained for a reaction time of 0-6000 mins. The difference in $\mathrm{pH}$ between the $1 \mathrm{M}$ CuNP-system and the results obtained in ref. [7] was allotted to the difference in the nature of raw materials adopted in both research works, (FA-Cu-tertiary amine system and lignocellulosic biomass), as well as the catalyst-type (i.e. $\mathrm{Cu}$ and cellulose/ $\beta$-glucosidase enzymes as catalysts), respectively. The latter also underwent simultaneous saccharification and fermentation steps prior to obtaining synthetic hydrogen. Based on the reported $\mathrm{pHs}$ of both systems, it then implies that the $\mathrm{pH}$ of the CuNP-solution is more acidic (3.19). Hence, in order to abate the situations of reactor material corrosion, the proposed material of construction for the reactor is stainless steel, which is highly resistant to all forms of acid corrosion. Furthermore, periodic checks/ inspections would be conducted as corrosion control measures in order to ascertain whether there is any need for cathodic protection, constant inspection and monitoring, painting- with heat resistant paints, coating/ electroplating, chemical injection, laser cladding etc. as ways of ensuring a longer service-life of the material of construction.

\section{Monitoring reaction time}

Reaction time is also of paramount importance in the FAdehydrogenation process. For the CuNP-tertiary amine system, the volume of hydrogen produced, increased with reaction time. At 0-10 mins, the CuNPs began to have effect on the volume of $\mathrm{H}_{2}$ released from the FA. Below the peak period ( $6 \mathrm{~h})$, the volume of hydrogen produced from 0 to 360 mins increased progressively at every 60 min-interval (Table 10).

The hourly-hydrogen production rate of some catalysts used by Akbayrak et al. [154] gave lower volumes of hydrogen production when compared with those recorded of the $1 \mathrm{M}$ CuNPs + Cu-amine system. This further justifies the outstanding performance of the catalyst-amine system for FA-dehydrogenation.

\section{Cost of chemicals and reagents}

Based on the estimated costs at the time of this investigation (July 2019), the cost of the $500 \mathrm{~g}$ copper sulphate pentahydrate salt was 7,500 naira (i.e. $\$ 20.83$ (USD)), $500 \mathrm{~g}$ ascorbic acid $=7,700$ naira (21.39 USD), $500 \mathrm{~g}$ PVP cost 29,000 naira (80.56 USD) and the cost of $500 \mathrm{~mL}$ of $\mathrm{FA}=10,000$ naira (27.78 USD). The then estimated total cost of reagents/chemicals was N 49,200 $=150.56$ USD, which implies that the cost of all relevant chemicals $=\mathrm{N} 49,200$ (i.e. 49, 200 naira) or 150.56 USD, which suggests that the estimated cost is quite cheap and affordable compared to those of other heterogeneous catalysts which will not only increase the cost of procuring chemicals/reagents, but also add to the overall/overhead cost, thus making the process to be more expensive.

\section{Gas balloon/buffer and tubes/cylinders for storage of $\mathrm{H}_{2}$-gas}

Gas storage systems, range from cylinders to tubes which are compact and shaped to withstand gas pressures. Gas balloons/gas holders, gas-bags and gas recovery membranes (Fig. 16a-h) are also being used, which are flexible, inflatable bladders that are suitable for industrial applications, especially in sectors such as breweries, technical universities, research institutes and special recycling systems. They often serve as conventional/economic storage systems for gases such as $\mathrm{N}_{2}, \mathrm{CO}_{2}, \mathrm{H}_{2}$, He or other inert gases. For optimal and cost-effective use, these systems are gas-tight with their sizes usually spanning from 0.5$7500 \mathrm{~m}^{3}$ (17 cubic feet to 265,000 cubic feet) and may assume geometries such as spheres, cylinders, angular or cushion, pillow and custom shapes, based on the desired spatial conditions.

\section{Custom shapes or sizes for $\mathrm{H}_{2}$-balloons}

These flexible tanks offer the following merits: they are light in weight such that they can be inflated and deflated with ease hence, this expedites their installation or removal when the need arises. Based on customer specifications, they may be fitted with inflation and deflation adapters, such as clamps or screws on flanges constructed with stainless steel or other flexible fittings made from gas storage fabrics.

Special fabric for $\mathrm{H}_{2}$-buffers

Gas storage balloons are made from a very robust polyester fabric, 
(a)

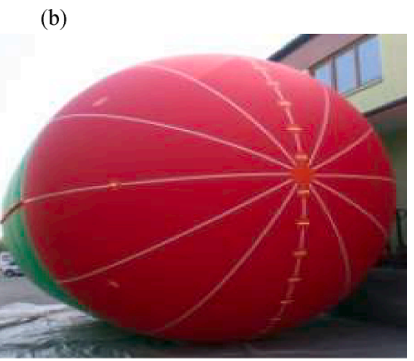

(c)

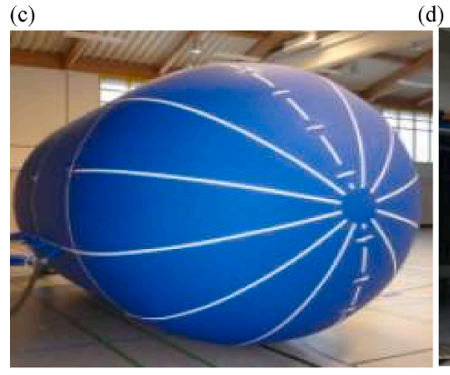

(e)

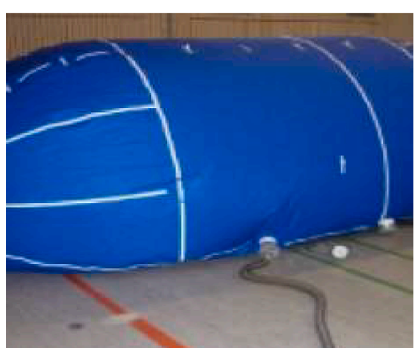

(g)

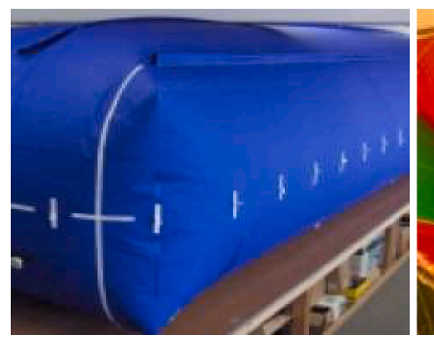

d)

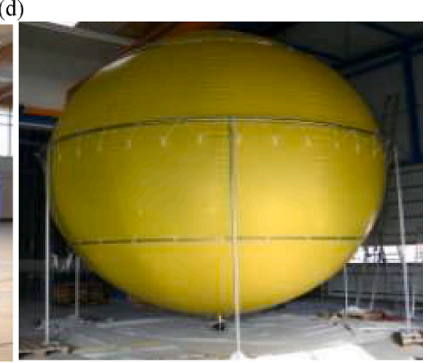

(f)

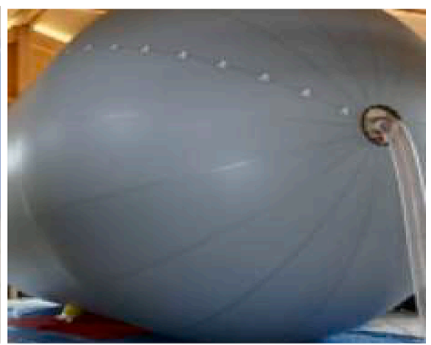

(h)

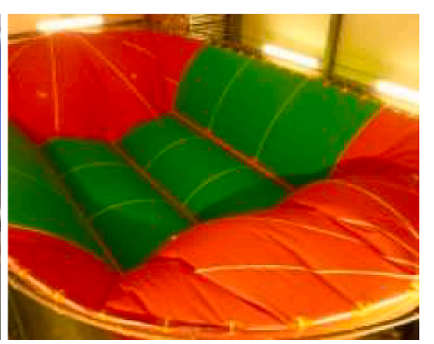

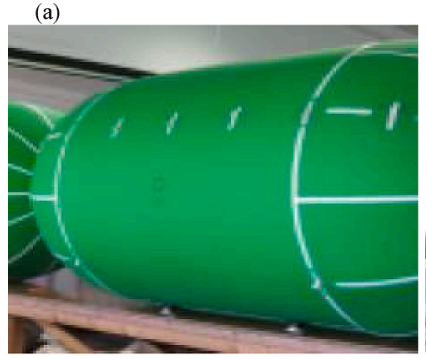

Fig. 16. a-h: Different shades of $\mathrm{H}_{2}$-gas buffers/balloons.

Source: https://www.ballonbau.de/en/sport-balloons [155]

coated with polyurethane on both ends. The fabric is designed to have a gas diffusion rate of less than $1 \mathrm{~L} / \mathrm{m}^{2}$ in $24 \mathrm{~h}$ (i.e. $0.292 \mathrm{ft} / \mathrm{h}$ ) based on its calibration with helium gas at $20^{\circ} \mathrm{C}$. To guarantee efficient/effective storage of several gases, each gas collector is designed for a specific type of gas. In other to meet the safety guidelines of the United States Department of energy (DoE), other special safety measures include, subjecting the balloon fabric to a special antistatic treatment.

\section{Securing and anchoring $\mathrm{H}_{2}$-Gas balloons using special tubular frames}

In order to keep the hydrogen gas balloons standing securely at their installed locations, the balloons need be suspended in tubular frames which may be suspended from the top/ceiling using steel cables that are fixed to the floor with basal supports. Based on their modes of design, the procedures do not require any skilled expertise as they can be easily understood and followed aptly by a reliable technician. In order to also guide against risks, the balloon is integrated with a safety mechanism to help guide against unintended over-inflation. The hydrogen-fill level of the $\mathrm{H}_{2}$-gas balloon is monitored using special wire-actuated encoders, as well as ultrasonic laser distance meters.

\section{Conclusion}

Indeed, there is no doubt about the possibility of hydrogen becoming the fuel of the future if all the already discussed sources are fully exploited to produce commercial quantities of FA for commercially synthesized hydrogen gas. The adoption of some very efficient catalysts with less poisoning potentials, have been proposed for FAdecomposition reactions. Also, it becomes very pertinent to mention that, the idea of producing hydrogen from FA regardless of its precursor/ source is guided by the process economics, market demand, and environmental policies as regards the world's clean energy policy. Several precursors (fossil fuels, nuclear power plants and renewable sources), such as biomass, wind, solar can be used to produce FA and thus $\mathrm{H}_{2}$; based on the description of the Energy Institute for hydrogen production processes, hydrogen recovered from natural gas with its $\mathrm{CO}_{2}$ emissions captured is known as blue hydrogen, whereas, if the hydrogen source is natural gas and the $\mathrm{CO}_{2}$ released is vented into the atmosphere, the hydrogen is tagged grey hydrogen, however, hydrogen produced from renewable energy/electricity with no $\mathrm{CO}_{2}$ emission is tagged green hydrogen but hydrogen from coal with $\mathrm{CO}_{2}$ vented into the atmosphere is labelled brown hydrogen; hence, the scheme described in this study falls into the blue hydrogen class where the associated $\mathrm{CO}_{2}$ is trapped in an alkaline medium. Hydrogen can serve as an alternative/additional energy carrier, which will encourage further domestication and exploitation of national resources/industrial processes towards full utilization of hydrogen, thereby reducing overdependence on the importation of petroleum. ICEs/gasoline engines can be modified or preferably, new engines can be manufactured to suit the use of $\mathrm{H}_{2}$ as fuel when these processes become fully commercialized. Without the use of catalysts, the quantity of hydrogen produced with time is highly energy consuming which will yield very high investment costs compared to the catalysed processes. Besides high-pressure cylinders, balloons can be used for the storage of hydrogen. Tubes are also proposed for the storage of hydrogen gas in cars, as well as the need to site FA conversion plants at hydrogen-fuelling/refuelling spots. In order to use hydrogen safely, leak-prevention, scenting with neutral constituents to give it an identifiable smell, flagging off hotspots with danger signposts, transporting it carefully and controlled burning of the gas, can help minimize the risks associated with storage. In addition, the gas can be stored in highpressure cylinders, or in high-texture polyurethane balloons, which may be kept in isolation or underground, within a suitable geology such as salt caverns, so as to abate adverse consequences in cases of emergencies. In today's world, over 95\% of the world's hydrogen is obtained from natural gas or coal, which usually give off greenhouse gases which trap the released heat and emits it into the earth's atmosphere, thus giving rise to high global temperatures and emissions. Sourcing for alternative fuel that is sustainable and gives less emissions underscores hydrogen as a viable alternative to fossil fuel. Therefore, switching to a low-carbon method of producing hydrogen requires that it must have little or no environmental impact, hence the need to choose apt feedstocks such as formic acid, while bearing in mind the energy required to drive the process. Based on the process scheme portrayed in this review, it is evident that, hydrogen-fuelled cars will soon be the spate of future automobiles.

\section{Data availability}

All data for this manuscript are already included in the manuscript.

\section{Funding statement}

This research was not at any stage funded by any commercial, governmental or not-for-profit organization. 


\section{Authors' contributions}

Sanni Samuel conceived the idea of developing the manuscript, presented the paper-frame work, designed the work flow, as well as drafted and edited the final version of the manuscript. Oluranti Agboola and Peter Alaba made substantial contributions in terms of discussing the reaction mechanisms. Emeka Okoro and Moses Emetere contributed few sections of the write-up in line with other methods of producing hydrogen fuel. Babalola Oni and Amanda Ndubuisi helped with language editing, and establishing the chemistry and mechanisms of few reactions defined in the manuscript.

\section{Declaration of Competing Interest}

The authors declare that they have no known competing financial interests or personal relationships that could have appeared to influence the work reported in this paper.

\section{Acknowledgement}

The authors wish to appreciate Samuel Sanni for conceptualising the thought of putting together the manuscript. Oluranti Agboola, Peter Adeniyi Alaba and Emeka Okoro are all appreciated, for their meaningful discussions and contributions at different stages of the work.

\section{References}

[1] Spath PL, Mann MK. Life Cycle Assessment of Hydrogen Production via Natural Gas Steam Reforming, Technical Report, National Renewable Energy Laboratory, NREL/TP-570-27637. DOI: 10.2172/764485.

[2] Camacho YSM, et al. Development of a robust and efficient biogas processor for hydrogen production. Part 1: Modelling and simulation. Int J Hydro Energy 2017; 42:22841-55.

[3] Bareiß K, De la Rua C, Möckl M, Hamacher T. Life cycle assessment of hydrogen from proton exchange membrane water electrolysis in future energy systems. Appl Energy 2019;237:862-72.

[4] Navlani-Garcia M, Mori K, Salinas-Torres D, Kuwahara, YYamashita H. New approaches toward the hydrogen production from formic acid dehydration over Pd-based heterogeneous catalysts. Front Mater 2019;6:44. https://doi.org/ 10.3389/fmats.201900044.

[5] Buffoni IN, Gatti MN, Santori GF, Pompeo F, Nichio NN. Hydrogen from glycerol steam reforming with a platinum catalyst supported on a SiO2-C composite. Int J Hydro Energy 2017;42:12967-77.

[6] Charisiou ND, Siakavelas G, Papageridis KN, Baklavaridis A, Tzounis L, Polychronopoulou K, et al. Hydrogen production via the glycerol steam reforming reaction over nickel supported on alumina and lanthana-alumina catalysts. Int J Hydro Energy 2017;42:13039-60.

[7] Wang Y-Z, Zhang L, Xu T, Ding K. Influence of initial anolyte $\mathrm{pH}$ and temperature on hydrogen production through simultaneous saccharification and fermentation of lignocellulose in microbial electrolysis cell. Int J Hydro Energy 2017;42: 22663-70.

[8] Wang Y, Chen KS, Mishler J, Cho SC, Adroher XC. A review of polymer electrolyte membrane fuel cells: technology, applications, and needs on fundamental research. Appl Energy 2011;88:981-1007.

[9] Ahmed S, Krumpelt M. Hydrogen from hydrocarbon fuels for fuel cells. Int J Hydro Energy 2001;26:291-301.

[10] Jakobsen RJ, Mikawa Y, Brasch JW. Far infrared studies of hydrogen bonding in carboxylic acids-I formic and acetic acids. Spectrochim Acta A Mol Biomol Spectrosc 1967;23(7):2199-209.

[11] Loges B, Boddien A, Gartner F, Junge H, Beller M. Catalytic generation of hydrogen from formic acid and its derivatives: useful hydrogen storage materials Top Catal 2010;53:902-14.

[12] Bulushev DA, Beloshapkin S, Ross JRH. Hydrogen from formic acid decomposition over Pd and Au catalysts. Catal Today 2010;154:7-12.

[13] Hu C, Pulleri JK, Ting SW, Chan KY. Activity of Pd/C for hydrogen generation in aqueous formic acid solution. Int J Hydr Energy 2014;39:381-90.

[14] Sachtler WMH, Fahrenfort J. The catalytic decomposition of formic acid vapor on metals. Proc. Second. Intern. Congr. Catalysis. Technip. Paris 1961; p. 831.

[15] Boudart M, Djega-Mariadassou G. Kinetics of heterogeneous catalytic reactions. Princeton: Princeton University Press; 1984.

[16] Madix RJ. Reaction kinetics and mechanism on metal single crystal surfaces. In: Eley DD, Pines H, Weisz PB, editors. Advances in catalysis, 29. Academic Press; 1980. p. 1.

[17] Yoo JS, Abild-Pedersen F, Norskov JK, Studt F. Theoretical analysis of transition metal catalysts for formic acid decomposition. ACS Catal 2014;4:1226-33. https://doi.org/10.1021/cs400664z.
[18] Herron JA, Scaranto J, Ferrin P, Li S, Mavrikakas M. Trends in formic acid decomposition on model transition metal surfaces: a density functional theory study. ACS Catal 2014;4(12):4434-45. https://doi.org/10.1021/cs500737p.

[19] Zahmakiran M, Ozkar S. Metal nanoparticles in liquid phase catalysis; from recent advances to future goals. Nanoscale 2011;3(9):3462-81. https://doi.org/ $10.1155 / 2014 / 324089$.

[20] Luque R, Varma RS, editors. Sustainale preparation of metal nanoparticles: methods and applications. London UK: RSC Publishing; 2012.

[21] White RJ, Luque R, Budarin VL, Clark JH, Macquarrie DJ. Supported metal nanoparticles on porous materials. Methods and applications. Chem Soc Rev 2009;38:481-94. https://doi.org/10.1039/B802654H.

[22] Campelo JM, Luna D, Luque R, Marinas JM, Romero AA. Sustainable preparation of supported metal nanoparticles and their applications in catalysis. Chem Sus Chem 2009;2(1):18-45. https://doi.org/10.1002/cssc.200800227.

[23] Astruc D, Lu F, Aranzaes JR. Nanoparticles as recyclable catalysts: the frontier between homogeneous and heterogeneous catalysis. Angew Chem Int Ed England 2005;44(48):7852-72. https://doi.org/10.1002/anie.200500766.

[24] Sanni SE, Alade TA, Agboola O, Alaba PA. Catalytic dehydrogenation of formic acid triethanolamine mixture using copper nanoparticles. Int J Hydro Energy 2020;45(7):4606-24. https://doi.org/10.1016/j.ijhydene.2019.12.121.

[25] Crampton L. Formic acid dangers and uses in nature and humans. Owlcation, a Maven Channel, 2020

[26] Fierro JLG. Hydrogen: production methods. Instituto de Catálisis y Petroleoquímica (CSIC); 2019. www.fgcsic.es/lychnos/en_en/articles/hydrogen_ production_methods. Accessed December, 2019.

[27] Johnson TC, Morris DJ, Wills M. Hydrogen generation from formic acid and alcohols using homogeneous catalysts. Chem Soc Rev 2010; 39: 81-8.

[28] Do JY, Kwak BS, Kuk-Park N, Lee TJ, Lee ST, Jo SW, et al. Effect of Acidity on the performance of a Ni-based catalyst for hydrogen production through propane steam reforming: $\mathrm{K}-\mathrm{AlSi}_{\mathrm{x}} \mathrm{O}_{\mathrm{y}}$ support with different $\mathrm{Si} / \mathrm{Al}$ ratios. Int J Hydro Energy 2017;42:22687-97.

[29] Bareiß K, del Rua C, Möckl M, Hamacher T. Life cycle assessment of hydrogen from proton exchange membrane water electrolysis in future energy systems. Appl Energy 2019;237:862-72.

[30] Chin HL, Chen ZS, Chou CP. Fed batch operation using Clostridium acetobutylicum suspension culture as biocatalyst for enhancing hydrogen production. Biotechnol Prog 2003;19:383-8.

[31] Kumar N, Das D. Continuous hydrogen production by immobilized Enterobacter Cloacae IIT-BT 08 using lignocellulosic materials as solid matrices. Enzyme Microb Technol 2001;29:280-7.

[32] Melis A, Happe T. Hydrogen production. Green algae as a source of energy. Plant Physiol 2001;127:740-8.

[33] Nandi R, Bhattacharya PK, Bhaduri AN, Sengupta S. Synthesis and lysis of formate by immobilized cells of Escherichia coli. Biotechnol Bioeng 1992;39:775-80.

[34] Tsygankov AA, Hirata Y, Miyake M, Asada Y, Miyake J. Photobioreactor with photosynthetic bacteria immobilized on porous glass for hydrogen photo production. J Ferment Bioeng 1994;77:575-8.

[35] Lee KS, Lo YS, Lo YC, Lin PJ, Chang JS. $\mathrm{H}_{2}$ production with anaerobic sludge using activated-carbon supported packed-bed bioreactors. Biotechnol Lett 2003; 25:133-8.

[36] Woodward J, Orr M, Cordray K, Greenbaum E. Enzymatic production of biohydrogen. Nature 2000;405:1014-5.

[37] Alexeeva S, Hellingwerf KJ, De Mattos MJT. Requirement of ArcA for redox regulation in Escherichia coli under microaerobic but not anaerobic or aerobic conditions. J Bacteriol 2003;185:204-9.

[38] Yoshida A, Nishimura T, Kawaguchi H, Inui M, Yukawa H. Enhanced hydrogen production from formic acid by formate hydrogen Lyase-overexpressing Escherichia coli strains. Appl Environ Microbiol 2005:6762-8. https://doi.org/ 10.1128/AEM.71.11.6762-6768.2005.

[39] De-Vos P, Stevens P, De-Lay J. Hydrogen gas production from formate and glucose by different members of enterobactericeae. Biotechnol Lett 1983;5:69-74.

[40] Kawamura S, O'Neil JG, Wilkinson JF. Hydrogen production by methylotrophs under anaerobic conditions. J Ferment Technol 1983;61:151-6.

[41] Schon G, Voelskow H. Pyruvate fermentation in Rhodospirillum rubrum and after transfer from aerobic to anaerobic conditions in the dark. Arch Microbiol 1976; 107:87-92.

[42] Alotaibi MH, Alotaibi RL, Aldosari OF. Hydrogen generation from formic acid decomposition using an Iradium-Palladium (Ir-Pd) nanoparticles supported on different supports. 24th Global Organic \& Inorganic Chemistry Conference, Organic Chem. Curr. Res. 2018; 7: 43. DOI: 10.4172/2161-0401-C3-028.

[43] Sigma-Adrich. (2011). Sigma-aldrich. Accessed August 8, 2019. www. sigmaaldrich.com/MSD/.

[44] Aguilo A, Horlenko T. Formic acid. MacKetta JJ, Cunningham WA (Eds.), In: Encyclopedia of chemical processing and design, Marcel Dekker, Inc., New York, 1988; 23: 371-397.

[45] Reutemann W, Kieczka H. Formic acid, In Elvers B, Hawkins S, Ravenscroft M, Rounsaville JF, Schulz G (Eds.), Ullmann's encyclopedia of industrial chemistry, 5th ed., A12: 13-33 Wiley-VCH, Weinheim, Germany, 1996.

[46] Bulushev DA, Beloshapkin S, Ross JRH. Hydrogen from formic acid decomposition over Pt and Au Catalysts. Catal Today 2010;154:7-12. https://doi. org/10.1016/j.cattod.2010.03.050.

[47] Xue-li L, Feng S, Xiang-yuan M, Liu-jin L, You-Quan D. (2010). Selective catalytic formic acid decomposition for hydrogen generation in ionic liquids. J. Fuel Chem. Technol., 2010; 38, 5: 544-553.

[48] Sanchez F, Motta D, Roldan A, Hammond C, Villa A, Dimitratos N. Hydrogen generation from additive-free formic acid decomposition under mild conditions 
by Pd/C: experimental and DFT studies. Top. Catal. Article in Press. https://doi. org/10.1007/s11244-018-0894-5.

[49] Müller K, Brooks K, Autrey T. Hydrogen storage in formic acid: a comparison of process options. Energy Fuels 2017;31:12603-11. https://doi.org/10.1021/acs. energyfuels.7b02997.

[50] Li S, Scaranto J, Mavrikakis M. On the structure sensitivity of formic acid decomposition on Cu catalysts. Top Catal 2016;2016(59):1580-8. https://doi. org/10.1007/s11244-016-0672-1.

[51] Columbia MR, Thiel PA. The interaction of formic-acid with transition metal surfaces, studied in ultrahigh vacuum. J Electroanal Chem 1994;369(1-2):1-14.

[52] Madix RJ. Surface reaction modifiers-general overview. Abstracts of papers of the American Chemical Society, 1980; 180: 26.

[53] Larson LA, Dickinson JT. Decomposition of formic acid on Ru(1010). Surf Sci 1979;84(1):17-30

[54] Solymosi F, Kiss J, Kovacs I. Adsorption of $\mathrm{HCOOH}$ on Rh(111) and its reaction with preadsorbed oxygen. Surf Sci 1987;192(1):47-65.

[55] Senanayake SD, Mullins DR. Redox pathways for $\mathrm{HCOOH}$ decomposition over CeO2 surfaces. J Phys Chem C 2008;112(26):9744-52.

[56] Kubota J, Bandara A, Wada A, Domen K, Hirose C. IRAS study of formic acid decomposition on $\mathrm{NiO}(111) / \mathrm{Ni}(111)$ surface: comparison of vacuum and catalytic conditions. Surf Sci 1996;368:361-5.

[57] Dilara PA, Vohs JM. TPD and HREELS investigation of the reaction of formic acid on $\mathrm{ZrO}_{2}(100)$. J Phys Chem 1993:97(49):12919-23.

[58] Iglesia E, Boudart M. Decomposition of formic acid on copper, nickel, and copper-nickel alloys. Catalytic and temperature-programmed decomposition of formic acid on $\mathrm{Cu} / \mathrm{SiO}_{2}, \mathrm{Cu} / \mathrm{Al}_{2} \mathrm{O}_{3}$, and $\mathrm{Cu}$ powder. J Catal 1983;81(1):214-23.

[59] Bowker M, Madix RJ. XPS, UPS and thermal desorption studies of the reactions of formaldehyde and formic acid with the Cu(110) surface. Surf Sci 1981;102(2-3): 542-65.

[60] Marcinkowski MD, Murphy CJ, Liriano ML, Wasio NA, Lucci FR, Sykes ECH. Microscopic view of the active sites for selective dehydrogenation of formic acid on Cu(111). ACS Catal 2015;5(12):7371-8.

[61] Youngs TGA, Haq S, Bowker M. Formic acid adsorption and oxidation on $\mathrm{Cu}$ (110). Surf Sci 2008;602(10):1775-82.

[62] Bowker M, Haq S, Holroyd R, Parlett PM, Poulston S, Richardson N. Spectroscopic and kinetic studies of formic acid adsorption on $\mathrm{Cu}(110)$. J Chem Soc Faraday Trans 1996;92(23):4683-6.

[63] Quinn DF, Taylor D. Decomposition of formic acid and methanol on copper-nickel alloys. J Chem Soc 1965:5248-51.

[64] Rundell DN, Saltsburg HM, Smith WD. The role of multiple gas-solid collisions in the catalytic decomposition of formic acid. Chem Eng Sci 1980;35(5):1113-9.

[65] Inglis HS, Taylor D. Decomposition of formic acid on titanium, vanadium, chromium, manganese, iron, cobalt, nickel and copper. J Chem Soc Inorg Phys Theor 1969:19:2985-7.

[66] Nakano H, Nakamura I, Fujitani T, Nakamura J. Structuredependent kinetics for synthesis and decomposition of formate species over $\mathrm{Cu}(111)$ and $\mathrm{Cu}(110)$ mode catalysts. J Phys Chem B 2001;105(7):1355-65.

[67] Hu ZM, Boyd RJ. Structure sensitivity and cluster size convergence for formate adsorption on copper surfaces: a DFT cluster model study. J Chem Phys 2000;112 (21):9562-8

[68] Bowker M, Rowbotham E, Leibsle FM, Haq S. The adsorption and decomposition of formic acid on Cu\{110\}. Surf Sci 1996;349(2):97-110.

[69] Gokhale AA, Dumesic JA, Mavrikakis M. On the mechanism of low-temperature water gas shift reaction on copper. J Am Chem Soc 2008;130(4):1402-14.

[70] Grabow LC, Gokhale AA, Evans ST, Dumesic JA, Mavrikakis M. Mechanism of the water gas shift reaction on Pt: first principles, experiments, and microkinetic modeling. J Phys Chem C 2008;112(12):4608-17.

[71] Caner N, Buluta A, Yurderia M, Ertasa IE, Kivrakb H, Kayac M, et al. Atomic layer deposition- $\mathrm{SiO}_{2}$ layers protected $\mathrm{PdCoNi}$ nanoparticles supported on $\mathrm{TiO}_{2}$ nanopowders: exceptionally stable nano catalyst for the dehydrogenation of formic acid. Appl Catal B: Environ 2017;210:470-83.

[72] Wachs IE. Raman and IR studies of surface metal oxide species on oxide supports: Supported metal oxide catalysts. Catal. Today 1996; 27: 437-455. SSDI 0920-586 1(95)00203-0.

[73] Sadovskaya EM, Chesalov YA, Goncharova VB, Soboleva VI, Andrushkevicha TV. Formic acid decomposition over V-Ti oxide catalyst: mechanism and kinetics. J Molecular Catal A: Chem 2017;430:54-62.

[74] Liu D, Gao ZY, Wang XC, Zeng J, Li YM. DFT study of hydrogen production from formic acid decomposition on Pd-Au alloy nanoclusters. Appl Surf Sci 2017;426: 194-205. https://doi.org/10.1016/j.apsusc.2017.07.165.

[75] Zavras A, Khairallah GN, Krstić M, Girod M, Daly S, Antoine R, et al. Ligandinduced substrate steering and reshaping of $\left[\mathrm{Ag}_{2}(\mathrm{H})\right]^{+}$scaffold for selective $\mathrm{CO}_{2}$ extrusion from formic acid. Nat Commun 2016;7:11746. https://doi.org/ 10.1038 /ncomms11746.

[76] Edwards JK, Ntainjua E, Carley AF, Herzing AA, Kiely CJ, Hutchings GJ. Direct synthesis of $\mathrm{H}_{2} \mathrm{O}_{2}$ from $\mathrm{H}_{2}$ and $\mathrm{O}_{2}$ over gold, palladium, and gold-palladium catalysts supported on acid-pretreated $\mathrm{TiO}_{2}$. Angew Chem Int Ed 2009;48: $8512-5$.

[77] Edwards JK, Solsona B, Ntainjua E, Carley AF, Herzing AA, Kiely GJ, et al. Switching off hydrogen peroxide hydrogenation in the direct synthesis process. Science 2009;323:1037-41.

[78] Allison EG, Bond GC. The structure and catalytic properties of palladium-silver and palladium-gold alloys. Catal Rev 1972;7:233-89.

[79] Zhu Q-L, Tsumori N, Xu Q. Sodium hydroxide-assisted growth of uniform Pd nanoparticles on nanoporous carbon MSC-30 for efficient and complete dehydrogenation of formic acid under ambient conditions. Chem Sci 2014;5: 195-9.

[80] Zhou X, Huang Y, Xing W, Liu C, Liao J, Lu T. High-quality hydrogen from the catalysed decomposition of formic acid by $\mathrm{Pd}-\mathrm{Au} / \mathrm{C}$ and $\mathrm{Pd}-\mathrm{Ag} / \mathrm{C}$. Chem Commun 2008:3540-2.

[81] Bi QY, Du XL, Liu YM, Cao Y, He HY, Fan KN, Efficient subnanometric goldcatalyzed hydrogen generation via formic acid decomposition under ambient conditions J. Am. Chem. Soc. 2012; 134, 21: 8926-8933. Doi: 10.1021/ ja301696e.

[82] Tedsree K, Li T, Jones S, Chan CWA, Yu KMK, Bagot PAJ, et al. Hydrogen production from formic acid decomposition at room temperature using an Ag-Pd core-shell nanocatalyst. Nat Nanotechnol 2011;6:302-7.

[83] Wang Z-L, Yan J-M, Wang H-L, Ping Y, Jiang Q. Au@Pd core-shell nanoclusters growing on nitrogen-doped mildly reduced graphene oxide with enhanced catalytic performance for hydrogen generation from formic acid. J Mater Chem 2013;A1:12721-5.

[84] Wang ZL, Yan JM, Ping Y, Wang HL, Zheng WT, Jiang Q. An efficient CoAuPd/C catalyst for hydrogen generation from formic acid at room temperature. Angew Chem Int Ed 2013;2(16):4406-9. https://doi.org/10.1002/anie.201301009.

[85] Wang ZL, Wang HL, Yan JM, Ping Y, Li SJ, Jiang Q. DNA-directed growth of ultrafine CoAuPd nanoparticles on graphene as efficient catalysts for formic acid dehydrogenation. Chem Commun 2014;50(21):2732-4. https://doi.org/ $10.1039 / \mathrm{c} 3 \mathrm{cc} 49821 \mathrm{~b}$

[86] Metin Ö, Sun X, Sun S. Monodisperse gold-palladium alloy nanoparticles and their composition-controlled catalysis in formic acid dehydrogenation under mild conditions. Nanoscale 2013;5:910-2.

[87] Karatas Y, Bulut A, Yurderi M, Ertas IE, Alal O, Gulcan M, et al. PdAuMnOxnanoparticles supported on amine-functionalized $\mathrm{SiO}_{2}$ for the room temperature dehydrogenation of formic acid in the absence of additives. Appl Catal B: Environ 2016;180:586-95. https://doi.org/10.1016/j. apcatb. 2015.06.060.

[88] Bulut A, Yurderi M, Karatas Y, Say Z, Kivrak H, Kaya M, et al. MnOx-promoted PdAg alloy nanoparticles for the additive-free dehydrogenation of formic acid at room temperature. ACS Catal 2015;5:6099-110. https://doi.org/10.1021/ acscatal.5b01121.

[89] Yurderi M, Bulut A, Caner N, Elebi MC, Kaya M, Zahmakiran M. Amine grafted silica supported CrAuPd alloy nanoparticles: superb heterogeneous catalysts for the room temperature dehydrogenation of formic acid. Chem Commun 2015;57: 11417-20. https://doi.org/10.1039/C5CC02371H.

[90] Yurderi M, Bulut A, Zahmakiran M, Kaya M. Carbon supported trimetallic PdNiAg nanoparticles as highly active, selective and reusable catalyst in the formic acid decomposition. Appl Catal B: Environ 2014;160-161:514-24. https://doi.org/ 10.1016/j.apcatb.2014.06.004.

[91] Bulut A, Yurderi M, Karatas Y, Zahmakiran M, Kivrak H, Gulcan M, et al. PdMnOx nanoparticles disperse donamine grafted silica: highly efficient nanocatalyst for hydrogen production from additive-free dehydrogenation of formic acid under mild conditions. Appl Catal B Environ 2015;164:324-33. https://doi.org/10.1016/j.apcatb.2014.09.041.

[92] Yan J-M, Wang Z-L, Gu L, Li S-J, Wang H-L, Zheng W-T, Jiang Q. AuPd-MnOx/ MOF-graphene: an efficient catalyst for hydrogen production from formic acid at room temperature. Adv Energy Mater 2015; pp. 15001001-1500107. DOI: 10.1002/aenm.201500107.

[93] Wang ZL, Yan JM, Wang HL, Ping Y, Jiang Q. Au@Pd core-shellnanoclusters growing on nitrogen-doped mildly reduced graphene oxidewith enhanced catalytic performance for hydrogen generation from formic acid. J Mater Chem A 2013;1:12721-5.

[94] Zhou X, Huang Y, Xing W, Liu C, Liao J, Lu T. High-quality hydrogen from the catalyzed decomposition of formic acid by $\mathrm{Pd}-\mathrm{Au} / \mathrm{C}$ and $\mathrm{Pd}-\mathrm{Ag} / \mathrm{C}$. Chem Commun 2008;30:3540-2.

[95] Huang Y, Zhou X, Yin M, Liu C, Xing W. Novel PdAu@Au/C core-shellcatalyst: superior activity and selectivity in formic acid decomposition for hydrogen generation. Chem Mater 2010;22:5122-8.

[96] Gu X, Lu ZH, Jiang HL, Akita T, Xu Q. Synergistic catalysis of metal-organic framework-immobilized Au-Pd nanoparticles in dehydrogenation of formic acid for chemical hydrogen storage. J Am Chem Soc 2011;133:11822-5.

[97] Wang ZL, Yan JM, Ping Y, Wang HL, Zheng WT, Jiang Q. An efficient CoAuPd/C catalyst for hydrogen generation from formic acid at room temperature. Angew Chem Int Ed 2013;52:4406-9.

[98] Yu WY, Mullen GM, Flaherty DW, Mullins CB. Selective hydrogen production from formic acid decomposition on Pd-Au bimetallic surfaces. J Am Chem Soc 2014;136:11070-8.

[99] Yan JM, Wang ZL, Gu L, Li SJ, Wang HL, Zheng WT, et al. An efficient catalyst for hydrogen production from formic acid at room temperature. Adv Energy Mater 2015;5:1500107.

[100] Detwiler MD, Milligan CA, Zemlyanov DY, Delgass WN, Ribeiro FH. Kinetics of gas phase formic acid decomposition on platinum single crystal and polycrystalline surfaces. Surf Sci 2016;648:220-6.

[101] Navlani-García M, Mori K, Kuwahara Y, Yamashita H. Recent strategies targeting efficient hydrogen production from chemical hydrogen storage materials over carbon-supported catalysts. NPG Asia Mater 2018;10:277-92. https://doi.org/ 10.1038/s41427-018-0025-6.

[102] Wang Y, Qi Y, Zhang D, Liu C. New insight into the decomposition mechanism of formic acid on Pd(111): competing formation of $\mathrm{CO}_{2}$ and $\mathrm{CO}$. J Phys Chem $\mathrm{C}$ 2014;118:2067-76. 
[103] Tang Y, Roberts CA, Perkins RT, Wachs IE. Revisiting formic acid decomposition on metallic powder catalysts: exploding the $\mathrm{HCOOH}$ decomposition volcano curve. Surf Sci 2016;650:103-10.

[104] Ojeda M, Iglesia E. Formic acid dehydrogenation on au-based catalysts at nearambient temperatures. Angew Chem Int Ed 2009;48(26):4800-3. https://doi.org/ 10.1002/anie.200805723.

[105] Jia L, Bulushev D, Ross JRH. Formic acid decomposition over palladium catalysts doped by potassium carbonate. Catal Today 2016;259:453-9.

[106] Silbaugh TL, Karp EM, Campbell CT. Energetics of methanol and formic acid oxidation on Pt (111): mechanistic insights from adsorption calorimetry. Surf Sci 2016;650:140-3.

[107] Suenobu T, Shibata S, Fukuzumi S. Catalytic oxidation of formic acid by dioxygen with an organoiridium complex. Catal Sci Technol 2014;4:3636-9. https://doi. org/10.1039/C4CY00957F.

[108] Celaje JJA, Lu Z, Kedzie EA, Terrile NJ, Lo JN, Williams TJ. A prolific catalyst for dehydrogenation of neat formic acid. Nat Commun 2016;7:11308-13. https:// doi.org/10.1038/ncomms11308.

[109] Noto Y, Fukuda K, Onishi T, Tamaru K. Mechanism of formic acid decomposition over dehydrogenation catalysts. Trans Faraday Soc 1967;63:3081-7.

[110] Zhong H, Iguchi M, Song F-Z, Chatterjee M, Ishizaka T, Nagao I, et al. Automatic high-pressure hydrogen generation from formic acid in the presence of nano-Pd heterogeneous catalysts at mild temperatures. Sust Energy Fuels 2017;1:1049-55.

[111] Li Z, Xu Q. Metal-nanoparticle-catalyzed hydrogen generation from formic acid. Acc Chem Res 2017;50(6):1449-58. https://doi.org/10.1021/acs. accounts.7b00132.

[112] Jiang Q, Lu HM, Zhao M. Modelling of surface energies of elemental crystals. J Phys Condens Matter 2004;16:521-30.

[113] Yi CW, Luo K, Wei T, Goodman DW. The composition and structure of Pd-Au surfaces. J Phys Chem B 2005;109:18535-40.

[114] Ding Y, Fan F, Tian Z, Wang ZL. Atomic structure of Au-Pd bimetallic alloyed nanoparticles. J Am Chem Soc 2010;132:12480-6.

[115] Dong W, Hafner J. $\mathrm{H}_{2}$ dissociative adsorption on Pd (111). Phys Rev B 1997;56: $15396-403$.

[116] Singh S, Li S, Carrasquillo-Flores R, Alba-Rubio AC, Dumesic JA, Mavrikakis M. Formic acid decomposition on Au catalysts: DFT, microkinetic modeling, and reaction kinetics experiments. AIChE J 2014;60:1303-19.

[117] Yu WY, Mullen GM, Mullins CB. Hydrogen adsorption and absorption with Pd-Au bimetallic surfaces. J Phys Chem C 2013;117:19535-43.

[118] Yadav M, Xu Q. Liquid-phase chemical hydrogen storage materials. Energy Environ Sci 2012;5:9698-725. https://doi.org/10.1039/C2EE22937D.

[119] Mackay GI, Hopkinson AC, Bohme DK. Acid catalysis in the gas phase: dissociative proton transfer to formic and acetic acid. J Am Chem Soc 1978;100 (24):7460-4. https://doi.org/10.1021/ja00492a003.

[120] Holmes JL, Mommers AA, De Koster C, Heerma W, Terlouw JK. Four isomeric [C, $\left.\mathrm{H}_{3}, \mathrm{O}_{2}\right]^{+}$ions. Chem Phys Lett 1985;115:437-40.

[121] Sekiguchi O, Bakken V, Uggerud E. Decomposition of protonated formic acid: one transition state-two product channels. J Am Soc Mass Spectrom 2004;15:982-8.

[122] Lias SG, Rosenstock HM, Deard K, Steiner BW, Herron JT, Holmes JH et al. NIST Chemistry Web book, 2002. (http://webbook.nist.goc/ chemistry).

[123] Wang Z, Hao X, Hu D, Li L, Song X, Zhang W, et al. PdAu bimetallic nanoparticles anchored on amine-modified mesoporous ZrSBA15 for dehydrogenation of formic acid at ambient conditions. Electronic Supplementary Material (ESI). Catal Sci Technol 2017.

[124] Bi QY, Lin JD, Liu YM, He HY, Huang FQ, Cao Y. Dehydrogenation of formic acid at room temperature: boosting palladium nanoparticle efficiency by coupling with pyridinic nitrogen-doped carbon. Angew Chem Int 2016;55:11849-53. https://doi.org/10.1002/anie.201605961.

[125] Zhang S, Metin Ö, Su D, Sun S. Monodisperse AgPd alloy nanoparticles and their superior catalysis for the dehydrogenation of formic acid. Angew Chem Int Ed 2013;52:3681-4.

[126] Wang ZL, Ping Y, Yan JM, Wang HL, Jiang Q. Hydrogen generation from formic acid decomposition at room temperature using a NiAuPd alloy nanocatalyst. Int $J$ Hydr Energy 2014;39:4850-6.

[127] Li SJ, Ping Y, Yan JM, Wang HL, Wu M, Jiang Q. Facile synthesis of AgAuPd/ graphene with high performance for hydrogen generation from formic acid. J Mater Chem A 2015;3:14535-8. https://doi.org/10.1039/C5TA03111G.

[128] Wang ZL, Wang HL, Yan Ping, Li YsioSJ, Jiang Q. DNA-directed growth of ultrafine CoAuPd nanoparticles on graphene as efficient catalysts for formic acid dehydrogenation. Chem Commun 2014;50:2732-4. https://doi.org/10.1039/ c3cc49821b.

[129] Wang ZL, Yan JM, Zhang YF, Ping Y, Wang HL, Jiang Q. Facile synthesis of nitrogen-doped graphene supported $\mathrm{AuPd}-\mathrm{CeO}_{2}$ nanocomposites with highperformance for hydrogen generation from formic acid at room temperature. Nanoscale 2014;6:3073-7.

[130] Ke F, Wang L, Zhu J. An efficient room temperature core-shell AgPd@MOF catalyst for hydrogen production from formic acid. Nanoscale 2015;7(18): 8321-5. https://doi.org/10.1039/C4NR07582J.

[131] Koh K, Seo JE, Lee JH, Goswami A, Yoon CW, Asefa T. Ultrasmall palladium nanoparticles supported on amine-functionalized SBA-15 efficiently catalyze hydrogen evolution from formic acid. J Mater Chem A 2014;2:20444-9. https:// doi.org/10.1039/C4TA04538F.

[132] Sun Q, Wang N, Bing RS, Liu J, Bai R, Zhang P, et al. Subnanometric Hybrid Pd-M $(\mathrm{OH}) 2, \mathrm{M}=\mathrm{Ni}$ Co, Clusters in Zeolites as Highly Efficient Nanocatalysts for Hydrogen Generation. Chem 2017;3:477-93. https://doi.org/10.1016/j. chempr.2017.07.001.

[133] Benck JD, Hellstern TR, Kibsgaard J, Chakthranont P, Jaramillo TF. Catalyzing the Hydrogen Evolution Reaction (HER) with Molybdenum Sulfide Nanomaterials. ACS Catal. 2014; 4: 3957-3971. dx.doi.org/10.1021/cs500923c.

[134] Scotti N, Psaro R, Ravasio N, Zaccheria F. A new Cu-based system for formic acid dehydrogenation. RSC Adv 2014.

[135] Zhu Q-L, Tsumori N, Xu Q. Immobilizing extremely catalytically active palladium nanoparticles to carbon nanospheres: a weakly-capping growth approach. J Am Chem Soc 2015;137:11743-8.

[136] Bielinski EA, Lagaditis PO, Zhang Y, Mercado BQ, Würtele C, Bernskoetter WH, et al. Lewis acid-assisted formic acid dehydrogenation using a pincer-supported iron catalyst. J Am Chem Soc 2014;136:10234-7.

[137] Sanni SE, Ewetade AP, Emetere ME, Agboola O, Okoro E, Olorunshola SJ, et al. Enhancing the inhibition potential of sodium tungstate towards mitigating the corrosive effect of Acidithiobaccillus thiooxidan on X-52 carbon steel. Mater Today Commun 2019;19:238-51. https://doi.org/10.1016/j. mtcomm.2018.12.010.

[138] James B, Bushman P. Corrosion and cathodic protection theory. Int J Renew Energy Res 2014;4:3-10.

[139] Mannari V, Patel CJ. Introduction to paints and coatings. In: understanding raw materials, introduction to paints and coatings, Vincentz Network, Hanover, Germany, Ch. 1, pp. 19-27, 2015. ISBN: 978-3-86630-603-5.

[140] Sanni SE, Adefila SS, Anozie AN. Prediction of sand kinematic pressure and fluid particle interaction coefficient as means of preventing sand-induced corrosion in crude oil pipelines. Ain Shams Eng'g J 2019;10:55-62.

[141] Sugama T. High-Performance Coating Materials. Energy sciences and technology department/energy resources division, Brookhaven National Laboratory, 2006. BNL-77900-2007-IR.

[142] Kelly PJ, Hisek J, Zhou Y, Pilkington RD, Arnell RD. Advanced coatings through pulsed magnetron sputtering. Surf Eng'g 2004;20(3):157-62. https://doi.org/ $10.1179 / 026708404225010702$.

[143] Ngobiri NC, Oguzie EE, Oforka NC, Akaranta O. Comparative study on the inhibitive effect of Sulfadoxine-Pyrimethamine and an industrial inhibitor on the corrosion of pipeline steel in petroleum pipeline water, Arab. J. Chem., 2015; 1-11, Article in Press.

[144] Li E, Wu J, Zhang D, Sun Y, Chen J. D-phenylalanine inhibits the corrosion of Q235 carbon steel caused by Desulfovibrio Sp. Int Biodeter Biodegrad 2018;127: 178-84. https://doi.org/10.1016/j.ibiod.2017.11.027.

[145] Héctor AV, Liz KH. Microbiologically influenced corrosion: looking to the future. Int Microbiol 2005;8:169-80.

[146] Sanni SE, Fayomi SIO, Emetere ME, Tenebe TI. Corrosion inhibition of mild steel in aqueous HCL using bitter leaf and fenugreek seed oils. Pro Metals Phys Chem Surf 2019;55(2):389-99. https://doi.org/10.1134/S2070205119020254.

[147] Agboola O, Achile F, Fayomi SO, Sanni SE, Abatan O, Sadiku ER, et al. Adsorptive performance mechanism of the DNA of calf thymus gland (CTGDNA) on 3CR12 stainless steel as corrosion inhibitor in acidic medium. J Bio-Tribo-Corr 2019;5 (52):1-17. https://doi.org/10.1007/s40735-019-0245-5.

[148] Okafor PC, Ikpi ME, Uwah IE, Ebenso EE, Ekpe UJ, Umoren UJ. Inhibitory action of Phyllanthus amarus extracts on the corrosion of mild steel in acidic media. Corros Sci 2008;50:2317. https://doi.org/10.1016/jcorsci.2008.05.009.

[149] Ostovari A, Hoseinieh SM, Peikari M, Shadizadeh SR, Hashemi SJ. Corrosion inhibition of mild steel in $1 \mathrm{M} \mathrm{HCl}$ solution by henna extract: a comparative study of the inhibition by henna and its constituents (Lawsone, gallic acid, a-D-glucose and tannic acid). Corros Sci 1949;2009:50. https://doi.org/10.1016/ jcorsci.2008.05.024.

[150] Balasubramanyam N, Prasanthi SG, Yugandhar M. Study of coated TiN and TiC on cutting tools for the PVD and CVD coated tungsten carbide by sand blasting pretreatment of nickel and carbon. Int J Adv Sci Technol 2015;75:51-8. https:// doi.org/10.14257/ijast.2015.75.06.

[151] Sander G, Tan J, Balan P, Gharbi O, Feenstra DR, Singer L, et al. Corrosion of additively manufactured alloys: a review. Corrosion 2018;74(12):1318-50.

[152] Tedsree K, Li T, Jones S, Chan CWA, Yu KMK, Bagot PAJ, et al. Hydrogen production from formic acid decomposition at room temperature using a $\mathrm{Ag}-\mathrm{Pd}$ core-shell nanocatalyst. Nat Nanotechnol 2011;6:302-7.

[153] Wang ZL, Wang HL, Yan JM, Ping SIO, Li SJ, Jiang Q. DNA-directed growth of ultrafine CoAuPd nanoparticles on graphene as efficient catalysts for formic acid dehydrogenation. Chem Commun 2014;50:2732-4. https://doi.org/10.1039/ c3cc49821b.

[154] Akbayraka S, Tonbul Y, Özkar S. Nanoceria supported palladium(0) nanoparticles: Superb catalyst in dehydrogenation of formic acid at room temperature. Appl Catal B: Environ 2017;206:384-92.

[155] https://www.ballonbau.de/en/sport-balloons. 